\section{ABSTRACTS OF SCIENTIFIC PAPERS SECOND ANNUAL MEETING OF THE SOCIETY FOR TECHNOLOGY IN ANESTHESIA}

\author{
January 30-February 1, 1992 \\ San Diego, California \\ Sponsored by Hewlett Packard Company
}

\section{Planning}

Jerry M. Calkins, Annual Meeting Chaiman

\section{SCIENTIFIC PROGRAM}

James H. Philip, Chairman

Damon C. Sutton

\section{SPONSORS}

Becton-Dickinson Vascular Access

Blue Bell Bio-Medical

Datascope

Datex Medical Instrumentation

Diatek Patient Management Systems

Drägenwerk $A G$

Interflo Medical, Inc

Level 1 Technologies

Little, Brown and Company

Marquette Electronics Inc

North American Drager

Ohmeda

Organon, Inc

PPG Bio-Med

Puritan Bennett Corp

Siemens Medical Systems, Inc

Spacelabs, Inc

Yardley Software

\section{SESSION 1: ANESTHESIA WORKSTATION COMPONENTS}

\author{
LESSONS LEARNED IN BUILOING INTEGRATED ANESTHESIA DELIVERY AND \\ MOHITORIMG SYSTEMS \\ Wesley T. Frazier, MD, ${ }^{*}$ S. H. Odom, MD, ${ }^{*}$ Emory \\ University School of Medicine, Atlanta, GA; and TBrigham $E$ \\ Women's Hospital and Harvard Medical School, Boston, MA
}

Summary. After 15 years developing and using integrated anesthesia delivery and monitoring systems, we are simultaneously pleased and concerned by today's commercial integrated anesthesia delivery and monitoring systems.

Introduction. Since the mid-1970s, we have built approximately 20 integrated anesthesia delivery and monitoring systems (IADMSs) by modifying "standard," commercially available anesthesia machines (Ohmeda models 2000, UNITROL, MODULUS-I, II, and II +). These systems have been used from 1 to 15 years; a few have been retired (e.g., all 2000s) and many have undergone multiple revisions.

Methods. The basic problem driving our work was the lack of a commercially available system to accommodate a large and varable number of complex devices to monitor the anesthesia delivery system and patient. Furthermore, we wanted to explore an integrated automated record keeping system and to provide for modularity and flexibility. This would allow convenient equipment changes to accommodate for equipment failures, allow use of different or newer monitors, and allow us to explore various locations and spatial arrangements for a variety of devices.

The basic approaches we used were to add shelves, brackets, broader base, etc, to the supporting structure or, more commonly, to remount the essential gas delivery components on a structure that we fabricated ourselves. A cardinal principle was to leave the essential portions of the machine intact and only change the supporting structure. We paid particular attention to ease of access to vital components and mechanical stability to reduce "tipability" of the system. Whenever possible, we used inexpensive, off-the-shelf hardware to minimize expensive custom machine shop fabrication.

One of the earliest IADMSs we developed was the most complex. It incorporated a digital plotter for computerassisted record keeping, terminals for data management, a time-shared mass spectrometer, and all the monitors required for the most complex cases [1,2]. Through the years, some IADMSs have been changed multiple times as new generations of old devices were marketed, monitoring priorities changed, and new classes of devices became available.

Results. Fabricating IADMSs has allowed us to bring more devices to the "bedside" than would have been possible otherwise. In addition, we centralized and consolidated the monitor display area (to the anesthetist's right) and eliminated the need for a monitoring cart.

Clinicians have been pleased by having additional monitors incorporated. However, the large IADMS size and resulting immobility (due to poor caster and wheel design, etc) have remained concerns. The central dilemma and need for compromise persists: somehow, we must provide more function packed into less space.

Discussion. The evolutionary development of our own and 
commercial IADMSs has resulted in patient monitors being located near the gas delivery system. It is clear that a commercial version of our IADMSs could be at least 30 to $40 \%$ more compact than our present versions. This would be achieved by better design and manufacturing.

In watching IADMSs emerge from multiple manufacturers, we are pleased to see excellent designs, but we are concerned about the following:

1. The mechanics of the Emory system was modular, allowing for rapid design, inexpensive assembly, and easy redesign. New commercial systems allow little flexibility and are not modular. In some instances, there seems to be a tilt toward planned obsolescence.

2. Our systems have been built to allow for very rapid replacement of any failed monitor, requiring a few minutes at most. Highly integrated commercial systems require both routine service and emergency repair to be performed "after hours."

3. The current commercial trend of bundling (mechanical, electrical, and marketing) patient monitors in a very rigid fashion limits the clinician's choice of monitors. It remains to be scen if the benefits (single source, compactness, "neatness," etc) outweigh the disadvantages.

\section{REFERENCES}

1. Frazier WT, Paulsen AW, Harbort RA, et al. Integrated anesthesia delivery/monitoring system with computer assisted anesthetic record generation. Presented at the 55th Congress of the International Anesthesia Research Society, Atlanta, GA, March 1981

2. Frazier WT, Paulsen AW, Harbort RA, et al. Integrated anesthetic delivery/monitoring system with computer assisted anesthetic record generation. Proceedings of AAMI, 17th Annual Meeting, May 9-12, 1982, San Francisco, CA

\section{INTEGRATION CONCEPTS FOR ANESTHESIA WORKSTATION DISPLAYS}

Jan J. van der Aa, PhD, Jan E. W. Beneken, PhD, Johannes H. van Oostrom, ME, J. S. Gravenstein, MD, University of Florida, Gainesville, $F L$

Summary. We present an integrated anesthesia workstation incorporating dramatic reconceptualization of perioperative information management based on a requirement analysis rather than using the conventional evolutionary approach that has led to stacking additional monitoring equipment on top of old.

Introduction. Providing care for anesthetized patients is an integrated process combining information from a number of sources for examination, preoperative evaluation, laboratory results, pharmacy orders, diagnostic tests, intraoperative monitoring, and information concerning pharmacodynamics and pharmacokinetics. At present, however, there is no comprehcnsive integration of preoperative, intraoperative, and postoperative information. Preoperative information is embedded in unmanageable records, intraoperative information is collected by hand, and data in separate administrative or computer systems are impossible or difficult to access. The anesthesia record is written by hand and often illegible so that it cannot be used for post hoc analysis of events. We present concepts by which the intraoperative workstation can be improved.

Methods. We performed a requirement analysis and noted the following. Prospective users stressed the need for an integrated display/control unit. Controls for gas supply and ventilation should always be at hand; other controls are used infrequently. The display should present coherently a wide variety of information (e.g., preoperative, ward-baseline, and diagnostic data) as well as other information and data (e.g., expert opinions on intraoperative procedures and drugs, updated laboratory results, smart alarm messages, and model-based predictions of concentrations of anesthetic agents). "User friendliness" could be improved with an expert system-driven display that is context sensitive. The system should facilitate the concurrent recording of all relevant data by integrating

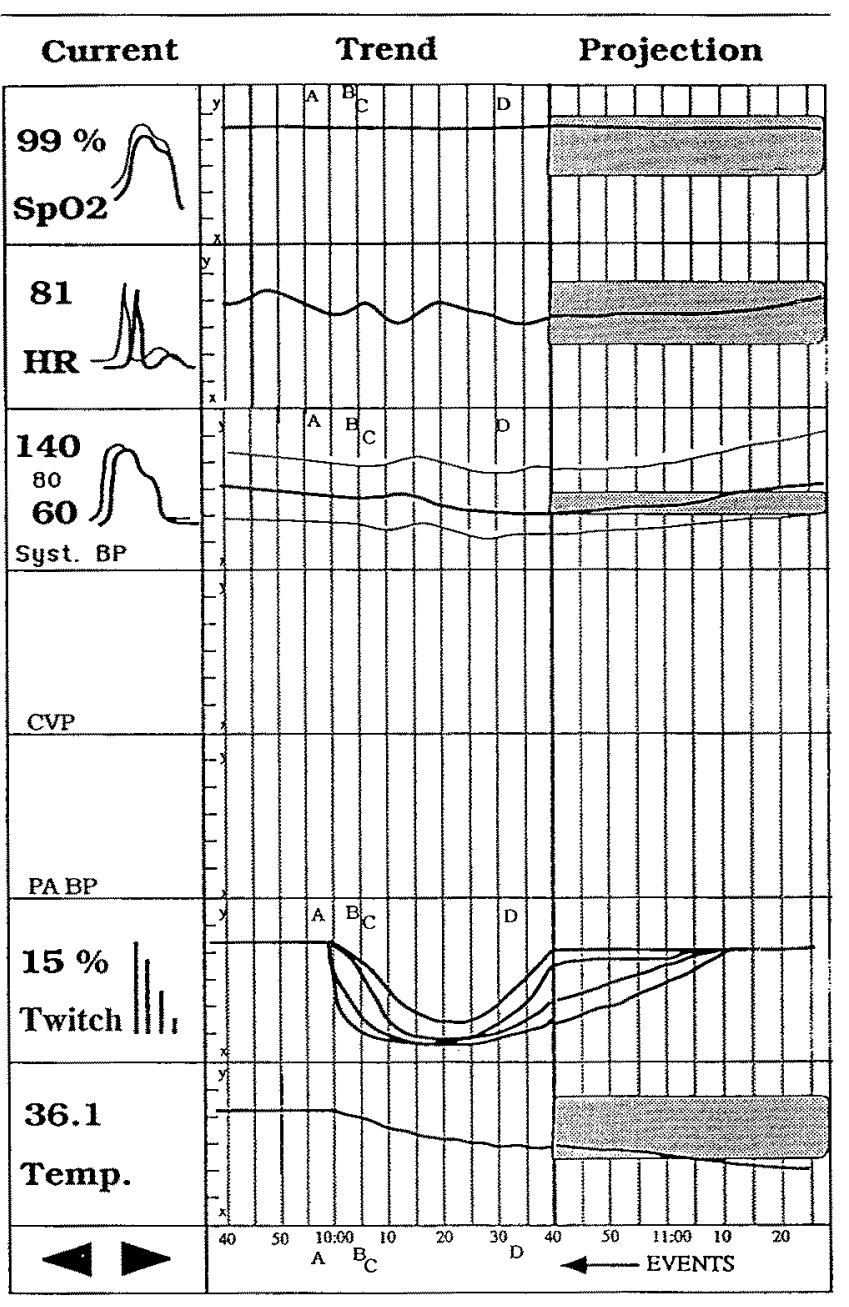

Fig 1. This display design for monitoring physiologic variables of a patient during anesthesia and operation is based on a requirement analysis. It shows the preceding trend, the current value, and the predicted trend, and allows for notation of events along the time line. 

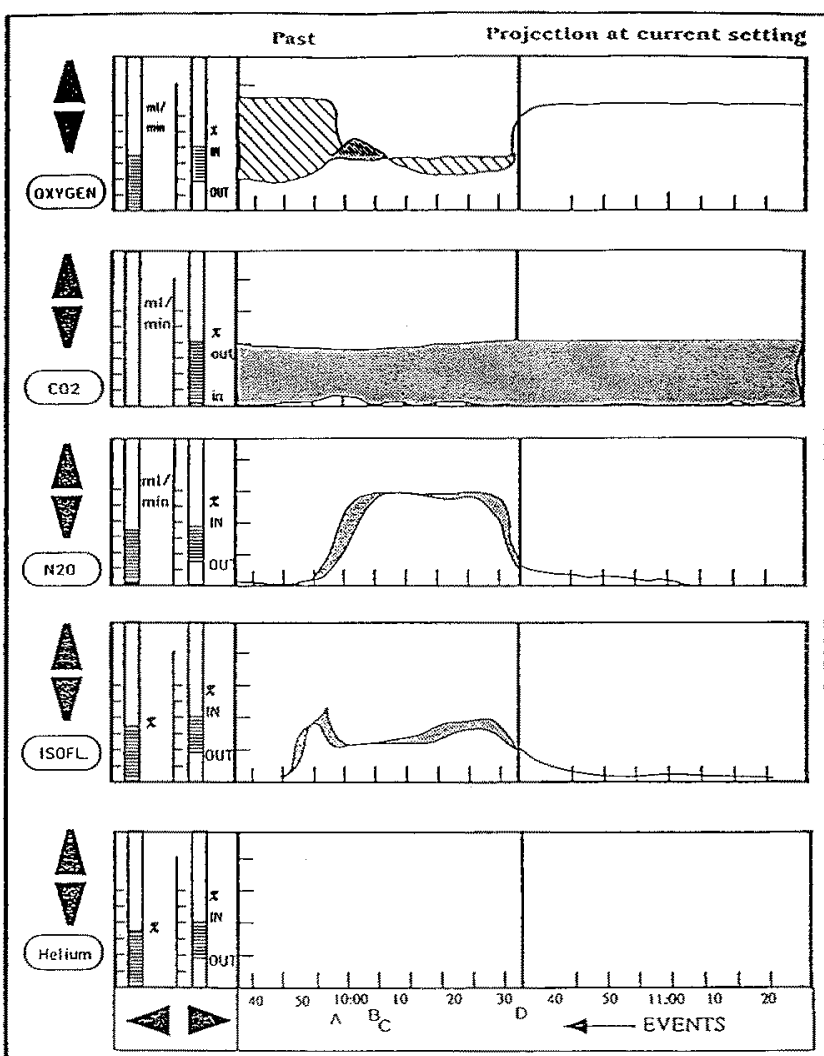

Fig 2. This display design for monitoring flow rates and inspired and expired values of anesthetic gases during anesthesia and operation, which is based on a requirement analysis, shows the preceding trend, the current value, and the predicted trend, and allows for notation of events along the time line.

various sources (e.g., information obtained automatically and from menus and handwritten text). These data should then be made available electronically to postoperative care providers.

Results. We propose a main console with a large display area (Figs 1 to 3) and an array of control knobs on the right, for example, to control ventilation. The breathing circuit remains visible throughout. One screen will present monitored physiologic variables with pertinent waveforms, derived numeric features, trend displays, and model-based projections. Another screen will present data from the literature and expert system consultation, anesthesia record entries, and external communications. A handwriting recognition system will convert handwritten entries into input.

Discussion. The design of an anesthesia workstation based on a requirement analysis by prospective users facilitates the accommodation of system needs, mandatory standards, and user needs and wishes. Contrarily, evolutionary designs often lead to systems modified by add-ons. We have studied many of the design components and have confirmed the feasibility of our design.

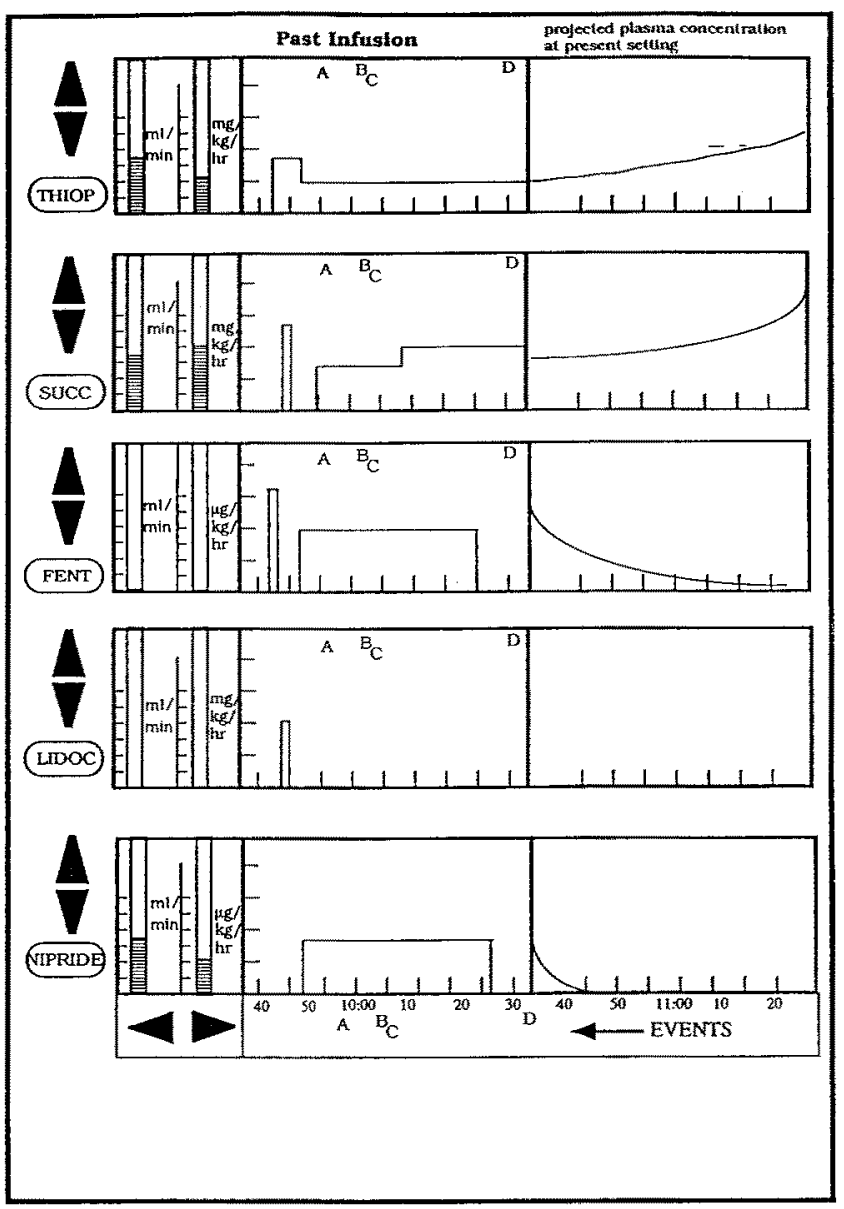

Fig 3. This display design for monitoring anesthetic infusion rates and plasma concentrations during anesthesia and operation, which is based on a requirement analysis, shows the preceding trend, the current value, and the predicted trend, and allows for notation of events along the time line.

\section{A MODERN BASIC AMESTHESIA WORKSTATION}

Alexander A. Birch, MD, Henry Casson, MD, Barbara

Tardiff, MD, Bruce Hinshaw, MD, Takeyasu Yamamura, MD, $P h D$, Oregon Health Sciences University, Portland, $O R$

Summary. A modern basic anesthesia workstation that is compact, light, and easy to use is offered as an enhancement to current design.

Introduction. Today's anesthesia machines are big, heavy, and unwieldy. The electronic monitors are located high above the anesthesia machine, making them difficult to visualize, especially through bifocals. The monitors give out multiple redundant values and alarms. A machine design based on human factors engineering is needed. The machine should be easy to use and reduce operator stress instead of enhancing it. The machine should be as ergonomically correct as possible. This report demonstrates one such design.

Methods. Following rough design sketches by members of the department, a newly designed basic anesthesia machine 
drawing was created using a computerized graphics program. The printout and components of this design will be demonstrated on posters at the meeting.

Results. Incorporated into the new design will be a below eye level anesthesia machine, a central drug injector and flusher, a pen-based computer record, remote monitors, and a lightweight compact anesthesia machine housing a fluidic ventilator. A backup "low tech" circle system will be retained in this prototype.

Discussion. The need for a new type of anesthesia machine is obvious to the authors. It is hoped that this new design will obviate many of the problems clinicians face with "current" machincs.

\section{AN ANESTHESIA WORKSTATION CREATED FROM AN ANESTHESIA MACHINE AND A PHYSIOLOGIC MONITOR}

J. Fox, CRNA, P. Drew, CRNA, Pennsylvania Hospital, Philadelphia, $P A$

Summary. A simple modification to an Ohmeda Modulus Plus Anesthesia Machine and a Marquette Tramscope 12 Monitor created a functional anesthesia workstation that met defined goals.

Introduction. The Pennsylvania Hospital is a 400-bed acute general hospital with an anesthesia department consisting of MDs, CRNAs, rotating residents, and student CRNAs. In 1983, the hospital began constructing a new 14-room operating suite. The Department of Anesthesia was asked to evaluate its equipment needs and to make recommendations to the hospital. The department decided that it would retain 7 existing anesthesia machines (Ohmeda Modulus II Plus) and replace 7 older machines. The then current mixture of ECGpressure-temperature monitors in all 14 rooms would be replaced.

The goal of the evaluation was to find equipment that would:

1. Locate as much information and as many controls as possible at eye level and within easy reach from a sitting position.

2. Keep patient cabling from crossing in front of the information screen or flow meters.

3. Provide large, easy-to-view information screens.

Methods. After much trial and many failures with unmodified combinations of equipment, we realized that some modifications would be needed to meet our goals. We relocated the monitoring pod shelf backward, tilted it upward in front, and placed a Marquette Tramscope 12 monitor on it. We then placed a Tram Rack 4 Patient Input System on its side on four $1 / 4$-inch rubber feet on the tilt shelf above the monitoring pod.

Results. Goals no. 1 and 3 were met by placing a relatively large screen at eye level in line with the flow tubes. It is easily viewed in the sitting position and controls are easy to reach. Goal no. 2 was accomplished by bringing the patient cabling down the side of the pod and out of the clinician's view.

Discussion. A simple modification to an anesthesia machine and monitoring system enabled us to merge two different manufactures' equipment into a workable, acceptable workstation that meets our defined goals (Fig). The department constructed 15 Marquette/Ohmeda workstations.

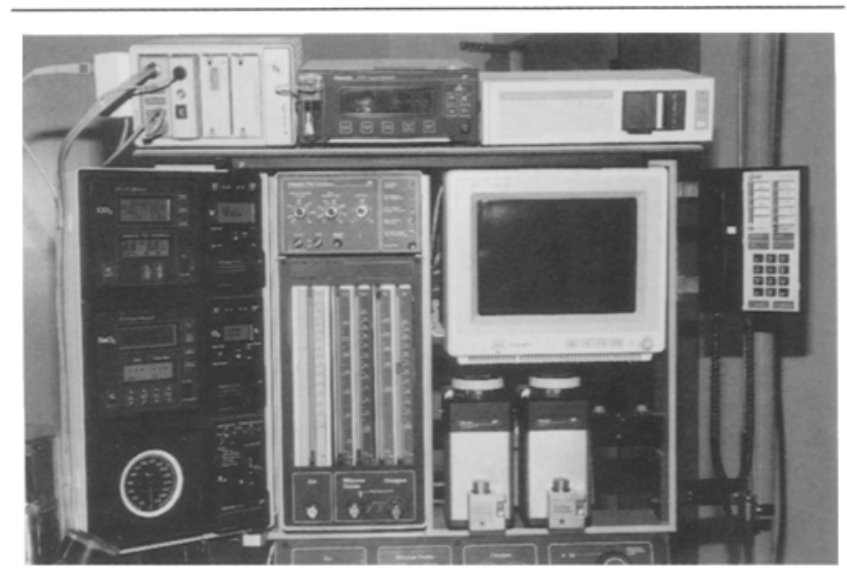

Anesthesia workstation.

\section{IHTRAOPERATIVE INFORMATION TRAISFER: A SUMMARY DISPLAY OF PATIENT STATUS}

Jan J. van der Aa, PhD, Jan E. W. Beneken, PhD, Johannes $H$. van Oostrom, ME, J. S. Gravenstein, MD, University of Florida, Gainesville, $F L$

Summary. A summary display controlled by an expert system is sufficient and effective for an initial rapid assessment of a patient's intraoperative condition.

Introduction. An abundance of information is available to anesthesiologists from many new sources, such as preoperative diagnostic tests, advanced intraoperative monitoring modalities, and prospective outcome studics. This has resulted in information overload: it is impossible for the clinician to process all the pertinent information while caring for the patient perioperatively and, particularly, intraoperatively. To resolve this problem, we developed an intraoperative summary display that conveys essential information in an eye-catching and immediately comprehensible form.

Methods. We first determined that the clinical assessment of a patient undergoing anesthesia was divided into an evaluation of 6 subsystems: circulation, ventilation, oxygenation, fluid balance, central nervous system, and relaxation. We also determined that the condition of the patient could be divided into 3 categories: acceptable, caution, and alarm. To manage information from monitors, for each subsystem an expert system evaluates which of the 3 conditions pertain to the particular subsystem.

Results. Because the 3-color warning system (greenyellow-red) is so pervasive in our society, for each subsystem an indication of the current status is implemented as a 6-pack of "traffic lights" giving the clinician a quick insight into the status of each subsystem (Figs 1 and 2). When all systems are well, this is displayed as a "green" light in each of the 6 subsystems. The expert system driving the displays shields the clinician from unnecessary details collected from a variety of intraoperative displays. When yellow or red is displayed, the most likely cause of the change in status is given as a text string.

Discussion. It must be stressed that our display augments, and is not a substitute for, the current displays. At any time, the clinician can gain access to more detailed information by calling up screens that provide an explanation of the change 


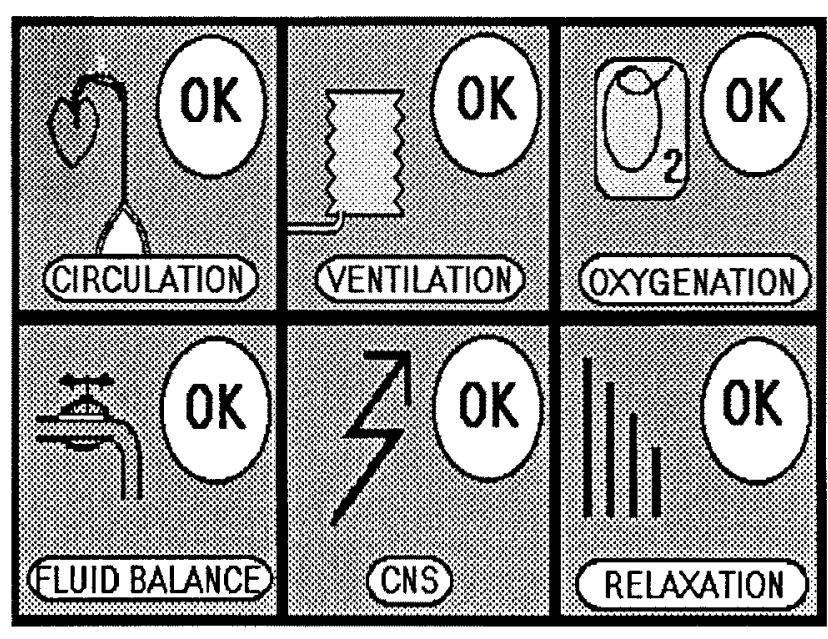

Fig 1. Summary display during "all is well" condition.

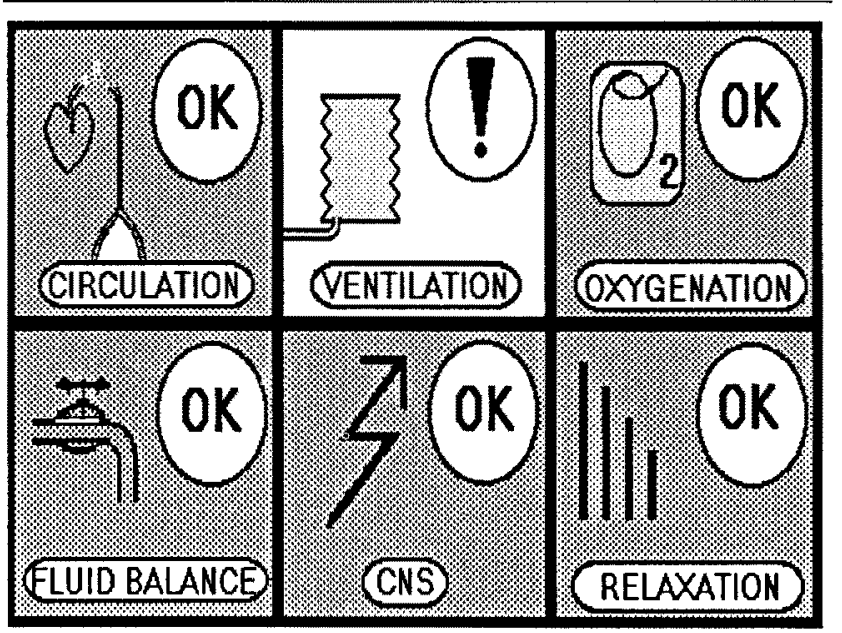

INSPIRATOHY VALVE DEFICIENT!! !

Fig 2. Summary display during a valve insufficiency.

in the patient's condition. With such a system, information is accessible in order of priority relative to the patient's condition and, thus, the risk of information overload is decreased. Our screen could be attached to the left of the current anesthesia machine or be mounted on a "balanced arm" located near the patient.

\section{Deyelopment of an electronic clipboard model, PEN-Based ANESTHESIA RECORD-KEEPING SYSTEM}

Barbara Tardiff, $\boldsymbol{M D}$, Henry Casson, MD, Alexander Birch, $M D$, Oregon Health Sciences University, Portland, $O R$

Summary. A prototype design for a clipboard model, pen-based anesthesia record that is founded on human factors guidelines and user-centered constraints is presented.

Introduction. Anesthesiologists must gather, process, and record a tremendous amount of information in a relatively short period of time. Systems that use automatic electronic anesthetic record-keeping are avalable but have not been widely adopted, possibly because they ignore the workstyle of physicians in general and anesthesiologists in particular. The primary problem appears to be a psychological opposition by anesthesiologists to a major change in their style of interaction with the record. Electronic clipboards, with data entered using a pen-like instrument, may permit introduction of automated record-keeping without requiring additional effort or adaptation by the anesthesiologist.

Methods. Desirable functionalities, which included types of information to be retrieved, processing necessary, priority of display, useful automatic computations, and information to be recorded, were selected based on formal and informal consultations with anesthesiologists in academic and private practice. Human-computer interface followed guidelines taken from the human factors literature, collective experience, and experiments and surveys. Prototype interfaces were implemented, and iterative design is continuing based on observations and analyses of user performance and reactions.

Results and Discussion. A model of an electronic anesthesia clipboard and sample charts has been created. The model is based on human factors criteria and takes into account the idiosyncrasies of how anesthesiologists create their records. The model record is indistinguishable from records in use in terms of user interaction and allows for incremental conversion to electronic record-keeping. Preliminary results of prototype testing and the iterative design process are also presented. The pen and clipboard represent a familiar conceptual model for anesthesiologists. An electronic translation that is compatible at a cognitive level with anesthesiologists and allows for easier and more efficient interaction should encourage exploration and be readily accepted.

\section{AMESTHESIA VIDEO DATA RECORDING SYSTEM}

James Piepenbrink, BS, Joseph Cullen, BS, Timothy Stafford, $M D, P h D$, Boston City Hospital, Boston, MA

Summary. Recording monitor screens on videotape offers an inexpensive yet robust solution to anesthesia signal recording.

Introduction. Perioperative data presented to the anesthesiologist has frequency characteristics that are functions of several variables: (1) physiologic model of the patient, (2) filtering characteristics of the monitor, and (3) high-frequency morphologic signal components.

The anesthesiologist and, more recently, the automatic computerized data acquisition system, are required to record or $\log$ these data. The validity of these records as a true representation of events during anesthesia is of importance, particularly during acute episodes.

Methods. We used video records of monitor displays during several anesthesia inductions and performed frequency analysis on several different signals. We then compared video recording with the conventional paper record and the data logged by a number of computer systems.

Results. The use of video recording allowed complete analy- 
sis of signal morphology. Time and frequency domain analyses demonstrated the relative importance of the individual signals and allowed recommendations for system configurations.

Discussion. Use of a video system that records all signals indicates that filtered systems (manual or computerized) do not provide a complete representation of physiologic data. Complete representation becomes particularly vital when reconstructing critical events. The need to record a complete record of data presented to the anesthesiologist is being promoted by legal pundits and the monitoring industry, yet present automated systems fall short in meeting this requirement.

\section{SILENT PAGE: A VIBRATORY ALARM FOR THE HEARIMG-IMPAIRED ANESTHESIOLOGIST}

Mark S. Wallace, MD, Michael N. Ashman, MD, MS, University of Maryland Hospital, Baltimore, $M D$

Summary. We investigated the adaptability of a vibratory wrist-watch called Silent Page for monitoring anesthesia alarms and found this device to be reliable and practical for the hearing-impaired anesthesiologist.

Introduction. Presbycusis is the effect of aging on the auditory system characteristically resulting in a bilaterally symmetric neurosensory high-frequency hearing loss (above 2,000 $\mathrm{Hz}$ ) [1]. Presbycusis is not only the most common communicative problem among the aging but also the most common auditory disorder in the entire population [2].

Currently there is no accepted standard for monitor alarms. The design process has paid little attention to the hearing acuity of the anesthesiologist population. The consequences of this will be poor detection of the high-frequency alarms among hearing-impaired anesthesiologists. We addressed this problem by testing the adaptability of a vibratory wristwatch, termed a Silent Page, for use in our operating rooms.

The Silent Page consists of a sensor-transmitter that is placed near the alarm source and a receiver that is worn on the wrist. When the monitored alarm sound occurs, the sensor-transmitter sends a radio signal to the receiver, which then vibrates. Several sensor-transmitters can be used to monitor a number of alarms.

Methods. We used the Silent Page to monitor two alarms, the Critikon Oxycheck Oxygen Analyzer and the Narkomed Anesthesia Machine. The Silent Page was tested in an unused operating room and during surgical procedures. The alarms were triggered 25 times each and the receiver was observed for vibration. When the specified alarms sounded during the surgical procedures, the receiver was observed for vibration.

The Silent Page was then tested in a soundproof booth with known frequencies and intensities of sound to determine the frequencies to which the sensor-transmitter was most sensitive. White background noise of known intensity was also tested to determine (1) whether sensing by the sensortransmitter occurred and (2) whether interference with an alarm sound at a frequency of 3,000 to $4,000 \mathrm{~Hz}$ (which was the frequency at which the sensor-transmitter was most sensitive) occurred.

Results. The receiver vibrated $100 \%$ of the time in the empty operating room, with no cross-triggering between alarms and no false alarms. During 10 separate surgical procedures, the Narkomed alarmed 5 times with $100 \%$ receiver vibration. There was one false alarm that occurred when the sensor- transmitter was accidentally bumped. The Critikon Oxycheck did not alarm during the 10 procedures.

In the sound-proof booth it was determined that the sensortransmitter was most sensitive at 3,000 to $4,000 \mathrm{~Hz}$, requiring an $85-\mathrm{dB}$ sound to trigger. When a $50-\mathrm{dB}$ white background noise was added, the intensity of the sound required to trigger the pager was decreased to $75-\mathrm{dB}$, but the background noise alone did not trigger the pager.

Discussion. We determined that the Silent Page is adaptable for monitoring the alarms in our operating rooms. By placing the sensor-transmitter next to the alarm to be monitored, consistent detection of the alarm sound was accomplished. The sensor-transmitter is most sensitive at 3,000 to $4,000 \mathrm{~Hz}$, which is the frequency range of most alarms in our operating room. In addition, the sensor-transmitter does not seem to be sensitive to the background noise of the operating room. Rather, background noise makes the sensor more sensitive. We conclude that the Silent Page has a place in alarm detection for the hearing-impaired anesthesiologist.

\section{REFERENCES}

1. Bess FH, Humes LE. Audiology: The Fundamentals. Baltimore: Williams \& Wilkins, 1990

2. Maurer JF, Rupp RR. Hearing and Aging: Tactics for Intervention. New York: Grune \& Stratton, 1979

3. Sander MS, McCormick EJ. Human Factors in Engineering and Design, 6th ed. New York: McGraw-Hill, 1987

Special thanks to Quest Electronics for donating the Silent Page for this investigation.

\section{CAUSES, EFFECTS, AND DETECTION OF IMCORRECT MEDICAL GAS DELIVERY}

J. Hutchinson MD, E. Lee, MD, S. Nagle, MD, C. F. Mackenzie, MD, University of Maryland Hospital, Baltimore, $M D$

Summary. There are many causes for incorrect medical gas delivery, and mass spectrometers can identify most of them.

Introduction. Although an uncommon event, the accidental substitution of one anesthetic gas for another can have devastating consequences. This review details some of the ways delivery of incorrect medical gases may occur during anesthesia, lists the safety features and industry standards designed to prevent these occurrences, shows which monitors would optimally detect accidental substitutions, and categorizes the types of reactions that could result from incorrect mixtures of oxygen, nitrous oxide, carbon dioxide, air, nitrogen, or helium.

Delivery of incorrect gas. Medical gases are supplied by bulk storage containers and pipeline systems or by cylinders. Bulk storage tanks may be filled with the wrong gas and the oxygen/nitrogen proportioning system used to manufacture reconstituted air may malfunction $[1,2]$. Pipelines may become damaged or misconnected during installation or repair [3-5]. Cylinders may be filled with the wrong gas, mislabelled, or painted the wrong color. Faulty valves or yoke indexing pins may permit attachment to the wrong yoke on an anesthesia machine $[6,7]$. 
Safety features, Bulk storage containers have pressure and thermal alarm systems. Air tanks have alarms to signal malfunction of the compressors or the oxygen/nitrogen proportioning system and elevations in water content. Fill hoses from supply trucks are indexed to prevent misfilling. Containers must be labelled and color-coded, and gas analyzers are present to determine the identity and concentration of gases. Pipelines also contain pressure alarms and gas analyzers, and may have different diameters or be color-coded [8]. Gas outlets terminate in gas specific-labelled connectors. Cylinders must be labelled and color-coded and have pin-index holes to prevent connection to yokes specific for another gas. The anesthesia machine incorporates a flow ratio alarm and oxygen pressure failure safety valve to help prevent delivery of hypoxic mixtures.

Monitoring to detect gas substitution. The in-line oxygen analyzer is an important defense against delivery of hypoxic gas mixtures as it reports the concentration of oxygen delivered to the patient $[9,10]$. Although potentially lifesaving in the event of a misconnection involving oxygen, the oxygen analyzer does not determine which gas has been wrongly administered. Capnography detects incorrectly administered carbon dioxide while mass spectroscopy provide gas-specific evaluation of oxygen, nitrous oxide, nitrogen, and carbon dioxide [11]. Helium, however, is not detected by the mass spectrometer, and will cause incorrect readings of other gases [12]. Pulse oximetry alerts the anesthesiologist to decreases in the patient's oxygen saturation, one cause of which is delivery of a hypoxic gas mixture [13]. Clinical signs such as cyanosis and heart rate or blood pressure change are also useful.

Consequences of gas substitution. We divided the consequences of gas substitutions into four categories: disastrous, potentially problematic, anesthetic changes, or no noticeable change. Disastrous substitutions are those in which too little oxygen is given, and they represent the threat of death or permanent neurologic damage $[14,15]$. Situations that may pose a problem for certain subclasses of patients include the administration of carbon dioxide, failure to deliver helium or air, accidental administration of nitrous oxide or helium, or prolonged administration of $100 \%$ oxygen. Changes in anesthetic management may be noticed with an increase or decrease in the concentration of nitrous oxide, or by changes in vaporizer or flowmeter dynamics [16]. Cross-connections between air, nitrogen, and helium are not likely to show any effect on anesthetic concentration.

Case reports. Six references, for a total of 10 cases, were found in the anesthesia literature $[1,7,14,15,17,18]$. In none of the cases involving hypoxia was an in-line oxygen analyzer in use, as recently as $1990[1,14,15,17,18]$. In most cases, mass spectroscopy would have pinpointed the substitution $[1,14,15,17,18]$.

\section{REFERENCES}

1. Sprague DH, Archer DW. Intra-operative hypoxia from an erroneously filled liquid $\mathrm{O}_{2}$ reservoir. Anesthesiology 1975;42:360-362

2. Gilmor IJ, McComb RG, Palahriuk RJ. Contamination of a hospital $\mathrm{O}_{2}$ supply. Anesth Analg 1990;71:302-304

3. Tingay MG, llsley AH, Willis RJ, et al. Gas identity hazards and major contamination of the medical gas system of a new hospital. Anesth Intensive Care 1978;6:202-209
4. Arrowsmith LWM. Medical gas pipelines. Eng Med 1979;8:247-249

5. Lane GA. Medical gas outlets-A hazard from interchangeable "quick connect" couplers. Anesthesiology 1980; $52: 86-87$

6. Feeley TW, Bancroft ML, Brooks RA, et al. Potential hazards of compressed gas cylinders. Anesthesiology $1978 ; 48: 72-74$

7. Holland R. Foreign correspondence: Another "wrong gas" incident in Hong Kong. APSF Newsletter 1991;Spring:9

8. Cundy JM. A safety feature for piped gas supplies. Anesthesiology 1976;31:109-110

9. Mazze R. Misadventures with oxygen delivery systems: The need for continuous in-line oxygen monitors. Anesth Analg 1972;51:787-789

10. Dorsch JA, Dorsch SE. The breathing system. In: Dorsch and Dorsch, eds. Understanding Anesthesia Equipment. Baltimore: Williams \& Wilkens, 1984:136-181

11. Chen L, Marshall B. The diagnosis and management of perioperative hypoxemia. In: ASA Refresher Courses. Chapter 4, vol. 16, 1988, pp 41-56

12. Williams EL, Benson DM. Helium-induced errors in clinical mass spectrometry. Anesth Analg 1988;67:83-85

13. Kelleher JF. Pulse oximetry. J Clin Monit 1989;5:37-62

14. Bonsu AK, Stead AL. Accidental cross-connection of oxygen and nitrous oxide in an anesthesia machine. Anesthesiology 1982;38:767-769

15. Epstein RM, Rackow H, Lee AS, et al. Prevention of accidental breathing of anoxic gas mixtures during anesthesia. Anesthesiology 1962;23:1-4

16. Diaz PM. The influence of carrier gas on the output of automatic plenium vaporizers. Br J Anaesth 1976;48: $387-391$

17. Jawan B, Lee JH. Cardiac arrest caused by an incorrectly filled oxygen cylinder: A case report. Br J Anaesth 1990;64:749-751

18. Sato T. Fatal pipeline accidents spur Japanese standards. APSF Newsletter, 1991

\section{DEVELOPMENT OF PROBLEM CATEGORIES FOR COMPUTERIZED PREANESTHESIA EVALUATION OF OUTPATIENTS}

G.L. Gibby, MD, K.I. Jackson, ME, J.S. Gravenstein, MD, and D.A. Paulus, MD, Departments of Anesthesiology and Mechanical Engineering, University of Florida, Gainsville, FL

Summary. We designed and implemented a computerized anesthesia preoperative evaluation that structures the review system's (ROS) findings into problem subcategories. Despite the use of 49 specific subcategories, an "OTHER" subcategory was still required for more than $25 \%$ of the problems in six areas of the ROS.

Introduction. We designed and implemented a computerized anesthesia preoperative evaluation system for outpatients. Information in the system, which comprises 7 networked computers for physicians and secretaries, was divided into 11 system categories: allergy (ALGY), central nervous system (CNS), cardiovascular (CV), endocrine (ENDO), gastrointestinal (GI), genitourinary (GU), hematology (HEME), infectious disease (ID), respiratory (RESP), skeletal (SKEL), and miscellaneous (MISC). These categories were subdivided into 60 subcategories, such as "CNS-scizure" and "CV- 
hypertension." Each category also included its own miscellaneous subcategory to allow entry of medical problems that are not easily categorized. When a subcategory was selected on the system, dozens of descriptive options, such as "febrile" and "well-controlled" could be chosen by mouse and entered or edited by keyboard. Entry by either mouse or keyboard of any text into a subcategory caused that subcategory to be marked as a "problem." We devised a study to test whether our subcategories were adequate.

Methods. Patient data collected for 4 months and 4 days were collected by computerized review. The subcategories marked "significant" and the text length in each were collected. We counted the frequency with which the subcategories were marked as a problem, which served as a measure of utility, and the number of characters used in each problem description, which served as a measure of the importance of the problems being categorized and of the difficulty in categorizing.

Results. The computerized system contained evaluations on 1,027 patients: 269 ASA I (26.2\%), 468 ASA $2(45.6 \%), 191$ ASA $3(18.6 \%)$, and $99(9.6 \%)$ patients whose ASA classification was not computer readable. These patients had 3,229 problems (3.1 problems/patient). The 5 most frequently used subcategories were habits $(\mathrm{n}=573,55.8 \%)$, allergy $(\mathrm{n}=$ $424,41.3 \%)$, hypertension $(\mathrm{n}=161,15.7 \%)$, arthritis ( $\mathrm{n}=$ $119,11.6 \%)$, and hiatal hernia/reflux ( $\mathrm{n}=106,10.3 \%)$. The miscellaneous subcategory in each system category was never the least-selected subcategory and exceeded $25 \%$ of the total problems in the systems categories of CNS, GI, HEME, ID, RESP, and SKEL. In the miscellaneous subcategories, RESPmiscellaneous required the highest number of characters per problem (144.6), while the average number of characters per problem for the entire system was 80.9 .

Discussion. The computerized evaluation system aids the user in categorizing patient problems. This also allows a count of the medical problems within a population and may allow quantitative documentation of the relative illness of a patient population served by a hospital. The high incidence of problems categorized as medication allergy or habit probably reflects the insertion of text to document significant negative results, a user preference that emerged. An unexpected finding was the extreme importance of providing a miscellaneous category within each system category, despite 49 other possible subcategories based partially on our previous handwritten form. Substantial numbers of characters were used to describe problems that the user categorized as miscellaneous.

\section{A COMPUTER-BASED INTELLIGENT ASSISTANT FOR PREOPERATIVE EVALUATION}

R. G. Carovano, K. I. Jackson, G. L. Gibby, Department of Anesthesiology and Medicine, University of Florida, Gainesville, $F L$

Summary. A 16-rule expert system to serve as an intelligent assistant to aid in preoperative anesthetic evaluation has been implemented easily and shown to function in a modular manner.

Introduction. Patients undergoing anesthesia at the study institution are seen preoperatively by anesthesiologists. These clinicians must assess the patient's physical status and prepare for the upcoming anesthetic treatment. Presently, patient data are collected by using the preoperative assessment program
(PAP), a computer-based information system (HewlettPackard and University of Florida Department of Anesthesiology). While this program provides a systematic method to elicit patient information, the anesthesiologist must sift through the collected data to extract the clinically meaningful information. A computer-based "intelligent assistant" can assist anesthesiologists in preoperative patient evaluation.

Methods. Our research team investigated the expert system approach to preoperative patient assessment. The expert system consisted of five components: a user interface, a patient database, a knowledge base, an inference engine, and an explanation system. Because the intelligent assistant is an extension of PAP, the existing information system provided the user interface and patient database. Next, a knowledge base was developed to establish how the computer should analyze patient information and suggest a specific course of action. The knowledge base was developed through several interviews with one of the authors (G. L. G.), an expert anesthesiologist. Once the knowledge base was established, the inference (or reasoning) engine was developed and programmed. The knowledge collected during the interviews was recorded as "if-then rules" for reasoning; for example, if patient has experienced seizures, then output "avoid enflurane." Moreover, as each of these rules is invoked, the expert reasoning behind these rules is also presented to the anesthesiologist.

To evaluate the feasibility of the rule-based expert system, 16 "if-then" rules were implemented and are being tested.

Results. Preliminary results show that the expert system approach provides modularity and ease of implementation.

Discussion. The expert system approach provides a modular way to add intelligence to PAP because the knowledge base, inference engine, and explanation system are separated from the user interface and patient database. As the knowledge base expands, new rules are added incrementally to the system.

\section{CREATING A PROLDG PROGRAM IN A HANDHELD PERSOMAL COMPUTER FOR MANAGING THE CARDIOVASCULAR SYSTEM FOLLOWING SPINAL ANESTHESIA INDUCTIOH}

M. L. Smith, MD, T. Scanlon, MD, N. Ty Smith, MD, VA Medical Center, University of California, San Diego, and US Naval Hospital, San Diego, CA

Summary. We created an artificial intelligence program to help manage the cardiovascular system after spinal anesthesia and demonstrated the feasibility of hand-held artificial and expert systems.

Introduction. The technology of miniaturization has advanced to the point at which the full power of a personal computer can be held in the palm of the hand. There are several "palmtop" computers available today. They range from personal managers with limited memory to full-fledged personal computers. The HP 95LX is notable among them. It is smaller and lighter than most $(11 \mathrm{oz})$, but has the full power of an IBM PC. It has a serial interface for communication and file transfer. In normal use, a shell program manages the $1 \mathrm{Mbyte}$ of ROM-packaged utilities. For special purposes like ours, the shell can be exited, DOS entered, a compiled algorithm downloaded into RAM, and the executable code run. The HP 95 has 512 Kbytes of RAM memory and will accommodate any standard RAM memory card (128 Kbytes to 4 Mbytes). These cards are recognized as a disk drive.

Concurrently with hardware technology, the area of artifi- 
cial intelligence and expert systems (AI) software has continued to improve. Prolog is one of several computer languages developed for AI research. We chose this language to implement our clinical system to aid anesthesiologists in clinical care. We combined 3 areas of new technology (hardware, software, and a special-purpose AI language) into a palm-sized tool. We have implemented a prototype algorithm that helps the clinician manage the patient's cardiovascular system after spinal anesthesia is induced.

Methods. A prototype expert system was developed using a UNIX mainframe-based Prolog language, UNH Prolog. This code was then transferred to a DOS-based personal computer and, using the Prolog language by Cogent, was modified to run in a DOS environment and compiled into an executable program. This executable code was then downloaded to an HP 95LX that could be taken to the clinical location where spinal anesthesia was to be induced.

Results. The clinical tool functioned satisfactorily in helping manage the cardiovascular system after spinal anesthesia induction. The output from the computer was in the form of either recommended course of action for cardiovascular stability or an alert to impending danger.

Although the keyboard was barely adequate for entering lengthy sentences, it was very good for the succinct entry of vital signs. The HP 95LX managed real-time function when driven by keyboard entry.

Discussion. Spinal anesthesia in a healthy young adult usually involves making decisions about the patient's cardiovascular system. These decisions are made with knowing the preexisting status of the cardiovascular system, the patient's current fluid status, and the vital signs. Management of spinal anesthesia requires frequent measurement of vital signs and occasional assessment of the level of anesthetic block. Typically, management may involve the use of fluid boluses, pressors, or chronotropic drugs. Interventions can be extensive early in the spinal anesthetic, but tend to plateau and diminish with time if problems are correctly addressed when they occur. Along with the urgent management demands of spinal anesthesia immediately after its induction, there are potentially more catastrophic scenarios. The algorithm must be able both to manage the routine events of spinal anesthesia and alert the clinician to potentially dangerous and emergent situations and suggest a course of action.

This type of AI management aid could be useful in several other situations. An anesthesia technician in a battlefield hospital situation could better care for the injured, or a paramedic in the field could provide better care before and during transport.

Several enhancements are suggested by our success thus far. The present prototype system requires manual keyboard entry of the patient's weight and vital signs. In the future, NIBP data could be sent directly to the computer through the builtin serial port. Since the program uses the built-in system clock of the HP 95LX, the computer could also act as a data logger of automated record keeper, recording and displaying vital signs input and the interventions recommended.

\section{ANALYSIS OF THE MORNING WARD ROUMD IN AN INTENSIVE CARE UNIT}

U. Ringeler, W. Freisdorf, B. Schwilk, H. Wiedeck, University of Ulm, Ulm, Germany

Summary. We evaluated the structure and content of the daily morning ward round on an intensive care unit, revealed deficits in information transfer, and developed a structured model for a standard morning ward round that includes organ system-oriented information classification.

Introduction. Intensive care medicine is characterized by extensive treatment and monitoring based on a huge amount of data that arises within a short time period. Thus, the management of patient-related data has become a major issue in the intensive care unit. As physicians and nurses are working in shifts, well-organized information transfer is a precondition for the successful work of the clinical team. The most important procedure for the generating and transferring information is the morning ward round (MWR).

Methods. In a preliminary study we analyzed and classified the items discussed during the MWR. On this basis we designed a form that enabled simple marking to quickly record items discussed. During the 3 -week study, a silent observer consultant accompanied the MWR to observe and record information transfer.

Results. We analyzed 255 bedside discussions during 21 days of the MWR referring to 65 different patients. The duration of discussions lasted from 1 to 15 minutes per patient; the mean value was 5 minutes.

The four most frequently mentioned subjects were neurologic status $(86 \%)$, respiratory system $(85 \%)$, nursing problems $(70 \%)$, and cardiovascular system $(62 \%)$. The most important deficits of information transfer concerned microbiology $(12 \%)$ and surgical aspects $(7 \%)$. All other subjects previously identified as important had deficits below $5 \%$.

Discussion. The bedside MWR showed a clear structure: (1) case history, (2) current status pointing out main problems, and (3) free discussion. Numeric parameters were used very seldomly. Access to information contained in the medical record was difficult and time consuming. Based on our observations, we recommend a standardized organ system-oriented classification of MWR items to communicate a complete survey of the patient's status.

\section{A SPINAL anesthesia database on a Personal computer}

N. Katchanov, K. Debolsky, Regional Hospital of Celinograd, USSR

Summary. We wrote a computerized database management system that we use for spinal anesthesia, and have discovered many interesting clinical relationships that have impacted our practice.

Introduction. Celinograd Regional Hospital performs approximately 1,500 operations annually using various forms of regional anesthesia; epidural and spinal block comprise $85 \%$. We analyzed clinical practices and determined the information necessary for clinical care. Rather than collect only this data, we decided to perform more extensive data collection. We hoped the computerized data management system would allow us to ask and answer new questions. Preliminary results from the spinal anesthesia version of our program are presented. These results show important clinical relationships.

Methods. Both clinical practice (e.g., spinal anesthesia administration position) and data recording were standardized for the variables collected. The computer program portions to input data, analyze results, and manage the database were written in the KARAT language. The program consisted of three parts:

1. keyboard entry of patient data (some items recorded were starting blood pressure, maximum blood pressure reduc- 
tion during block, medications administered preoperatively, medications administered intraoperatively, cerebrospinal fluid (CSF) pressure and results of analytic tests, spinal anesthetic drug volume and concentration, anesthetic level achieved, opiate type and administration method, duration of surgical anesthesia, and duration of postoperative analgesia),

2. database (the database management program, like all parts of the system, was written in the KARAT language), and 3. data analysis.

To detect and quantify relationships between measures, the program built a series of pseudographs, plotting two variables on the $\mathrm{x}$ and $\mathrm{y}$ axes with the outcome variable expressed as the color of the dot representing the clinical situation (pseudo-z axis). Patients were divided into two groups, obstetric and others. We sought to identify factors that affected the anesthetic level and the quality of postoperative analgesia.

One specific question we asked was what influence do the two opiates, natural morphine and synthetic moradol, have on spinal anesthesia duration and postoperative analgesia quality?

Another question we asked was what influence do blood and CSF composition, CSF pressure, pregnancy, and pregnancy beyond 12 weeks' duration have on anesthetic level?

Results

1. Keyboard entry. The program was simple to use.

2. The database is comprised of records from 148 patients who received spinal anesthesia for surgery.

3. Data analysis has allowed us to discover significant information about characteristics of our patients and quality of anesthesia. Some examples are as follows:

a. Factors that affected anesthesia quality were spinal anesthesia without introduction of opiates, spinal anesthesia with moradol epidural introduction, spinal anesthesia in combination with moradol intrathecal introduction, spinal anesthesia with morphine epidural introduction, and spinal anesthesia with morphine intrathecal introduction. Morphine intrathecal provided the best quality.

b. The level of anesthetic achieved in pregnant women was not related to biochemical blood or CSF measures, hormone levels, or CSF pressure. The level of anesthesia achieved became constant from the 12 th week of pregnancy.

Discussion. The program we created allowed us to identify important factors in our spinal anesthesia practice. We were able to determine the difference between anesthetic levels in pregnant and nonpregnant patients. In addition, we determined the relationship between duration of spinal anesthesia, postoperative analgesia, and use of morphine or moradol.

In our view, the best spinal anesthetic technique includes intrathecal morphine. While the program we developed is well suited to research, the present database can be used by new physicians as a practical guide for spinal anesthesia.

\section{IMPROVING ALARM SYSTEMS: HOW TO DEFIME ACCEPTABLE VITAL SIGUS DURING GEMERAL ANESTHESIA}

J. H. van Oostrom, ME, C. Gravenstein, J. E. W. Beneken, PhD, J. S. Gravenstein, MD, University of Florida, Gainesville, FL

Summary. Knowing the clinical operating range of physiologic variables is important in developing new moni- tor alarm strategies. Clinical operating range values for blood pressure, heart rate, $\mathrm{SpO}_{2}$, and $\mathrm{PETCO}_{2}$ are reported from 50 patients during 4 phases of anesthesia.

Introduction. Patients' vital signs change as a consequence of drugs, mechanical ventilation, body position, and surgical perturbations. Anesthesiologists anticipate the direction and magnitude of these changes and work with ranges of acceptable values for the vital signs of their patients. We call this range the clinical operating range (COR) for a given, monitored physiologic variable. COR limits are expected to be exceeded frequently. Monitoring equipment displaying COR ranges would be more useful than systems limited to alarm thresholds. We present an approach to determining COR values for systolic and diastolic blood pressure (BP), heart rate $(\mathrm{HR}), \mathrm{SpO}_{2}$, and $\mathrm{PerCO}_{2}$.

Methods. We studied 50 patients undergoing general anesthesia. Seventeen resident anesthesiologists were asked to state CORs for systolic and diastolic $\mathrm{BP}, \mathrm{HR}, \mathrm{SpO}_{2}$, and $\mathrm{PETCO}_{2}$ for the induction, intubation, maintenance, and emergence phases of the anesthesia. Frequency, duration, and magnitude of transgressions of these COR limits were recorded, as well as whether they were treated or tolcrated, or whether the COR limit was changed.

Results. Transgressions of COR values for $\mathrm{BP}$ and $\mathrm{HR}$ were common, treatment was frequent, and redefinition of CORs was rare. Generally, the difference between lowest and highest COR values was more narrow for the maintenance phase than for the other phases of anesthesia (Fig).

Seventy-six percent of the transgressions lasted less than 10 minutes and were within $20 \%$ of the designated COR limit. Upper COR values for systolic BP were $30 \pm 20 \%$ above the values recorded just before induction of anesthesia. Lower COR values for systolic BP were $31 \pm 11 \%$ below preinduction values. For $\mathrm{HR}$, upper and lower COR values were 53 $\pm 44 \%$ above and $38 \pm 17 \%$ below preinduction values. COR ranges for $\mathrm{PETCO}_{2}$ and $\mathrm{SpO}_{2}$ were narrow and did not change significantly for the different phases of anesthesia.

Discussion. Clinicians recognize ranges for vital signs during uneventful anesthesia. These CORs may differ from one stage of anesthesia to the next. Monitor alarm systems would be

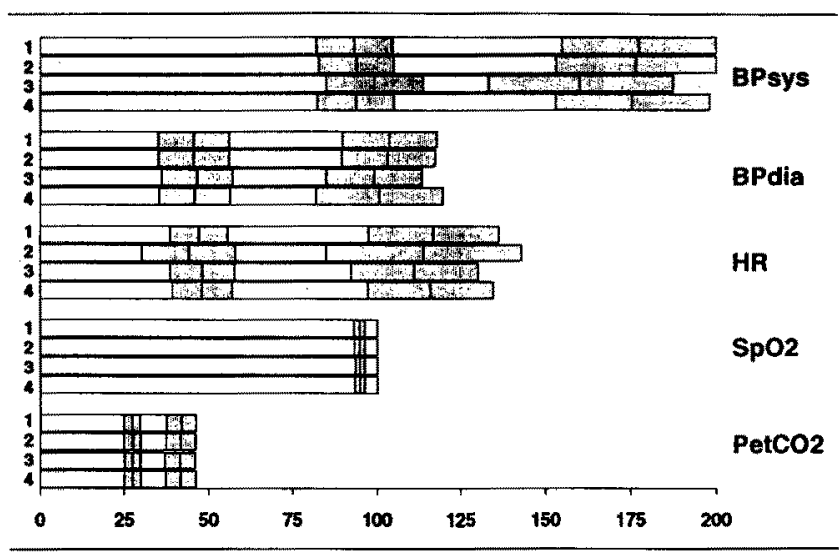

Average upper and lower COR limits, with standard deviations, during the 4 phases of anesthesia: (1) induction, (2) intubation, (3) maintenance, and (4) emergence. BPsys, systolic blood pressure ( $\mathrm{mm}$ $\mathrm{Hg}$ ), BPdia, diastolic blood pressure ( $\mathrm{mm} \mathrm{Hg}$ ); $\mathrm{HR}$, heart rate (beats/min); $\mathrm{SpO}_{2}$, oxygen saturation as measured by pulse oximetry (\%); $\mathrm{PETCO}_{2}$, end-tidal $\mathrm{PCO}_{2}(\mathrm{~mm} \mathrm{Hg})$. 
more valuable if they could anticipate the different ranges for each phase of anesthesia.

\section{ANALYSIS OF THE EFFICACY OF THE OHMEDA CENTRAL DISPLAY MODULUS II ALERT ZONE SYSTEM}

D. M. Feinstein, MD, MS BME, ${ }^{*}$ I. D. Calalang, $B S, t$ J. H. Philip, ME(E), MD, † D. C. Sutton, FFARACS,

* Beth Israel Hospital, Harvard Medical School, Boston, MA; and + Brigham and Women's Hospital, Harvard Medical School, Boston, $M A$

Summary. Use of the Ohmeda Alert Zone System (AZS) reduced blood pressure variation in a retrospective study, but this relationship was not confirmed in two prospective studies.

Introduction. The Ohmeda Central Display (CD) Modulus II anesthesia machine incorporates an Alert Zone System (AZS) designed as an early detector of physiologic variable changes. As with any monitoring modality, it is difficult to determine if this feature is helpful in patient management. Four studies were designed to assess the efficacy of the AZS: user interaction, user survey, rate of alert outputs, and variability of physiologic parameters with and without the AZS. An action logger system was designed to record the intraoperative responses of an anesthesiologist to alerts during anesthesia administration. An observer would determine the appropriateness of alert activations and actions taken. The second proposed method was a subjective questionnaire for anesthesiologists using the system. The third method, an objective study, was to determine the number of alerts generated over the course of an operation. The number of alerts per hour, however, might not necessarily indicate the usefulness of the AZS. Another possible objective study used analyzing blood pressure (BP) stability during cases with and without the AZS on. It was hoped that this study would show decreased variation in systolic BP when the alerts zones were used. This final design was implemented both retrospectively and prospectively. The retrospective analysis suggested a significant difference in BP variation between cases with and without the AZS. However, the prospective study did not show a significant difference for both blinded and unblinded analysis.

Methods. The AZS assessment study involved a 3-phase analysis of stored data from the Ohmeda CD Modulus II's disk logging feature. The first phase was a retrospective analysis of 14 laparoscopic cholecystectomy (Lap CCY) cases, 7 with the AZS on and 7 with the AZS off. In both groups, time epochs from 10 minutes after the skin incision to the end of the surgical procedure were extracted, and percent $B P$ variation was calculated as 100 times the standard deviation of BP divided by its mean.

The second phase was a blinded prospective study. A single anesthesiologist, unaware of the study objectives, was instructed to alternate AZS usage between Lap CCY cases using any anesthetic technique desired. Eighteen cases were analyzed, the same time epochs were extracted, BP variation was calculated for each case, and average $\mathrm{BP}$ variation with and without use of AZS were compared.

The final phase of the study challenged 2 anesthesiologists, each with 10 Lap CCY cases, to minimize BP variation using any anesthetic method. The AZS was active on alternate cases for each clinician. Again, time epochs were extracted, and BP

\begin{tabular}{llll}
\hline & $\begin{array}{l}\text { Avg BP } \\
\text { Tydy }\end{array}$ & $\begin{array}{l}\text { Avg BP } \\
\text { AZS Offiation }\end{array}$ & $\begin{array}{l}\text { \% Variation } \\
\text { AZS On }\end{array}$ \\
\hline Phase 1 & Retrospective & $9.3 \pm 3.2$ & $5.2 \pm 1.0$ \\
Phase 2 & Prospective & $9.1 \pm 5.3$ & $9.4 \pm 6.3$ \\
Phase 3a & Prospective & $9.2 \pm 3.2$ & $9.4 \pm 1.2$ \\
Phase 3b & Prospective & $7.6 \pm 2.0$ & $6.8 \pm 1.4$ \\
\hline
\end{tabular}

variation was calculated for each case and the values compared.

Results

Phase I-retrospective study: The retrospective study showed a significant difference in BP variability (Table). There was no difference in the average $\mathrm{BP}$ of each study group $(115 \mathrm{~mm} \mathrm{Hg})$. However, the average percent $B P$ variation of the two groups differed significantly $(9.3 \pm 3.2$ AZS off, 5.2 $\pm 1.0 \mathrm{AZS}$ on).

Phase 2-prospective blind study: The prospective blind study included 18 cases, $11 \mathrm{AZS}$ off and $7 \mathrm{AZS}$ on. The average percent $B P$ variation with the $A Z S$ on was $9.4 \pm 6.3$, while the average percent $B P$ variation with the $A Z S$ off was $9.1 \pm 5.3$.

Phase $3 \mathrm{a}$ and $\mathrm{b}$-prospective target study: For both physicians ( $a$ and $b$ ), the prospective nonblinded study showed similar average $B P$ variation between cases with and without AZS. For one clinician (a) the average percent BP variation with AZS on was $9.4 \pm 1.2$ compared with $9.2 \pm 3.2$ for AZS off. The other physician (b) had similar average percent $\mathrm{BP}$ variation for his cases: $6.8 \pm 1.4$ and $7.6 \pm 2.0$ for $\mathrm{AZS}$ on and off, respectively.

Discussion. The AZS was designed to be useful during the maintenance period of anesthesia (i.e., when the patient is thought to be stable). It is our assumption that maintaining low blood pressure variation during this period indicates a well-managed anesthetic.

The results of phase 1, the retrospective study, suggested that blood pressure variability is reduced when the AZS is on compared with when it is off, suggesting that the AZS is a helpful feature for anesthetic management.

The phase 2, prospective study failed to show a difference in blood pressure variation between cases with and without the AZS on. Similarly, phase 3 failed to show a decrease in blood pressure variation when the AZS was on, even though the anesthesiologists were told their objective and could use any anesthetic technique.

The difference between results from the retrospective study and from the prospective studies suggests that there may be a number of limitations to our analysis of AZS efficacy. Differences in anesthetic technique, unrecognized biases, insufficient case numbers, type of surgical procedure, time period analyzed, and patient selection may all contribute to the deviation seen.

In summary, although retrospective study showed a significant decrease in blood pressure variation when the AZS was on, prospective studies were unable to corroborate the retrospective study results. Future prospective studies should address study design limitations to definitively assess AZS efficacy. 


\section{CONTIIUOUS QUALITY IMPROVEMENT USING ANESTHESIA INFORMATIOH MANAGEMENT SYSTEMS-BLOOD PRESSURE VERSUS INTUBATION: WHICH COMES FIRST? \\ David W. Edsall, MD, Patricia Deshane, CCRN, SNA, John Farrow, PhD, Burbank Hospital, Fitchburg, MA}

Summary. We used a computerized anesthesia information management system (AIMS) to measure and improved our incidence of obtaining baseline blood pressures prior to intubation and discovered reasons why we occasionally failed to do so.

Introduction. The automation of the anesthesia workstation has been controversial. To date, the technology has only shown that the computer-generated medical record is more complete, more accurate, and less time-consuming to produce than the hand-generated medical record [1-11]. However, the value of AIMS is in its ability to turn data into information. This study represents an example of the application of continuous quality improvement (CQI) theory to an anesthesia database $[12-14]$.

In CQI a good process is decided on in advance. Data is continuously gathered to assess whether the desired process is followed. Solutions are generated to bring the process in line with expectations. Our department of anesthesiology agreed that good quality anesthesia involved obtaining a noninvasive blood pressure (NIBP) before intubation.

Methods. All anesthesia data were collected using a commercial AIMS that automatically records electronic data (NIBP) and allows rapid entry of clinical data (intubation) by the anesthetist. Data are analyzed using the ARKIVE Database Analysis System [15], a relational database based on Paradox.

A total of 3,491 consecutive intubations by 11 anesthetists were analyzed. In December 1990 , feedback was given to the department after 2,239 intubations. Each anesthetist was informed of his or her incidence of error (intubation being recorded before the first noninvasive blood pressure). Reasons for the documentation errors were discussed. After 4 months, 1,252 new cases were analyzed.

Results. Analysis shows a consistent $3.7 \%$ incidence of error before December 1990. Three causes were found. First, the anesthetist made errors resulting in the intubation time being recorded before the first NIBP value $(1.0 \%)$. Second, the technology failed to capture the NIBP value, creating another artifactual relationship $(0.3 \%)$. The third was inaccurate representations of reality $(2.1 \%)$. Further exploration identified an ergonomic cause: the NIBP monitor displayed the last value of the previous case. The anesthetist assumed that the value displayed was current data. The cases then proceeded without actually obtaining an initial value.

After discussion of these results there were immediate and lasting decreases in the frequency of the error $(1.9 \%$ ) (Chi square $=7.88$, d.f. $=1, p<0.005$, directional test . The rate of incidence of the three different causes were $0.5 \%, 0.7 \%$, and $0.3 \%$, respectively. Three anesthetists had no errors.

Discussion. AIMS has helped us change and improve the quality of our anesthesia care. What about outcome? CQI teaches that quality is judged by observing process. This report is about obtaining baseline vital signs, which is one of many golden rules that we have chosen to help define what good anesthesia care is. Some rules are based on the science of anesthesia. This rule, about obtaining baseline vital signs, is based on our knowledge of the art of anesthesiology. There is no proof of its value. AIMS technology has helped us define one small aspect of this rule, and not only tells us whether we practice what we preach, but why we occasionally drift from that intended practice.

By using a computerized AIMS we have not only improved our incidence of obtaining baseline blood pressures prior to intubation, but also discovered reasons why we occasionally failed to do so.

\section{REFERENGES}

1. Logas WG, et al. Analysis of the accuracy of the anesthetic record. Anesth Analg 1987;66:S107

2. Zollinger RM, Kruel JF, Schneider AJL. Man-made versus computer-generated anesthesia records. J Surg Res $1977 ; 22: 419-424$

3. Cook RI, McDonald JS, Nunziata E. Differences between handwritten and automatic blood pressure records. Anesthesiology 1989;71:385-390

4. Lerou JGC, et al. Automated charting and physiological variables in anesthesia: A quantitative comparison of automated versus handwritten anesthesia records. J Clin Monit 1988;4:37-47

5. Shibutani $K$, et al. Inaccuracy of arterial pressure and heart rate in the anesthesia record: A study of human factors. Anesth Analg 1990;70:S369

6. Edsall DW. Computerization of the anesthesia work station. J Clin Monit 1991;7:83

7. Edsall DW. Documentation time requirement: Computerized information management systems versus handwritten records. Anesthesiology 1990;73:A439

8. Jones BR, Smith NT. Type and frequency of artifacts recorded on automated anesthesia records. Anesth Analg 1990;70:S180

9. Stanley $T E$, et al. Incidence of vital sign artifact in automated anesthesia records. Anesthesiology 1990;73:A483

10. Westenskow DR. Understanding and avoiding artifacts. Sermin Anesth 1991;10:15-21

11. Edsall DW. Analysis and frequency of artifacts generated by anesthesia information management systems. Anesthesiology 1990;73:A481

12. Walton $M$. The Deming Management Method. New York: Putnam, 1986

13. Walton M. Deming Management at Work. New York: Putnam, 1990

14. Merry MD. Total quality management for physicians translating the new paradigm. QRB 1990; March:101-105

15. Edsall DW. Quality assessment with a computerized anesthesia information management system (AIMS). QRB 1991;17:182-193

\section{SESSION 2: NEW AND FUTURE DEVICES}

\section{A NONINVASIVE METHOD FOR ESTIMATING A NEW VARIABLE: ARTERIAL} COMPLANGE

T. S. Scanlon, MD, N. T. Smith, MD, H. Apple, PhD, G. Bergstrom, MSEE, L. Hersh, PhD, Naval Hospital, VA Medical Center, University of California, San Diego, Johnson $\mathcal{G}$ Johnson, and Critikon

Summary. Arterial compliance can be measured during Dinamap cuff deflation and the values obtained can be 


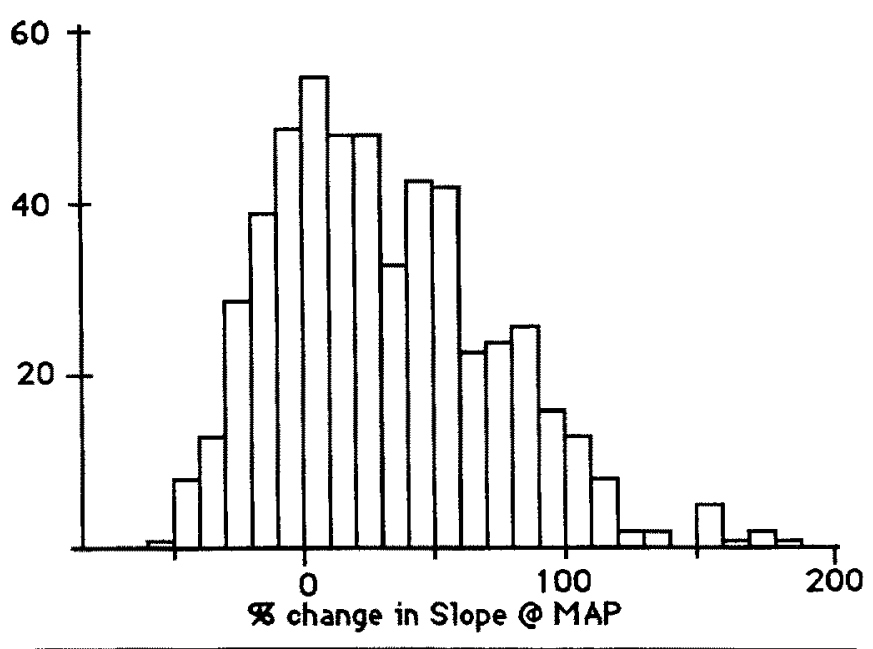

Frequency histogram of $A C$ changes from baseline.

used to compute arterial impedance, a parameter used to determine cardiac output by the pulse contour method.

Introduction. We developed a method to noninvasively intermittently determine arterial compliance (AC). The present study examined three questions:

1. Is the method for measuring $\mathrm{AC}$ robust enough to survive the hostile environment of cardiac surgery?

2. Do $A C$ values change during the course of surgery?

3. Do AC values correlate with conventional variables such as mean arterial pressure (MAP) or heart rate?

Methods. After securing approval from our two institutional review boards, we obtained written informed consent from 8 males scheduled for cardiac surgery. A standard blood pressure cuff encircled the arm contralateral to the arterial catheter. The cuff was automatically inflated and deflated in steps. During deflation, the ArtComTM system estimated arterial volume from cuff oscillations and pressure. The system also generated a pressure-volume (P-V) curve for the underlying artery, and $\mathrm{AC}$ was calculated as the slope of the P-V curve; $\mathrm{AC}=$ slope @ MAP. Recordings were taken as often as every 3 minutes and were logged onto a computer hard disk. Suspicious results were automatically detected, flagged, and recorded on disk.

Results. We answered the 3 questions posed in the introduction.

1. In 696 determinations, suspicious results were detected 139 times in $21 \%$ of the samples. These results were omitted from the analyses. AC measurement was encumbered by dysrhythmias to the same degree that MAP by Dinamap was encumbered.

2. The Figure shows a frequency histogram of $\mathrm{AC}$ changes from baseline. Fifty-five percent of the values exceeded $\pm 20 \%$ of the baseline value.

3. $\mathrm{AC}$ showed no correlation with heart rate (correlation $=$ 0.076 ) or MAP (correlation $=0.031$ ).

Discussion. The system proved remarkably robust for a prototype in its first clinical trial. The number of suspicious values was high, but will be decreased with software changes. We selected cardiac surgery to test the $A C$ because we reasoned that if no changes occurred during this stressful period, the device probably had no future as a monitor. However, we found wide variation in $\mathrm{AC}(0.05$ to 0.39 , equivalent to -58 to $+186 \%$ ) along with larger changes in MAP $(61-124)$, heart rate (40-134), and cardiac output (1.4-10.0). The lack of a relationship between $A C$ and conventional variables suggests that $A C$ may be a useful new variable that can be measured frequently. It may characterize the effects of drugs and other interventions. The fact that $\mathrm{AC}$ is noninvasive, relatively inexpensive, and can be obtained during conventional NIBP measurement suggests that further investigation is worthwhile.

One potential use is measuring arterial impedance and using this value to calibrate a cardiac output monitor that employs the pulse contour method. We measured and compared 20 readings of cardiac output from thermal dilution and from pulse contour. The correlation was 0.76 .

Compliance measurements may allow impedance measurement and provide calibration data for pulse contour cardiac output.

Supported in part by the Medical Research Service, Department of Veterans Affairs, as well as Johnson \& Johnson and Critikon.

\section{DOES ARTERIAL RIGIDITY AFFECT CARDIOVASCULAR FUICTION IN VASCULAR SURGICAL PATIENTS?}

Jorge Urzua, MD, Gladys Meneses, BS, Guillemo Lema, MD, Carla Sacco, MD, Hernan Muñoz, MD, Albrecht Krämer, MD, Francisco Valdes, MD, Marcello Guarini, PhD, Aldo Cipriano, PhD, Marcelo Matus, BA, Departments of Anesthesiology, Electrical Engineering, and Cardiology, Catholic University, Chile

Summary. We conclude that arterial surgical patients may present increased apparent arterial rigidity and isolated systolic hypertension in the operating room. Rigidity depends on the level of arterial pressure and may impair stroke volume.

Introduction. Arteriosclerosis alters blood circulation due to flow-limiting stenotic lesions. Physical alteration of arterial walls may also impair cardiovascular function due to decreased aortic compliance. We studied whether vascular surgical patients presented increased apparent arterial rigidity, and whether it affected systolic pressure or stroke volume.

Methods. Twenty-four patients aged 52 to 80 years subjected to arterial surgery were studied. Arterial blood pressure was recorded from a 20 -gauge, 4-inch brachial artery catheter, with hydraulic coupling slightly overdamped and resonant frequency $14 \mathrm{~Hz}$ (Combidyn, B Braun, Melsungen), and double checked with a noninvasive automated device (Dinamap). Cardiac output was measured by thermodilution from a $7 \mathrm{~F}$ Edwards pulmonary artery catheter. Apparent arterial rigidity was estimated from pulse pressure (systolic minus diastolic $\mathrm{mm} \mathrm{Hg}$ ) divided by stroke volume (ml). Measurements were obtained before anesthesia, after induction, and after skin incision but before aortic cross clamp. Normal distribution statistics were used.

Results. Before anesthesia, 19 patients presented isolated systolic hypertension (systolic above 160 and diastolic below 80 $\mathrm{mm} \mathrm{Hg}$ ). Pulse pressure exceeded $100 \mathrm{~mm} \mathrm{Hg}$ in 15 patients and systolic pressure exceeded $200 \mathrm{~mm} \mathrm{Hg}$ in 11. Apparent 


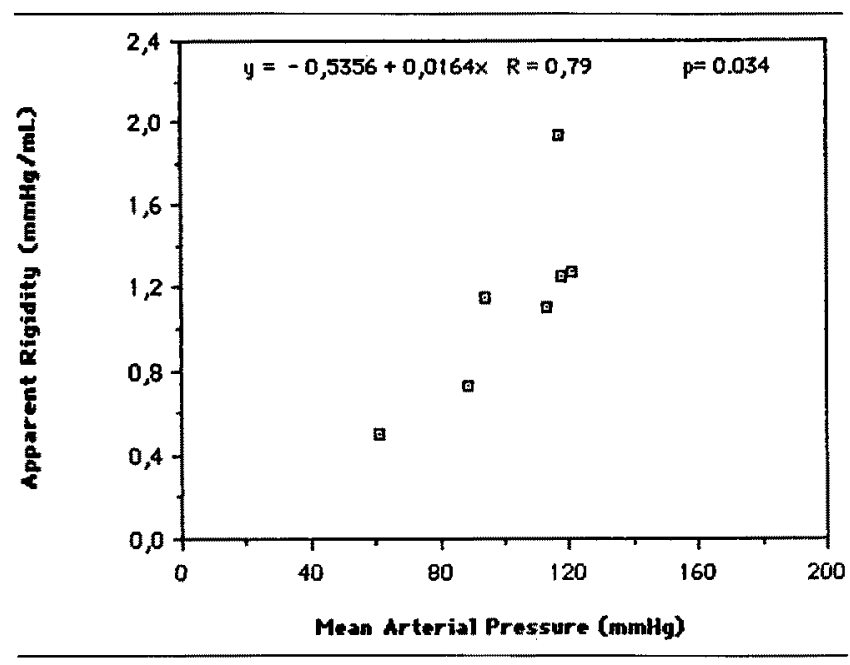

Fig 1. Apparent arterial rigidity was a function of the level of arterial pressure in all but one of 24 arterial surgical patients. This figure presents a typical result for 1 patient.

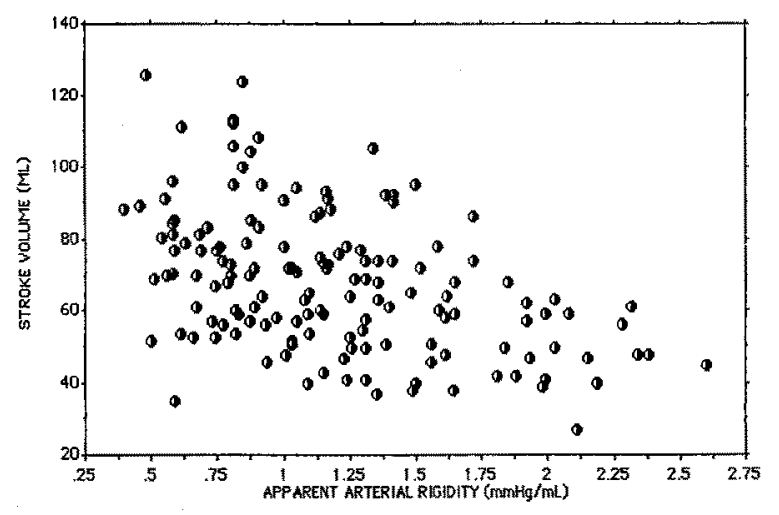

Fig 2. Stroke volume seemed to depend on the level of apparent arterial rigidity. The figure shows that at normal values of rigidity (approximately $1 \mathrm{~mm} \mathrm{Hg} / \mathrm{ml}$ ), stroke volume may exceed $70 \mathrm{ml}$; however, at higher rigidity values, stroke volume appeared limited.

arterial rigidity ranged from 0.48 to $2.60 \mathrm{~mm} \mathrm{Hg} / \mathrm{ml} ; 10 \mathrm{pa}-$ tients presented normal values $(<1 \mathrm{~mm} \mathrm{Hg} / \mathrm{ml})$, while 11 were between 1 and $2 \mathrm{~mm} \mathrm{Hg} / \mathrm{ml}$ and 3 were above $2 \mathrm{~mm}$ $\mathrm{Hg} / \mathrm{ml}$.

Following anesthesia, arterial pressure decreased in most patients. A pparent rigidity (Fig 1) decreased linearly with arterial pressure in all but one patient $(r>0.7$ in 21 patients, $p<$ 0.05 in 15). Rigidity also correlated with systemic vascular resistance $(r>0.7$ in 11 patients). Range of variation of apparent rigidity exceeded $1 \mathrm{~mm} \mathrm{Hg} / \mathrm{ml}$ in 9 patients.

Apparent arterial rigidity seemed to affect stroke volume (Fig 2). Below $1 \mathrm{~mm} \mathrm{Hg} / \mathrm{ml}$ apparent rigidity, stroke volume was above $70 \mathrm{ml}$ in 32 determinations and below $70 \mathrm{ml}$ in 23; between 1 and $2 \mathrm{~mm} \mathrm{Hg} / \mathrm{ml}$ apparent rigidity, stroke volume was above $70 \mathrm{ml}$ in 26 determinations and below $70 \mathrm{ml}$ in 51 ; above $2 \mathrm{~mm} \mathrm{Hg} / \mathrm{ml}$, stroke volume did not exceed $70 \mathrm{ml}$ in any determination, while it was below 70 in 11 . No relationship between stroke volume and pulse pressure was apparent.

\section{CARDIOVASCULAR PARAMETER ESTIMATION USING NONLINEAR CIRCULATORY MODELS}

Marcello Guarini, Jorge Urzua, Aldo Cipriano, Marcelo Matus, Pontificia Universidad Catolica de Chile, Santiago, Chile

Summary. We developed a computer program to estimate one nonlinear, one time varying, and one linear parameter from a 7-parameter physiologic model describing the human cardiovascular system. Data for model fit were obtained from the radial artery pressure waveform, and estimated parameters were within the physiologic range.

Introduction. Clinical monitoring of the cardiovascular system attempts to infer physiologic parameters from analog signals. In this work, we implemented numeric techniques directed toward estimating nonlinear cardiovascular parameters from an arterial pressure signal.

Methods. We used a modified Windkessel model of the arterial load [1] where the aortic elastance has been modified to include nonlinear behavior. To reproduce the known physiologic mechanical characteristics of the aorta, a combination of a linear and an exponential function was used, specifying different constants to account for the effect of age (Fig 1). The forcing function of the left ventricle and the electric analog of the model are shown in Fig 2. The differential equations describing the dynamic behavior of the model were solved using spectral techniques $[2,3]$.

Using nonlinear optimization methods based on the techniques proposed by Levenberg Marquardt [4] and spectral techniques, we wrote a software application (program) to estimate the parameters of the model. The program can estimate up to three parameters simultaneously. Parameters that can be estimated include nonlinear aortic elastance, peripheral resistance, aortic flow, and left ventricular maximal elastance (contractility). The model includes 7 parameters, of which one is nonlinear and another is time varying. To estimate 3 parameters we first input values for the remaining 4 parameters. Starting values were taken from the literature.

We tested the validity of this approach by using the program in the following manner. First, we used the model beginning with a predetermined set of parameters. Second, we obtained the distal arterial pressure signal. Third, we specified the parameters to be estimated, entering starting values near and close to real ones. Fourth, we entered values for the rest of the parameters, identical to the values used in the initial simulation. The program then estimated the remaining parameters from the analog distal arterial pressure signal previ-

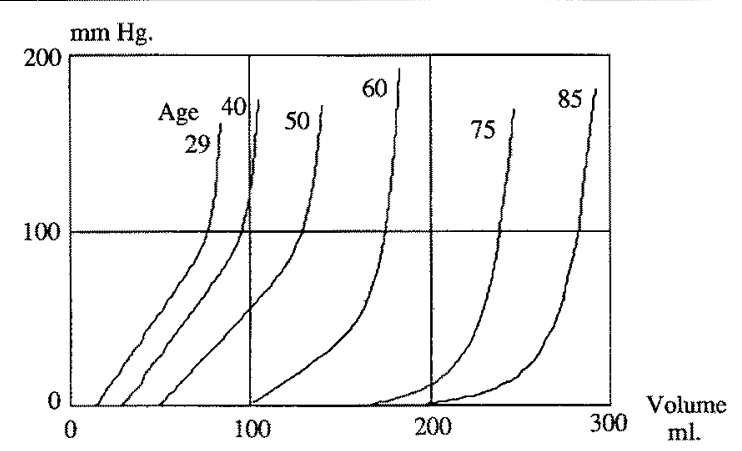

Fig 1. Mechanical characteristic of the aorta. 


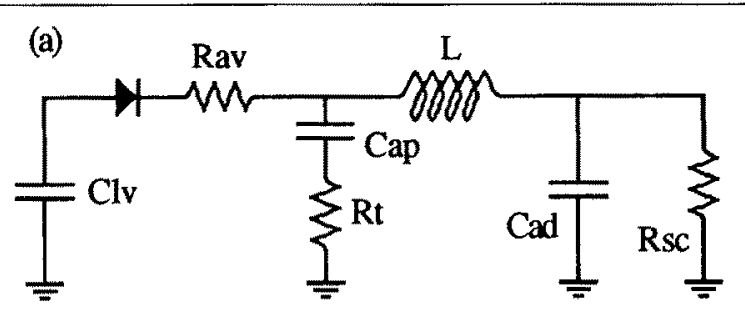

(b)

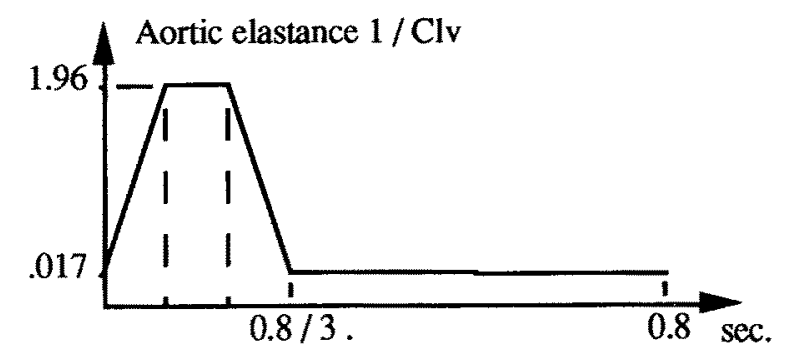

Fig 2. Model of the cardiovascular system (a) and left ventricle forcing function (b).

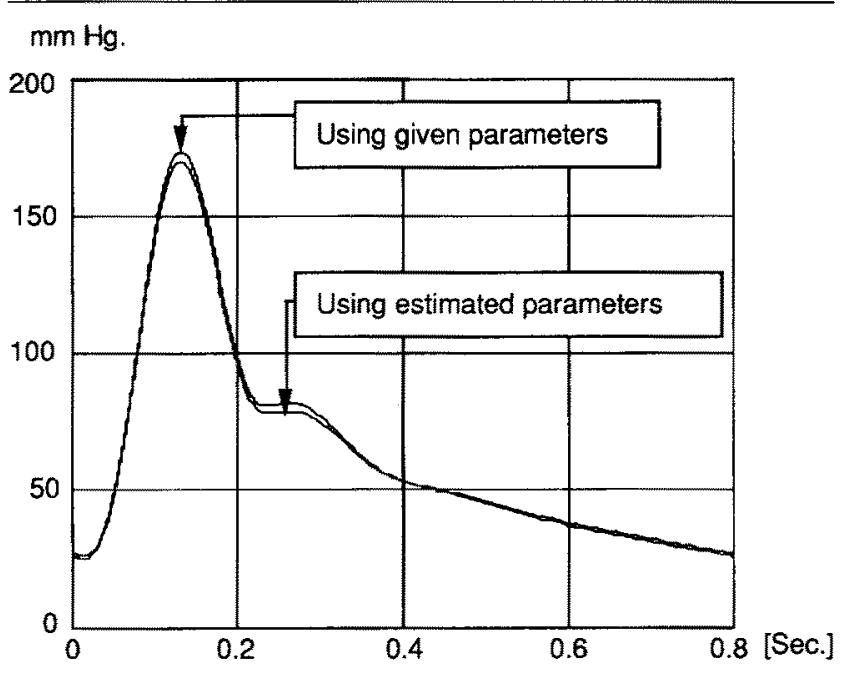

Fig 3. Comparison between simulated distal arterial pressure waveforms using given parameters and estimated parameters.

ously obtained. The accuracy of the estimation was assessed by comparing the estimated with the real values and by then running a new simulation with the estimated parameters. The simulation and system identification runs were performed on an Apollo 10000 workstation.

Results. Figure 3 shows a comparison between the original simulated signal and the one simulated with the estimated parameters (peripheral resistance and aortic elastance).

Discussion. This work proves the feasibility of simultaneously estimating several physiologic parameters from the distal arterial pressure signal. Preliminary testing using radial artery pressure waveforms from patients yielded values that were within the physiologic range.

\section{REFERENGES}

1. Clark J, Ling R, Srinivasan R, et al. A two-stage identification scheme for determination of the parameters of a model of the left heart and systemic arterial circulation. IEEE Trans Biomed Eng 1980;BME-27:20-29

2. Guarini M, Urzua J, Cipriano A, et al. Nonlinear cardiovascular simulation using spectral technique. Proceedings of the 1991 Summer Computer Simulation Conference, July 22-24, 1991, Baltimore, MD

3. Palusinski $O$, Guarini $M$, Wright $S$. Spectral technique in electronic circuit analysis. Int J Numeric Modelling Dev Fields 1988;1:137-151

4. Osborne MR. Nonlinear least squares-The Levenberg algorithm revisited. J Aust Math Soc 1976;19:343-357

\section{TRAMSFER FUNCTIOH FROM END-TIDAL AGENT TENSION TO BLOOD PRESSURE}

Xin Bo Ji, PhD, Ignatius D Calalang, BS, James H Philip, $M E(E), M D$, Brigham and Women's Hospital and Harvard Medical School, Boston, MA

Summary. Using a recursive least squares (RLS) estimator, the relationship between systolic blood pressure (SBP) and expired isoflurane tension change was found to be first order, estimating SBP within $10 \%$. This RLS approach will be extended to real-time estimation of SBP and anesthetic depth.

Intraduction. Anesthesiologists often control blood pressure by changing depth of anesthesia with volatile agents. To aid in this endeavor, a general linear model was derived to estimate systolic blood pressure (SBP) change in response to measured change in expired agent tension. Model parameters were calculated from data collected in 38 patients subjected to controlled changes in inspired and expired agent tension. Parameters were adjusted using the recursive least squares (RLS) method until estimated blood pressure was within $10 \%$ of actual for all data points in the sample epoch. The estimation technique used retrospectively can be applied in real time as an adaptive blood pressure estimator throughout anesthetic administration. The intraoperative use of this adaptive estimator with present gas monitors will aid in managing anesthetic depth and blood pressure. In addition, it will demonstrate the blood pressure measurement interval required for safe control of anesthetic depth.

Methods. The general model in the S-domain that characterizes SBP response to expired agent tension change was derived in the following manner. Intraoperative data for 38 patients were obtained using the data-to-disk logging feature of the Ohmeda Central Display (CD) Modulus II Anesthesia Machine. Expired agent tension was logged every 20 seconds. Blood pressure measurement interval was set to 20 seconds. (STAT mode, Dinamap module) and was logged when measured. Time, SBP, and expired isoflurane tension $(A \times E)$ were extracted from the data disks and the time epochs containing a change in $A \times E$ and associated SBP response (e.g. induction period) were analyzed.

An RLS estimation technique was applied to each data epoch. Parameter values and model order were modified until each measured blood pressure data point was estimated with an accuracy of $10 \%$. The figure shows the block diagram 


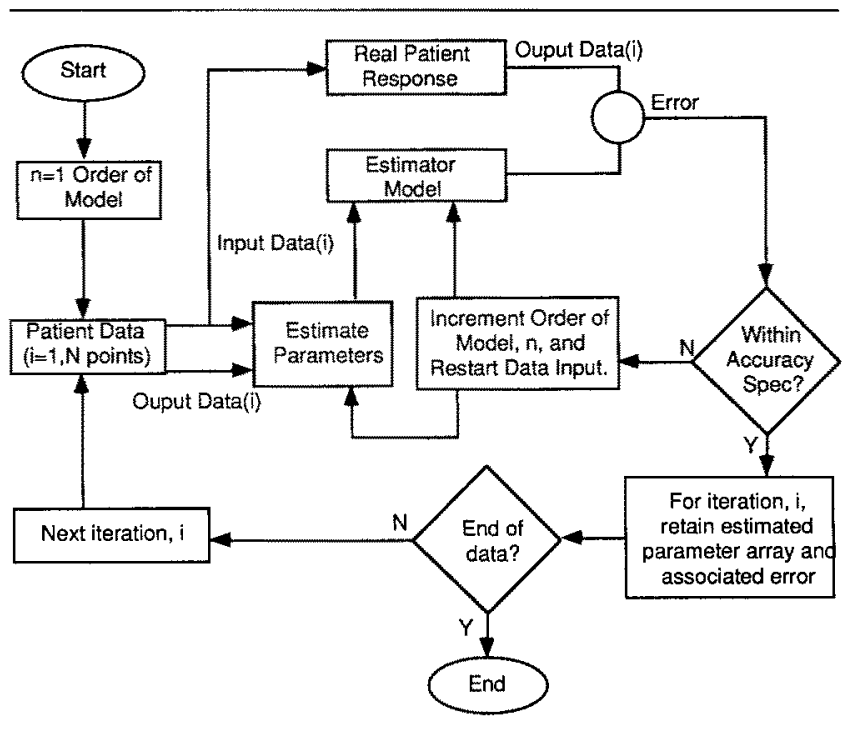

Recursive least squares procedure used to formulate system transfer function in matrix form for each patient.

of the RLS procedure used to formulate the system transfer function in matrix form for each patient. The lowest order model that satisfied the $10 \%$ accuracy criterion was selected. The estimated values for each parameter were analyzed across patients and epochs and the distribution of each parameter was plotted and analyzed to determine mean and standard deviation.

The resulting RLS's matrix form of the system transfer function was transcribed into differential equation format because, ultimately, the model's transfer function is implemented in the S-domain and perceived by the clinician in the time domain. Equations were derived to calculate the time constants of the transfer function from the RLS parameter estimates.

The completed model and real-time RLS estimator was implemented in compiled Better BASIC (Summit Software Technology) on an IBM-compatible portable computer (Toshiba $1100+$ ) for later use and testing in the clinical environment.

Results. A first order model satisfied our accuracy specification of $10 \%$. The RLS procedure produced estimates for three parameters for each patient, $a_{0}, b_{1}$, and $b_{0}$.

$$
y(t)=-a_{0} y(t-1)+b_{1} u(t)+b_{0} u(t-1) \quad\{\text { eq. } 1\}
$$

Where $\mathrm{t}=$ time, $\mathrm{y}(\mathrm{t})=\mathrm{SBP}$ output, $(\mathrm{u}) \mathrm{t}=\mathrm{A} \times \mathrm{E}$ input.

In the S-domain, the transfer function takes the form:

$$
G(s)=K\left\{\left(\tau_{2} s+1\right) /\left(\tau_{1} s+1\right)\right\}
$$

Where $\mathrm{G}(\mathrm{s})=$ output in the frequency domain, $\mathrm{K}=$ gain, $\tau$ $=$ time constant, $\mathrm{s}=$ frequency. Time constants were calculated from the RLS-estimated parameters for each patient epoch.

Expired agent tension increased in 28 patient data epochs and decreased in 10 epochs. As a result, parameter values were derived for the two groups separately. The table shows the
Estimated Parameter Values as Initial Conditions

\begin{tabular}{llrll}
\hline $\mathbf{A} \times \mathbf{E}$ & $\mathbf{a}_{\mathbf{0}}$ & \multicolumn{1}{c}{$\mathbf{b}_{0}$} & \multicolumn{1}{l}{$\mathbf{b}_{\mathbf{1}}$} & \multicolumn{1}{c}{$\boldsymbol{\tau}_{\mathbf{1}}$ (sec) } \\
\hline Increase & $0.89 \pm 0.05$ & $4.4 \pm 4.7$ & $-0.1 \pm 2.8$ & $385 \pm 106$ \\
Decrease & $0.91 \pm 0.02$ & $21.4 \pm 7.0$ & $2.6 \pm 3.6$ & $880 \pm 360$ \\
\hline
\end{tabular}

estimated parameter values and the dominant time constant, all expressed as mean \pm standard deviation.

Discussion. The relationship between expired anesthetic tension and SBP was found to require a simple first order model based on the data we collected and analyzed. Because we used an RLS estimator, ongoing real-time estimation of SBP response to anesthetic agent can be implemented using the same algorithm. In the real-time estimate, the parameter values obtained here are used as initial conditions and real-time values of expired agent tension provide the model input. The RLS procedure modifies parameter values as the data stream of agent tension and blood pressure continues, and the model becomes and remains optimal for each patient.

Prospective tests will be required to test the efficacy of this real-time RLS SBP estimator. If an accurate model is obtained, it can be used in clinical management and further advance our understanding and control of anesthesia depth.

\section{A NEW METHOD FOR ESTIMATIHG WORK OF BREATHING DURING PRESSURE SUPPORT VENTILATION}

M. Leon, MD, University of South Florida College of Medicine, Tampa, FL

Summary. A method that allows direct estimation of spontaneous inspiratory lung and airway work of breathing in a mechanical model during pressure support ventilation is described. If valid clinically, the method may contribute to the evaluation of the patient's share of the work of breathing during pressure support ventilation.

Introduction. Patient inspiratory lung and airway work of breathing $\left(\mathrm{W}_{\mathrm{L}+\mathrm{AW}}\right)$ cannot be assessed directly during pressure support (PS) ventilation (PSV) [1]. This experiment investigated the accuracy of a new method for estimating $W_{L+A W}$ in a modified mechanical lung analog (MLA) during PSV.

Methods. A two-bellows MLA was modified for simulation of pleural pressure $\left(\mathrm{P}_{\mathrm{PL}}\right)$. "Spontaneous" breathing in the MLA was generated by a volume-controlled Servo $900 \mathrm{C}$ ventilator inflating one of the bellows; this bellows lifted the second bellow (lung bellows). The lifting pressure was analogous to $\mathrm{P}_{\mathrm{PL}}$. The lung bellows was connected to a Bennett 7200 ventilator set to deliver PSV. Target tidal volumes of 300 to $800 \mathrm{ml}$ were achieved with increasing levels of PS $(0,2,4 \ldots$ $20 \mathrm{~cm} \mathrm{H} \mathrm{H}_{2} \mathrm{O}$ ) and the necessary "spontaneous" effort (given by the Servo $900 \mathrm{C}$ minute ventilation setting). When target volumes were reached, airway pressure, gas flow, and $\mathbf{P}_{\mathrm{PL}}$ were recorded. An estimate of the inspiratory work ( $\left.W_{E S T}\right)$ was calculated using the formula:

$$
\mathrm{W}_{\mathrm{EST}}=\int\left(\mathbf{P}_{\mathrm{PLMAX}}-\mathrm{P}_{\mathrm{PL}}\right) * \dot{\mathrm{V}} \mathrm{dt}
$$

where $\mathrm{P}_{\mathrm{PLMAX}}$ represents the largest $\mathrm{P}_{\mathrm{PL}}$ during inspiration and $\dot{V}$ represents the instantaneous gas flow. Thereafter, all PS was suspended and the "spontaneous" work $W_{L+A W}$ was 


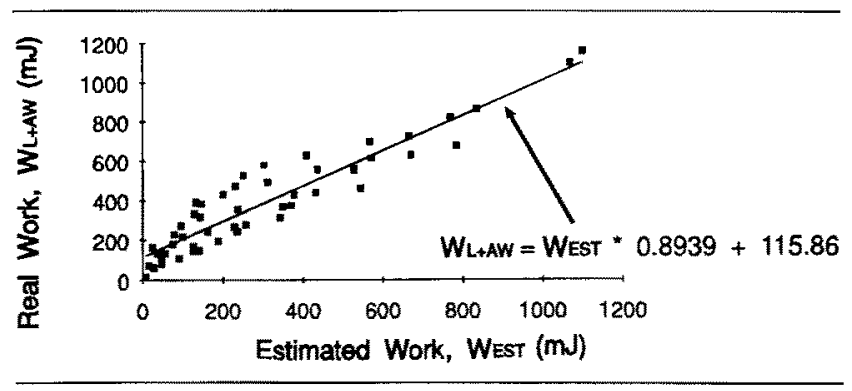

Data and regression line.

computed. Inspiratory time, respiratory rate, and static compliance were kept constant throughout the experiment.

Results. Linear regression between $\mathrm{W}_{\mathrm{EST}}$ and $\mathrm{W}_{\mathrm{L}+\mathrm{AW}}$ resulted in a slope of 0.89 and a $Y$ intercept of 115 . The value of $\mathrm{r}^{2}$ was 0.885 for all PS levels, and it increased for PS levels $\leq 6 \mathrm{~cm} \mathrm{H}_{2} \mathrm{O}$. The data and regression line are shown in the Figure.

Discussion. Conceptually, the method accounts for the work produced when the muscles lower $\mathrm{P}_{\mathrm{PL}}$ below the "ceiling level" generated by a PS breath. This method holds true only if at some point during PS the muscular effort is minimum and if the perturbation caused by PS on $\mathrm{P}_{\mathrm{PL}}$ is assumed to be square in shape. Further research is required to validate current results clinically. If applicable, the method may help to monitor the patient's share of work of breathing during PSV.

\section{REFERENGE}

1. Chest $1985 ; 87: 612-618$

\section{EVALUATION OF A HEW RESPIRATORY MONITOR}

Vasilios Pratilas, MD, Mount Sinai Medical Center, New York, NY

Summary. A flow-detecting ventilation monitor proved to be an accurate monitor of adequacy of ventilation in the 30 patients studied.

Introduction. The detection of inadequate ventilation in an anesthetized or heavily sedated patient is of concern to anesthesiologists. Low-pressure alarms or capnography are useful but not universally applicable. Pulse oximetry is also useful, but there is a delay between decreased ventilation and a fall in oxygen saturation.

We studied a new ventilation monitor designed to fill this gap in $30 \mathrm{IRB}$-approved patients. The device has a sensor that detects flow during inspiration and expiration. It is placed in the anesthetic circuit or is attached to an oxygen mask in sedated patients. A light flashes when adequate spontaneous respiration occurs. An alarm (Al) sounds when respiratory flow is inadequate.

Methods. Patients were studied in two groups. Group 1 comprised patients having local or regional anesthesia with monitored sedation. Group 2 comprised those having endotracheal anesthesia. Both groups were monitored during surgery, during transport, and during the recovery period.

Results. Results are indicated in the table.
Respiratory Depression Correlated to Alarm

\begin{tabular}{clll}
\hline & $\begin{array}{l}\text { Respiratory } \\
\text { Depression } \\
\text { With Al }\end{array}$ & $\begin{array}{l}\text { Respiratory } \\
\text { Depression } \\
\text { Without Al }\end{array}$ & $\begin{array}{l}\text { Al Without } \\
\text { Respiratory } \\
\text { Depression }\end{array}$ \\
\hline $\begin{array}{c}\text { Spontaneous } \\
\text { ventilation } \\
\text { with mask }\end{array}$ & $16 / 16$ & $0 / 15$ & $0 / 15$ \\
$\begin{array}{c}\text { Controlled } \\
\text { ventilation } \\
\text { with ETT }\end{array}$ & $14 / 14$ & $0 / 14$ & $0 / 14$ \\
\hline
\end{tabular}

\section{APPLICABILITY OF A FOURIER TRANSFORM MASS SPECTROMETER TO RESPIRATORY GAS AMALYSIS}

Kazuyuki Ikeda, MD,PhD, * Yoshimitsu Sanjo, $P h D$,* Yuichi Iritani, ${ }^{*}$ Department of Anesthesiology and Critical Care Medicine, Hamamatu University School of Medicine, Shizuoka, Japan; and TCentral Research Laboratory, Nikkiso Co., Ltd., Shizuoka, Japan

Summary. A compact Fourier transform mass spectrometer is presented that provides direct separation and continuous measurement of respiratory and anesthetic gases with similar mass numbers.

Introduction. The Fourier transform mass spectrometer (FTMS) is a device using a new method of mass spectrometry that provides excellent characteristics, among which are high resolution and very short measurement period [1]. Extremely high resolution in the low mass range is especially important since it allows direct separation and quantification of respiratory and anesthetic gases with almost equal masses [2].

Methods. Making use of the extremely high resolution in the low mass range, we constructed a new compact FTMS instrument for routine gas analysis. As shown in Fig 1, the instrument consists of four sections: a high-strength homogeneous permanent magnet, a high vacuum chamber surrounding the analyzer cell, electronics for signal detection and spectrometer control, and a built-in computer system for sig-

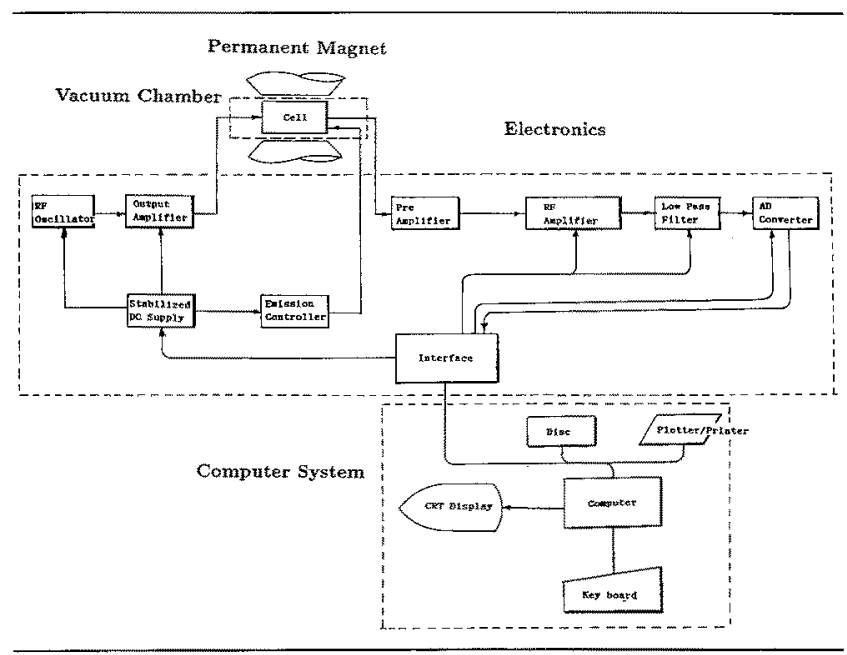

Fig 1. Schematic diagram of the compact FTMS. 

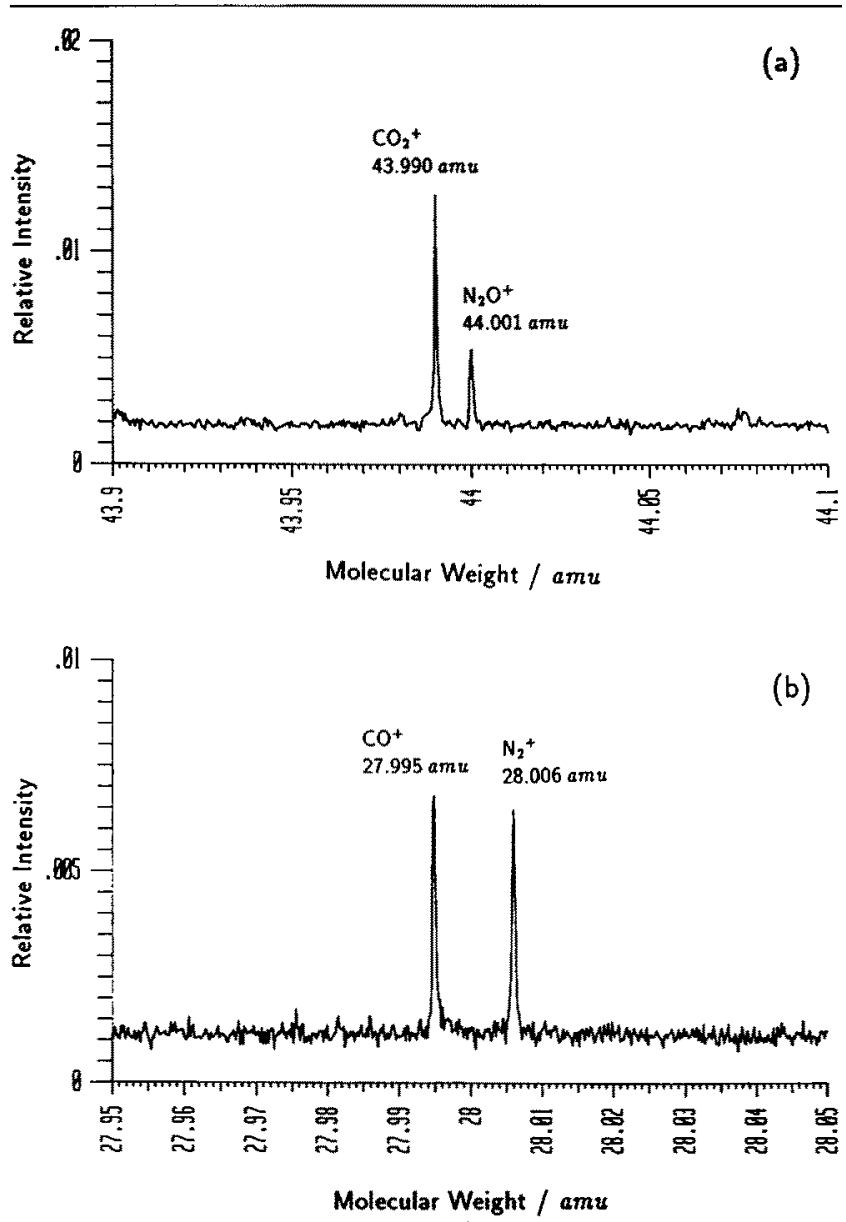

Fig 2. Mass spectra for gases of almost equal masses: (a) $\mathrm{CO}_{2}$ and $\mathrm{N}_{2} \mathrm{O}$; (b) $\mathrm{N}_{2}$ and $\mathrm{CO}$.

nal processing, display, and recording. By using a permanent magnet, neither liquid helium charging nor water cooling is required. However, long-term thermal field drift of the magnet will require careful control.

Results. Using the new compact FTMS, we obtained complete separation among $\mathrm{CO}_{2}(44)$ and $\mathrm{N}_{2} \mathrm{O}(44), \mathrm{N}_{2}(28)$ and $\mathrm{CO}_{2}(28)$, and four inhalation anesthetics. Examples of spectra are shown in Fig 2.

Discussion. The compact FTMS using a permanent magnet will be a powerful instrument for direct and continuous separation and measurement of respiratory and anesthetic gases. Nevertheless, our FTMS is a preliminary machine that needs a sampling system and clinical data processing software as well as further evaluation of linearity and sensitivity.

\section{REFERENCES}

1. Gross ML, Rempel DL. Fourier transform mass spectrometry. Science 1984;226:261-268

2. Wang M, Marshall AG. High-resolution multiple ion simultaneous monitoring of multiple-foldover Fourier transform ion cyclotron resonance mass spectrometry. Anal Chem 1988;60:341-344

\section{USE OF A PIEZOELECTRIC SENSOR TO MEASURE MEUROMUSCULAR BLOCKADE DURING ANESTHESIA}

S. E. Kern, MS, D. R. Westenskow, PhD, J. A. Orr, PhD, J. O. Johnson, MD, PhD, University of Utah, Salt Lake City, $U T$

Summary. The piezo sensor provides a convenient quantitative method of monitoring train of four ratio during recovery from neuromuscular blockade without the use of a fixed hand restraint.

Introduction. Anesthesiologists often monitor intraoperative levels of neuromuscular blockade by visually monitoring the response to a train of four (TOF) stimulus. While this method is convenient, it is imprecise and cannot adequately assure that neuromuscular blockade has been safely reversed at the end of surgery [1]. We have developed a new sensor that makes quantitative measurement of neuromuscular blockade easy. It uses a piezoelectric film that attaches to the patient's thumb and produces a signal proportional to thumb movement in response to stimulation of the ulnar nerve. Its performance in measuring TOF ratio was compared with results from an adductor pollicis force measuring system (APM) in patients recovering from neuromuscular blockade.

Methods. Institutional review board approval and informed consent was obtained for the study of 12 patients (ASA class I-III, age 18-63 years) scheduled for elective surgery. The piezo sensor was attached to the patient's right thumb at the first metacarpal joint. No fixed restraint was used to position the right hand. The APF transducer was attached to the patient's left hand, which was fixed to an armboard. TOF stimulation was provided to the ulnar nerve of each arm just proximal to the wrist. Anesthesia was induced with thiopental or propofol and was maintained with isoflurane and nitrous oxide. Neuromuscular blockade was initiated with succinylcholine for tracheal intubation and was maintained with boluses of vecuronium. During recovery from neuromuscular blockade, measurements were made at 20 -second intervals from both sensors until the patient left the operating room. Paired measurements were evaluated for bias and precision, as described by Bland and Altman [2]. Surface skin temperature

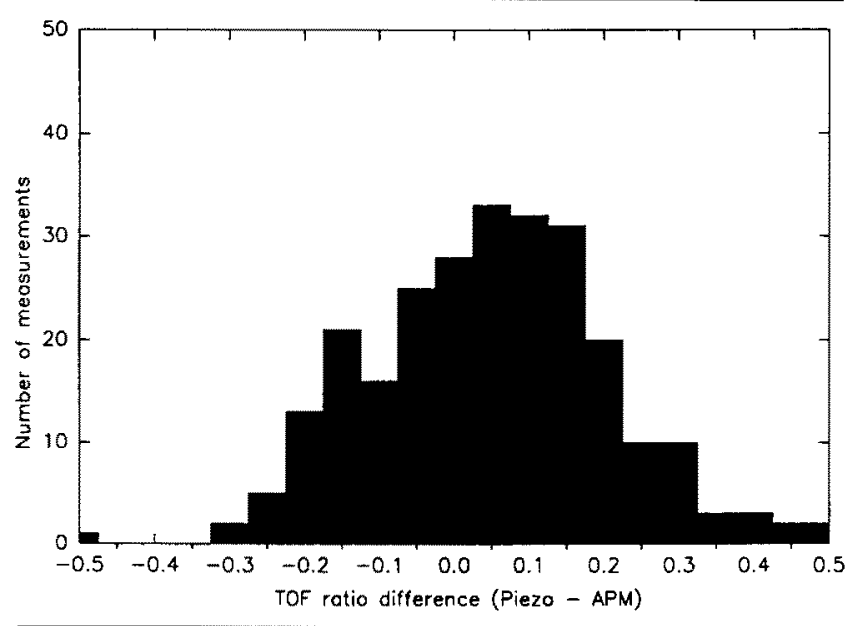

Histrogram of the difference between paired TOF ratio measurement from the piezo sensor and the APM. 
was monitored at both hands and manually recorded at the end of the procedure.

Results. A total of 256 paired measurements were made. A histogram of the TOF ratio difference between the paired measurements is shown in the Figure. The bias in TOF ratio measurement between the 2 sensors was 0.03 , with the a standard deviation of 0.15 . The limits of agreement between the two sensors, given by two standard deviations from the bias, were -0.29 to 0.34 . The $95 \%$ confidence interval for the bias was 0.008 to 0.047 based on a two-sided $t$-test. The skin temperature of both hands ranged from 80 to $91^{\circ} \mathrm{F}$.

Discussion. The bias between the paired TOF measurements was small, indicating that on average the two sensors gave similar results. The limits of agreement between the sensors were approximately $\pm 30 \%$ from the bias. The piezo sensor showed limits of agreement within the range reported for other studies that compared an APM to either an electromyogram or an accelerometer [1,3].

\section{REFERENCES}

1. Viby-Mogensen J, et al. Acta Anaesthesiol Scand 1982; $32: 45-48$

2. Bland JM, Altman DG. Lancet 1986;1:307-310

3. Weber S, Muravchick S. Anesth Analg 1986;65:771-776

\section{A SIMPLE GAS SCAVENGING HOOD FOR ANESTHESIA MACHINES}

Adel R. Abadir, MD, The Brookdale Hospital Medical Center, Brooklyn, NY

Summary. We constructed a scavenging hood applicable to new and old anesthesia machines and clearly demonstrated that the hood is an effective way to significantly reduce the levels of anesthetic gases in the operating room environment to below accepted OSHA standards.

Introduction. Some epidemiologic studies have suggested that chronic occupational exposure to the levels of anesthetic gases in the operating room environment may be associated with higher than normal incidences of infertility, spontaneous abortions, and congenital malformation of offsprings. Leakage in anesthesia machines is difficult to control and can occur even after anesthesia apparatus has been checked. We demonstrate the function of the anesthesia gas scavenger hood for anesthesia machines and show an effective and simple way of decreasing ambient anesthetic gas concentrations in the operating room environment.

Methods. We constructed a $42 \times 42 \times 72$ inch plexiglass or plastic hood to scavenge anesthetic gases from the operating room. We used a small fan and utility hose to vent the gases into the air exhaust system. The levels of $\mathrm{N}_{2} \mathrm{O} 50$, halothane $1 \%$, and enflurane $1 \%$ in the two operating rooms, with and without a scavenging hood around the anesthesia machine, were evaluated using a portable gas analyzer. The gas amounts were measured at the locations of 6 individuals in each room: (1) anesthesiologist, (2) surgeon, (3) first assistant, (4) second assistant, (5) scrub nurse, and (6) circulating nurse. As the anesthesiologist's location (close to the anesthesia machine) was by far the most contaminated, we chose this area for the calculations. After a 5-minute induction period the measure- ments were taken at 5,10,15, and 20 minutes. Continuous deliberate leakage of the anesthetic gases for up to 40 minutes was also measured. The rate of the flow was 2 and $4 \mathrm{~L}$ for each anesthetic gas.

Results. A low negative pressure hood during the postinduction period effectively and significantly reduced halothane, enflurane, and $\mathrm{N}_{2} \mathrm{O}$ gas tracings in the operating room within 5 to 10 minutes (3-4 times more than without hood). Overall $\mathrm{N}_{2} \mathrm{O}$ ppm levels were the highest in the room, followed by halothane and isoflurane. Prolonged leakage of all gases (up to $40 \mathrm{~min}$ ) was more difficult to scavenge using the hood; nevertheless, the device significantly improved the operating room contamination.

Discussion. Our results indicate that anesthetic trace gases from the operating room can be directly vented into the regular ventilation system without contaminating room air. This preliminary investigation shows that it is possible to use a low negative pressure hood that can be retrofitted around currently used anesthesia equipment. Halogenated hydrocarbons are heavier than air and, thus, can be evacuated closer to the floor. This principle also can be incorporated into a newly designed apparatus.

\section{MULTILEAD DIGITAL ELECTROCARDIOGRAPHIC MONITORING DURING CARDIAC SURGERY}

U. Jain, PhD, MD, A. Krighnamurthy, MS, M. Dasari, $M D, K$. Krishnamachari, MS, K. Zaworski, BS, Loyola University Medical Center, Maywood, IL

Summary. A system for the digital acquisition and processing of electrocardiographic, hemodynamic, and clinical data for the detection of ischemia is presented.

Introduction. A system was developed for the direct digital acquisition and processing of multi-lead, multi-feature electrocardiographic (ECG) data during coronary artery bypass surgery. The hemodynamic and clinical data were also recorded synchronously and all the data were analyzed together.

Methods. One hundred twenty patients were studied. The MAC-12R digital ECG (Marquette Electronics, Milwaukee, WI) was used to record a multilead ECG approximately every 3 minutes. A baseline roll-off filter and a $60 \mathrm{~m} H z$ filter were used. All recordings were in full compliance with the American Heart Association guidelines. To reduce the effect of noise and beat-to-beat variability, a median ECG complex was constructed and all the measurements were made on it. A number of measurements on the digitized ECGs were obtained by the Marquette MUSE system implemented on a PDP 11/73 computer. The measurements were further analyzed to determine the episodes of ischemia.

Many patients had fixed ST deviation that was present preoperatively and intraoperatively. Such deviation was not considered to be due to acute ischemia. ST elevation was often caused by reasons other than ischemia. ST elevation caused by cooling, defibrillation, cardiac conduction abnormalities, and pericarditis were not considered to be due to ischemia. Reversible ST depression was considered to be caused by ischemia, while persistent ST elevation was considered to be caused by injury leading to myocardial infarction (MI).

Systolic and diastolic arterial, pulmonary artery, and right atrial pressures were recorded synchronously with the ECG. 
Cardiac outputs were recorded at the times of interest. The various steps being performed by the surgeon and the anesthesiologist and the drugs administered were also recorded. A computerized database of the relevant hemodynamic and clinical data was constructed. The required ECG measurements were integrated with this database.

Results. Seven patients had ST depression on arrival to the operating room, considered to be due to reversible ischemia, that reduced by more than $1 \mathrm{~mm}$ after anesthetic induction. One other patient developed new ST depression during aortic cannulation. Seven patients had new persistent 1 -mm ST elevation prior to heparinization. These patients had perioperative myocardial infarction (PMI). Nine other patients who also had PMI developed persistent ST elevation in temporal association with the administration of protamine. Two patients with PMI did not have ST elevation and were considered to have MI during cardiopulmonary bypass.

Discussion. Direct digital acquisition allowed accurate noise-free recordings of intraoperative ECGs when the ST deviation could be precisely measured by the computer. Another prominent feature of this study was the interpretation of ST deviation in light of the synchronously recorded clinical and hemodynamic data. The entire database was saved in the digital format and could be reanalyzed in different ways.

\section{THE HAND SQUEEZE RESPONSE TEST PREDICTS LEARIING DURIIG EMERGENCE FROM GENERAL ANESTHESIA}

R. C. Dutton, MD, W. D. Smith, PhD, and N. Ty Smith, MD, Kaiser Permanente Medical Center, Hayward, CA; California State University, Sacramento, $C A$; and University of California, San Diego, VA Medical Center, San Diego, CA

Summary. The hand squeeze response test predicts a patient's ability to learn during emergence from general anesthesia and may be useful for evaluating anesthetic depth monitors. The patient who squeezes the anesthetist's hand other than 4 times in response to a request for 4 squeezes falls just short of the learning threshold.

Introduction. An important aspect of anesthetic depth is whether the patient will remember events during surgery. This can be assessed by measuring whether the patient is able to learn. Thus, the ability to predict the presence or absence of learning is an important characteristic of an anesthetic depth monitor. We studied the hand squeeze response test to see if it might serve as a simple predictor of learning.

Methods. Prior to induction of anesthesia, the study was described to 45 healthy 18 - to 55 -year-old patients. Each patient agreed to remember target items that would be presented to him or her on awakening from anesthesia.

During anesthesia emergence, each patient received a brief mental status examination. The investigator placed his or her hand in the patient's hand, called the patient by name, and requested tasks of increasing complexity, specifically (1) eye opening, (2) hand squeeze, (3) four hand squeezes, and (4) backwards count from 20 . Patient responses to the brief mental status examination were graded as follows: grade 1, eye opening, no hand squeeze; grade 2, one hand squeeze; grade 3 , several, but not 4 , hand squeezes; and grade 4 , exactly 4 hand squeezes.

After the brief mental status examination the investigator

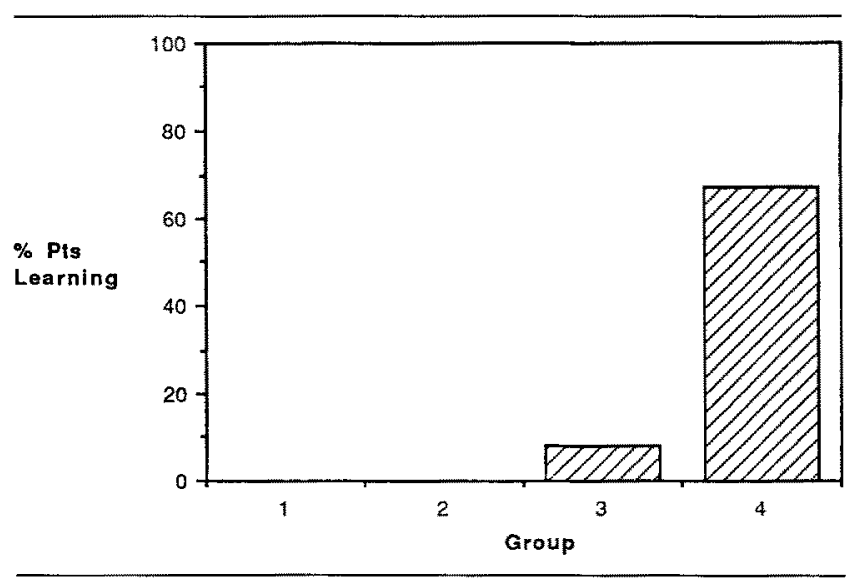

Hand squeeze response and learning.

presented the patient with the target item learning set. Target items were auditory (c.g., sound of a car trying to start) and visual (e.g., $\$ 1.00$ bill) and totalled 4 in number. The patient was then asked to name each target item and to describe an association to help recall it. The brief mental status examination was then repeated.

During the postoperative interview, each patient was tested for target item recall categorized as positive by the presence of any of the following: (1) free recall, (2) multiple choice forced recognition, (3) or cued recall. Free recall was assessed when the patient remembered target items without being prompted. The multiple choice test presented each target item along with 4 distractor items. The test was graded positive if the patient answered 3 of the 4 questions correctly $(p<0.05$ of occurring by chance). Cued recall was assessed positive if, after telling the patient the correct target item, he or she responded with the correct association (e.g., a cherry tree to remember a $\$ 1.00$ bill).

Results. The Figure shows that none of the 5 patients in grade 1 or the 10 patients in grade 2 had evidence of learning. In contrast, 1 of 12 patients $(8 \%)$ in grade 3 and 12 of 18 patients $(67 \%)$ in grade 4 had evidence of learning.

Discussion. We found that the hand squeeze response test predicted learning. The threshold of mental status for learning is the patient's ability to squeeze the anesthetist's hand at least once but not exactly 4 times. This measure lies just short of where most patients are able to learn.

The hand squeeze response test can be administered during surgery to patients receiving sufficient analgesics to suppress the response to noxious stimuli [1], and even to patients receiving muscle relaxants (isolated forearm technique [2]). This study shows that the hand squeeze response test is useful for predicting learning during emergence from anesthesia, and may be useful for evaluating anesthetic depth monitors.

\section{REFERENCES}

1. Dutton RC, Smith WD, Smith NT. EEG prediction of arousal during anesthesia with combinations of isoflurane, fentanyl, and $\mathrm{N}_{2} \mathrm{O}$. Anesthesiology 1991;75:A448

2. Tunstall ME. Detecting wakefulness during general anesthesia for caesarean section. Br Med J 1977;1:1321 


\section{QUALITY ASSURANCE IN IWTRAOPERATIVE TRANSESOPHAGEAL} ECHOCARDIOGRAPHY: A CRITICAL ANALYSIS OF A 2-YEAR EXPERIENGE

T. Rafferty, MD, K. LaMantia, MD, E. Davis, LPN, D. Phillips, BSEE, D. Gaal, MD, S. Harris, MD, J. Carter, $M D, G$. McCloskey, MD, H. Godek, $M D$, S. Rimar, $M D$, $P$. Kraker, $M D, D$. Jaeger, $M D, B$. Kosarussavadi, $M D$, R. Hines, MD, C. Kopriva, MD, T. O'Connor, MPH, Yale University, New Haven, CT

Summary. A transesophageal echocardiography quality assurance program in place for over 2 years showed that a transesophageal echocardiography endoscope handling service prevented equipment malfunctions and that most clinicians attained reasonable data acquisition skills.

Introduction. The purpose of this study was to evaluate a prototypical anesthesiology-based transesophageal echocardiography (TEE) program by comparing performance data to quality assurance criteria. The quality assurance criteria were as follows: (1) hospital record documentation of TEE examination; (2) completion of an examination database form; (3) provision of videotape for each case, to be subsequently assessed for quality by contracted cardiology reviewers and stored in an archival filing system; (4) technician maintenance of a daily log of personnel responsible for endoscope requisition; (5) data entry into a permanent computer database, with notation of lesions suitable for education/research; (6) weekly conferences featuring review of recent cases; and (7) monthly didactic seminar/lecture series on basic imaging principles.

Methods. The database was maintained with three software packages, with major and minor revisions. The most consistent and extensive data was within a Paradox system consisting of 846 procedure records, and forms the basis for derived values.

Results

Demographics: TEE endoscopy frequency was $36 \pm 11$ per month (range, 16-55). These endoscopies represented 2.2\% of total operative caseload, $40.2 \%$ of coronary artery bypass grafting cases, and $69.8 \%$ of valve surgery cases. The respective percentages of total pediatric caseload and pediatric cardiac surgery cases were $2.5 \%$ and $4.6 \%$. Twenty-six attending anesthesiologists were involved in the monitoring service. The average number of procedures performed per individual was $31.8 \pm 31.5$ (range, 1-103).

Attending anesthesiologist data acquisition performance: Hospital record documentation, database form annotation, and videotape provision occurred in $88 \%, 94 \%$, and $91 \%$ of cases, respectively. The corresponding values for individual attendings ranged from $0 \%$ to $100 \%, 73 \%$ to $100 \%$, and $79 \%$ to $100 \%$, respectively. Database form completion scores were $73 \pm 14 \%$ (range, $4 \%-97 \%$ ). Cardiology reviewer median grades $(1=$ excellent; $2=$ good; $3=$ poor $)$ for videotape 2-dimensional echocardiography and color flow-Doppler quality were 2 in both categories (ranges, 1-3). A grade of 1 or 2 was assigned to 84.8 and 79.7 of these 2 -dimensional echocardiography and color flow-Doppler quality evaluations, respectively. Grade 3, representing $15.2 \%$ and $20.3 \%$ of evaluations, respectively, was disproportionately associated with attendings no. $2,10,11$, and 13 .

Evaluation by extradepartmental reviewers: 277 of 846 videotapes were evaluated by two reviewers. Their review form completion score was $55.8 \pm 25.2 \%$. There was no significant difference between the scoring of reviewers $\mathrm{A}$ and $\mathrm{B}$.

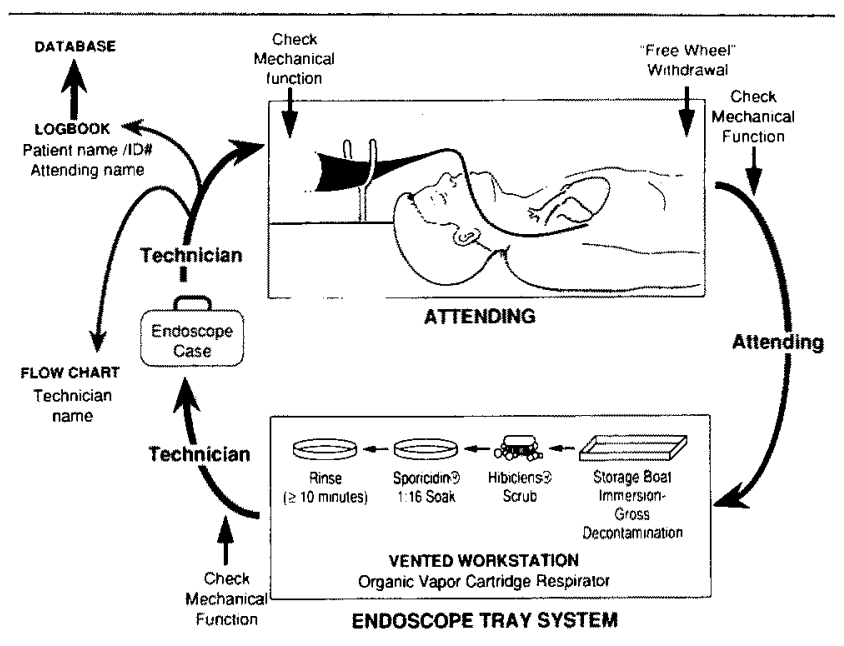

TEE endoscope requisition cycle.

Equipment mishaps: Console mishaps consisted of electrocardiograph cable avulsion and dislocation of an outside panel. Loss of integrity of the endoscope outer membrane occurred on two occasions; one was associated with a traumatic linear slit and the other with a tooth mark. A third membrane failure was associated with a false lumen. It was discovered when disinfectant was seen to discharge into a patient's pharynx during imaging. On four occasions, the endoscope was not cared for after use. After this observation we instituted a system to track and document endoscope use, cleaning, and testing (Fig).

Patient complications: Adverse sequelae consisted of a chipped tooth, a transient recurrent laryngeal nerve paresis, and presumed ingestion of glutaraldehyde disinfectant solution (vide supra).

Conclusions

1. TEE resource use was directed primarily to adult cardiac surgery cases. The procedure most frequently monitored was coronary artery bypass grafting, although only $40.2 \%$ of patients undergoing this procedure were monitored. In contrast, although lower in total number, the majority of valve replacement cases $(69.8 \%)$ were monitored.

2. Endoscopy frequency increased during the study period. While this increase was not precipitous $(r=0.63)$, it has yet to plateau.

3. The quality of data acquisition within the department was variable. "Substandard" performance was observed in an identifiable minority of attendings ( 4 of 26).

4. Extradepartmental review occurred in only $56 \%$ of cases, and this approach must be reevaluated.

5. Initiation of an endoscopy handling chain of responsibility was associated with a marked decrease in the incidence of equipment malfunction that was thought to be due to lack of care and/or abuse.

GARDIOPLEGIA-IHDUCED AORTIC REGURGITATION IN PATIENTS WITHOUT PREEXISTIMG AORTIC VALVULAR DISEASE

S.N. Harris, MD, T. Rafferty, MD, E. Davis, LPN, M. Durkin, MD, Yale University, New Haven, CT

Summary. In patients with competent aortic valves demonstrated by color-flow Doppler, saline-contrast 
echocardiography demonstrated that pressurized cardioplegia commonly induces aortic regurgitation without left ventricular distension.

Introduction. During aortography, forceful injection of contrast may result in aortic regurgitation in patients without preexisting valvular disease. During cardiac surgery, cardioplegia is administered via pressure infusion through the aortic root. The following study was performed to determine the effect of this maneuver on aortic valve (AV) integrity in patients without concomitant $A V$ dysfunction.

Methods. Twenty-two consecutive patients, fulfilling $\mathrm{Hu}-$ man Investigation Committee guidelines and undergoing cardiac surgery were studied. Transesophageal color flowDoppler (CFD) and two-dimensional echocardiographic (2D-echo) recordings were obtained with a $5.0-\mathrm{MHz}$, phased-array transducer. Patients demonstrating aortic regurgitation by CFD criteria were excluded. CFD and 2D-echo images were in standard left ventricular outflow tract (LVOT) planes at a focal depth of $12 \mathrm{~cm}$. Color gain and 2D-echo gray scale settings were standardized. Cardioplegia (CP) was administered by roller pump infusion via no. 14 aortic root cannulae at driving pressures of 150 to $200 \mathrm{~mm} \mathrm{Hg}$. Regurgitation of this crystalloid $\mathrm{CP}$ was assessed by $2 \mathrm{D}$-echo visualization of cavitations (microbubbles) associated with forceful administration (saline-contrast technique). LV penetration was graded as follows: grade 1, maintenance of AV integrity; grade 2, CP regurgitation confined to the LVOT; grade $3, \mathrm{CP}$ regurgitation extending to the LV body; grade $4, \mathrm{CP}$ regurgitation extending to the left atrium (LA). Data comparison was by repeated measure analysis of variance.

Results. Institution of cardiopulmonary bypass was associated with significant decreases in LV diameter and LVOT area $(p<0.001) . \mathrm{CP}$ infusion was associated with maintenance of $A V$ integrity in 2 of 22 cases, was confined to the LVOT in 2 of 22 cases, extended to the LV body in 1 of 22 cases, and extended into the LA in 17 of 22 cases (Fig 1). There were no significant differences between cardiopulmonary bypass and CP LVOT area and LV diameter, respectively (Fig 2 ).

Comment. Rapid intravascular administration of crystalloid is associated with agitation of the solution. The resulting microbubble formation (cavitation) provides an ultrasoundopaque medium that can be used as a source of $2 \mathrm{D}$-echo contrast, as in this series. The majority of our patients manifested transvalvular regurgitation of $\mathrm{CP}$ during standard aortic root

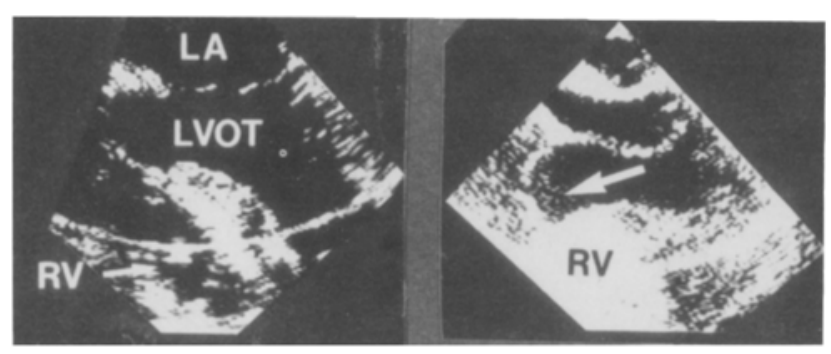

Fig 1. (Left) Transesophageal $2 D$-echo depicting the $L A$, $L V O T$, and right ventricle ( $R V)$. (Right) The LA is decompressed. The RA cavity is totally obliterated. CPAR cavitations can be seen to regurgitate into the LVOT.

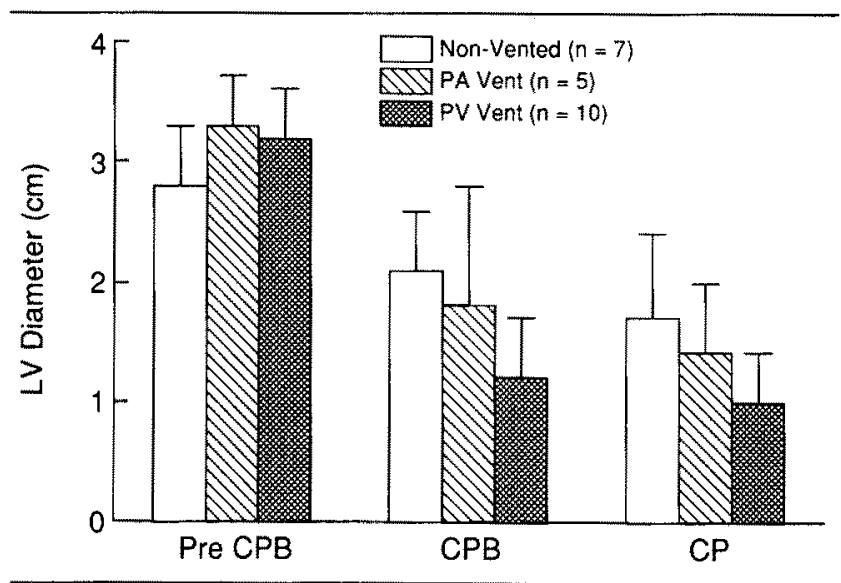

Fig 2. Differences in $L V$ diameter.

administration, despite demonstrable preinfusion AV integrity. However, LV dimensions did not exceed antecedent values during $C P$ infusion, suggesting a minimal regurgitant fraction. LV distension is a relatively common sequela of $\mathrm{CP}$ administration. Our data suggest that intraoperative CFD interrogation of the LVOT may provide a clinically useful means of identifying patients who are not at risk for CPassociated LV distension.

\section{PERFORMANCE OF TRANSTRACHEAL dOPPLER CARDIAC OUTPUT MONITORING}

A.C. Perrino, Jr, MD, T.Z. O'Connor, MPH, M. Luther, RN, Yale University, Yale-New Haven Hospital, New Haven, CT

Summary. Design improvements will be needed to produce a clinically acceptable transtracheal Doppler cardiac output monitor.

Introduction. Transtracheal Doppler (TTD) is a new method for continuous monitoring of cardiac output (CO). TTD uses a 5-MHz pulse-wave Doppler transducer mounted on the tip of an endotracheal tube (ETT) to measure the diameter of and blood flow velocity within the ascending aorta. A prospective evaluation to determine the accuracy, trending capability, and operator learning curve for TTD by comparison to thermodilution (TD) is described.

Methods. Following an ethical committee-approved protocol, TTD monitoring (ABCOM-1, Applied Biometrics) was performed in 27 patients undergoing noncardiac surgery. After induction of general anesthesia, the Doppler ETT was inserted and the position adjusted to obtain optimal Doppler signals. Once positioned, TTD provided continuous display of $\mathrm{CO}$ as well as an audible broadcast of the received Doppler signal. As a reference standard, TD measurements were obtained at end-expiration using room temperature injectate and a SpaceLabs TD CO computer. The TTD operator was blinded to the TD measurements. Simultaneous TD and TTD $\mathrm{CO}$ measurements were compared using regression analysis, following the method of Bland and Altman, and F-test for comparison of variances. A probability value of less than 0.05 was considered significant.

Results. Adequate Doppler signals were obtained in 24 of the 27 patients. Analysis of Doppler and TD CO data revealed 


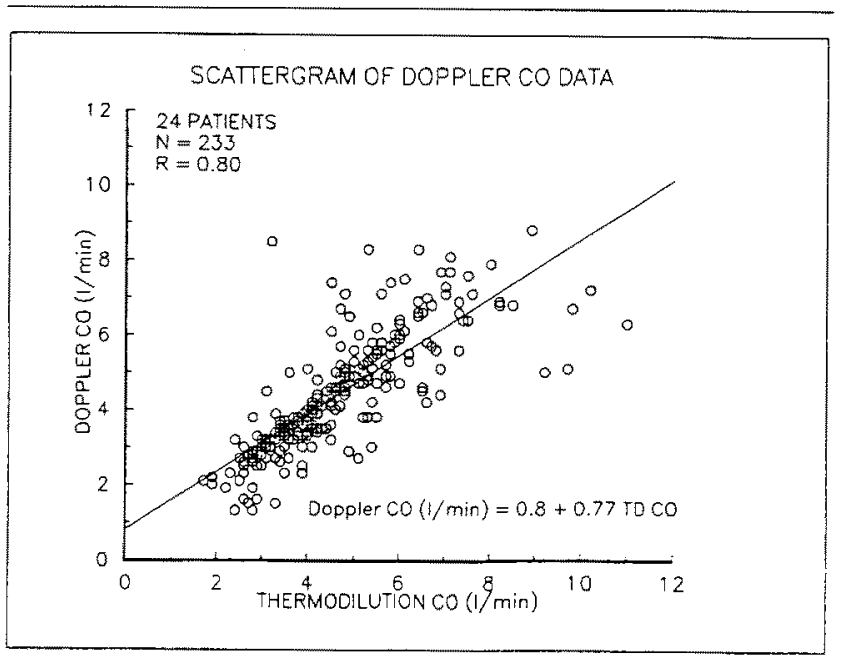

Scattergram of Doppler CO data.

a correlation coefficient $r=0.80$, a mean bias of $-0.28 \mathrm{~L} /$ min, and a standard deviation of the bias (SD) of $1.03 \mathrm{~L}$ / min (Fig). Trending data showed a strong correlation between changes in TD CO and changes in Doppler CO $(r=0.74)$. In the subgroup of patients whose Doppler signal quality was rated excellent (11 patients), the agreement between Doppler and TD was significantly improved $(r=0.92, \mathrm{SD}=0.61 \mathrm{~L} /$ min). Operator experience also affected TTD performance. TTD showed significantly less error in the second half of the study $(\mathrm{SD}=1.0 \mathrm{~L} / \mathrm{min})$ compared with the first half $(\mathrm{SD}=$ $1.4 \mathrm{~L} / \mathrm{min})$.

Discussion. Adequate TTD signals were unobtainable or of suboptimal quality in a significant percentage of patients undergoing noncardiac surgery. In those patients in whom the Doppler signal quality was excellent, TTD CO values were in close agreement with matched TD values. Increased operator experience also improved TTD performance. Modifications in TTD technology, including refined transducer design and signal processing, are currently being explored to improve the reliability of this device.

\section{COLOR-FLOW DOPPLER TRICUSPID REGURGITATION SHOULD BE EXPRESSED AS A FUNCTION OF RIGHT ATRIAL DIMENSIONS}

Terence Rafferty, MD, Michael Durkin, MD, Stephen N. Harris, MD, Joseph Mathew, MD, Roberta Hines, $M D$, Theresa $Z$. O'Connor, MPH, Yale University, New Haven, CT

Summary. Color flow Doppler tricuspid regurgitation jet should be expressed as a fraction of right atrial dimension; if so, tricuspid regurgitation is functionally significant when the jet area is greater than $3 \%$ of the atrial dimension.

Introduction. Color-flow Doppler (CFD) technology allows semiquantitative analysis of valvular regurgitation. In the case of mitral and aortic regurgitation it is recommended that CFD estimates be expressed as a function of receiving chamber dimensions (left atrial area and left ventricular outflow tract diameter, respectively). There are no corresponding data refer- able to tricuspid regurgitation (TR). The following study addressed this issue.

Methods. Twenty coronary artery bypass graft patients were studied. Studies fulfilled Human Investigation Committee criteria. Two-dimensional echocardiographic (2D-echo) and CFD data were obtained with a $5.0-\mathrm{MHz}$ transesophageal phased-array transducer. 2D-echo long axis views transected the right ventricle from base to apex with the mitral valve in the far field [1]. CFD data were obtained at a focal depth of $12 \mathrm{~cm}$ with the transducer orientated to maximally demonstrate the regurgitant jet [2]. Measurements included CFD TR jet area and CFD TR jet area expressed as a fraction of the corresponding right atrial (RA) area. TR was also assessed by the 2D-echo saline contrast technique described by Lieppe et al [3]. Measurements were made following inductionintubation, sternotomy, pericardiectomy, cardiopulmonary bypass, and sternal closure. Data analysis was by linear (correlation) and logistic regression as appropriate.

Results. CFD regurgitant jet area $\left(0.35 \pm 0.5 \mathrm{~cm}^{2}\right.$; range, $\left.0-3.12 \mathrm{~cm}^{2}\right)$ was significantly $(p<0.001 ; \gamma=0.94)$ related to CFD jet area to RA area ratio $(0.02 \pm 0.02$; range, $0-0.14)$. Continuous CFD regurgitant jet area and CFD jet area to RA area ratio were significantly $(p<0.001)$ related to the dichotomized saline contrast value (Fig 1). Respective model fit intercept and covariate $\mathrm{AIC} / \mathrm{SC} / \mathrm{G}$ values were $91.9 / 97.0 /$ 87.9 and $85.7 / 90.8 / 81.7$. The CFD jet area to RA area ratiocreated interval mean value versus saline contrast mean value (proportion) relationship demonstrated a cut-point of 0.04 (Fig 2, arrow).

Discussion. Despite the close relationship between the CFD regurgitant jet area and the CFD jet area to RA area ratio, comparable regression "best-fit" estimates demonstrated that the area ratio measurements reflected saline-contrast values more closely than corresponding uncorrected measurements. Comparison of the CFD jet area to RA area ratio-created interval values with the qualitative kinetic-volume standard revealed a sigmoid relationship with a well-defined cut-point. This finding, combined with consideration of the physiologic mechanism underlying positive saline-contrast values (ie, regurgitation of cavitations) suggests that CFD TR jets only become functionally meaningful when they occupy more than $3 \%$ of corresponding RA dimensions.

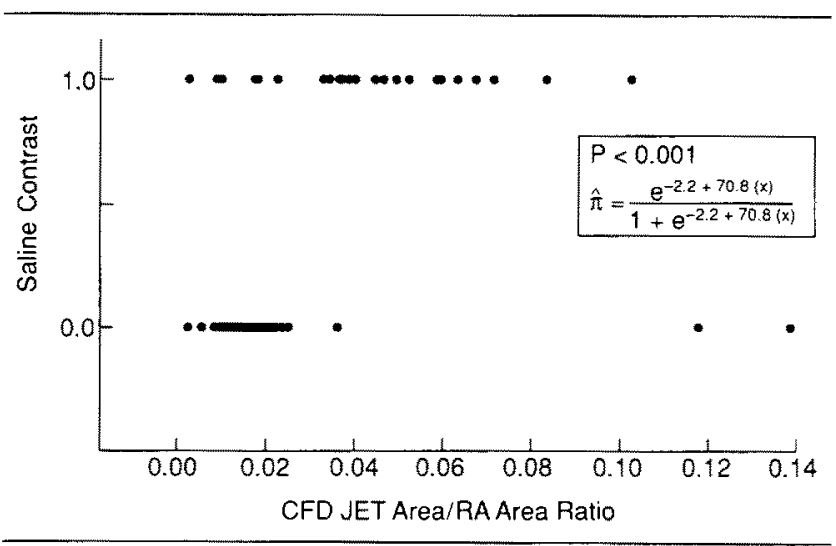

Fig 1. Scatterplot of $C F D$ jet area to $R A$ area ratio versus saline contrast values (proportion). 


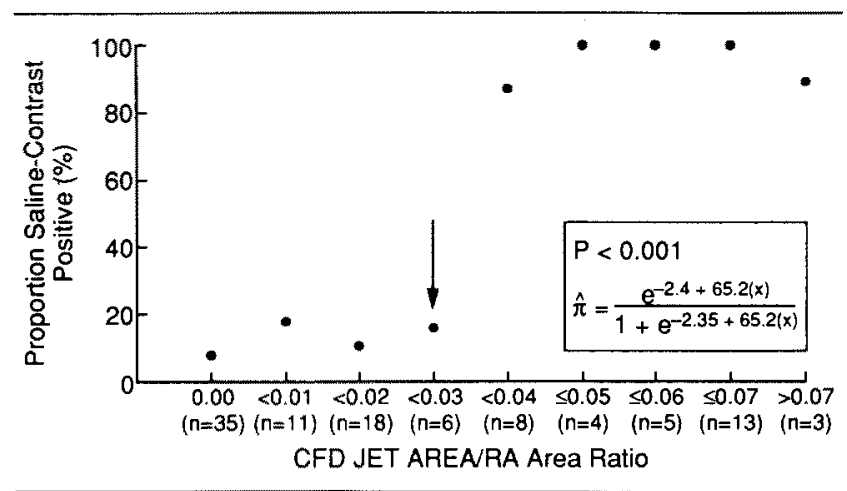

Fig 2. CFD jet area to $R A$ area ratio-created interval mean values versus saline-contrast mean values (proportion). The arrow delineates the cut-point.

\section{REFERENCES}

1. Am J Cardiol $1984 ; 53: 1173$

2. J Am Clin Cardiol 1987;9:952

3. Circulation $1978 ; 57: 128$

\section{ESTIMATION OF RIGHT VENTRICULAR TRANSGASTRIC SHORT AXIS ECHOCARDIOGRAPHIC PLANIMETERED DIMENSIONS BY QUALTATIVE MORPHOLOGIC CRITERIA}

Terence Rafferty, MD, Michael Durkin, MD, Stephen N. Harris, MD, Elizabeth Davis, LPN, Roberta Hines, MD, Theresa Z. O'Connor, MPH, Yale University, New Haven, CT

Summary. The analysis of right ventricular function may be complicated by right ventricular rotation during changing loading conditions.

Introduction. Right ventricular volume loading is associated with chamber rotation. The following study was performed to determine whether this axis shift might make it feasible to estimate respective echocardiographic planimetered dimensions in the plane of motion by anticipated shifts in position of right ventricular landmark structures.

Methods. Seventeen patients scheduled for coronary artery bypass graft and fulfilling Human Investigation Committee criteria were studied. Standardized supine transesophageal transgastric left ventricular midpapillary muscle plane short axis (SA) images (5.0-MHZ, phased-array transducer) were analyzed to obtain right ventricular end-systolic (RVSAS), end-diastolic (RVSAD) planimetered arca, and morphology (RD index). RD index grades were as follows: 0 , RV crescentic outline with intraluminal trabeculae; 1 , tricuspid leaflet apparatus (TLA) at posterior interventricular septum (IVS) level; 2, TLA at mid-IVS; and 3, TLA at anterior IVS. Data were obtained following induction-intubation, sternotomy, pericardiectomy, cardiopulmonary bypass, and sternal closure. Analyses were by linear regression.

Results. RVSAS $(9.6 \pm 8.6 \mathrm{~cm})$ was significantly related to RVSAD $(16.7 \pm 8.6 \mathrm{~cm})(p<0.001 ; r=0.94)$ (Fig 1). These

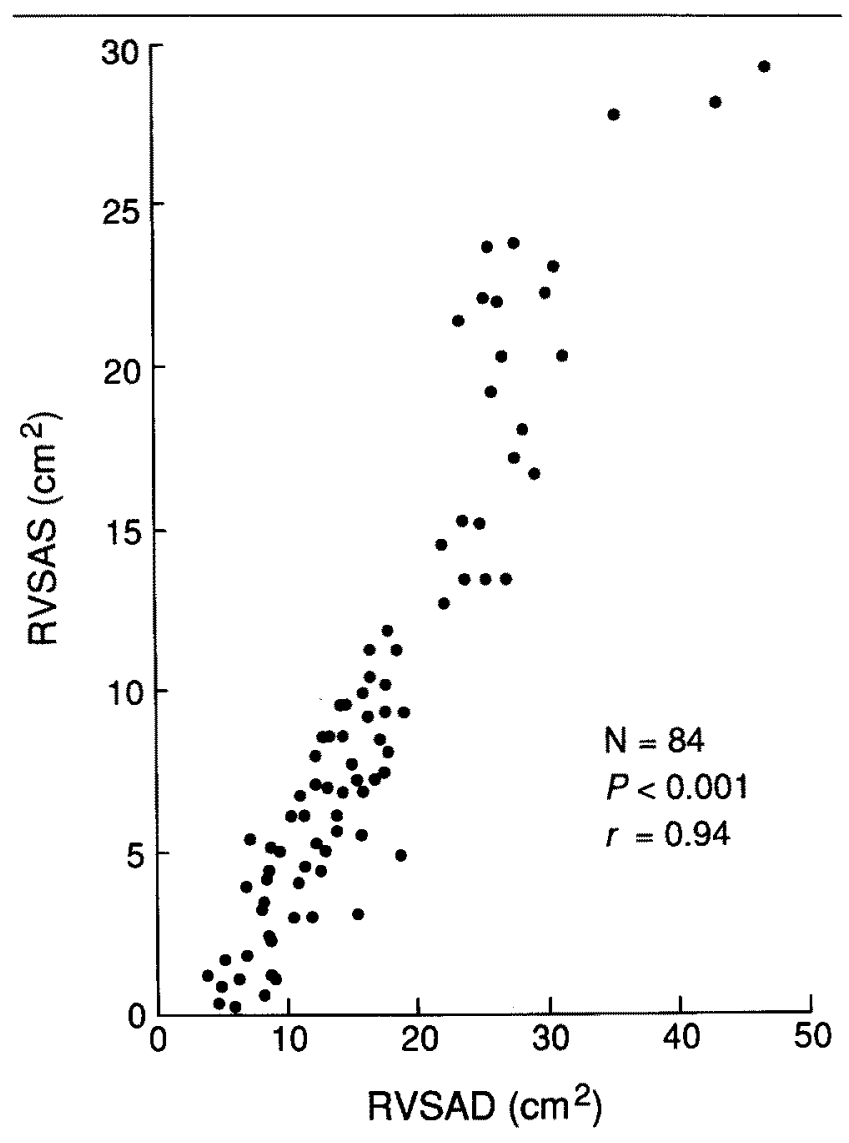

Fig 1. RVSAS versus RVSAD.

\begin{tabular}{cllll}
\hline RVSAS & $4.7 \pm$ & $9.3 \pm$ & $15.0 \pm$ & $21.9 \pm 7.7$ \\
$\left(\mathrm{~cm}^{2}\right)$ & 2.8 & 6.1 & 5.8 & \\
RVSAD & $11.0 \pm$ & $17.0 \pm$ & $22.1 \pm$ & $31.8 \pm$ \\
$\left(\mathrm{cm}^{2}\right)$ & 4.2 & 6.3 & 7.2 & 11.8 \\
RD index & 0 & 1 & 2 & 3 \\
\hline
\end{tabular}

variables were significantly related to $\mathrm{RD}$ index $(p<0.001$; $r=0.74$ and 0.70 , respectively) (Table, Fig 2 ). The null hypothesis that respective pre- and post-cardiopulmonary bypass regressions were parallel and coincident was not rejected $(p>$ $0.05)$.

Discussion. Right ventricular transgastric short axis echocardiographic dimensions can be assessed by qualitative criteria, facilitating expeditious data interpretation in rapidly evolving clinical situations. Concurrence of pre- and postcardiopulmonary bypass relationships infers validity under conditions of cardiopulmonary bypass-associated ventricular translocation. RD index grade progression can be explained best by right ventricular rotation. Accordingly, right ventricular image standardization in terms of left ventricular references may not offer consistent right ventricular regions for analysis, thus complicating precise delineation of right heart regional wall motion abnormalities. 


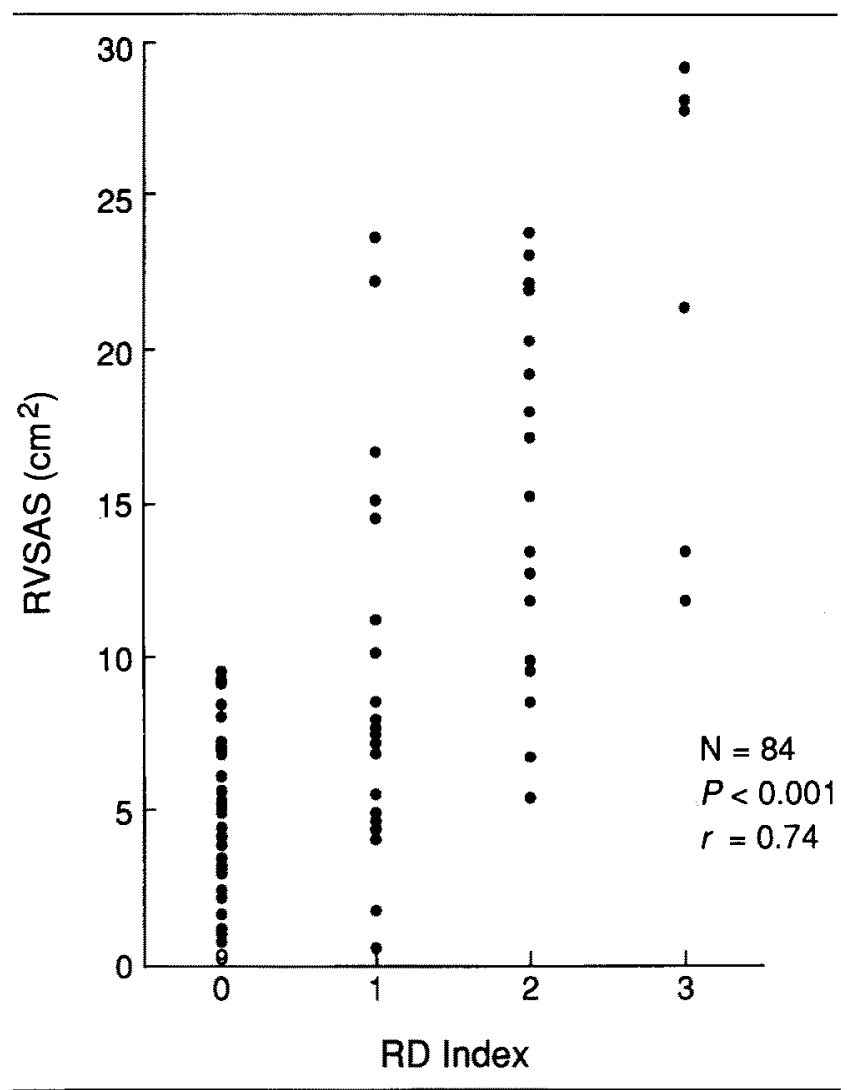

Fig 2. Scatterplot of RVSAS versus RD index.

\section{SESSION 3: INFORMATION OBTAINED USING TECHNOLOGY}

\section{CHANGES IN $\mathrm{SYO}_{2}$ DO NOT PREDICT CHANGES IN THERMODILUTION GARDIAC OUTPUT}

D. H. Wong, PharmD, MD, P. Weir, MD, D. Mest, MD, J. Zaccari, BS, S. Daves, MD, L. Ferraro, MD, S. Barker, $P h D, M D$, Long Beach VA Hospital and University of California, Irvine, $C A$

Summary. Changes in mixed venous oximetry $\left(\mathrm{SvO}_{2}\right)$ do not predict changes in thermodilution cardiac output.

Introduction. Mixed venous oximetry $\left(\mathrm{SVO}_{2}\right)$ is often used to monitor changes in cardiac output $(\mathrm{CO})$. This assumes that the patient's $\mathrm{SaO}_{2}, \mathrm{Hb}$, or ${ }^{\circ} 2$ consumption is stable; if this is true, then changes in $\mathrm{SvO}_{2}$ should reflect changes in $\mathrm{CO}$ [1]. Using a change in one physiologic parameter to predict a change in another means that the first parameter is being used as a diagnostic test for the second. Therefore, the accuracy of changes in $\mathrm{SvO}_{2}$ to predict changes in $\mathrm{CO}$ should be quantifiable in terms of sensitivity and specificity. Other investigators have anecdotally reported that $10 \%$ changes in $\mathrm{SvO}_{2}$ are related to changes in $\mathrm{CO}$, but actual sensitivities and specificities have not been reported [2]. The purpose of this study was to

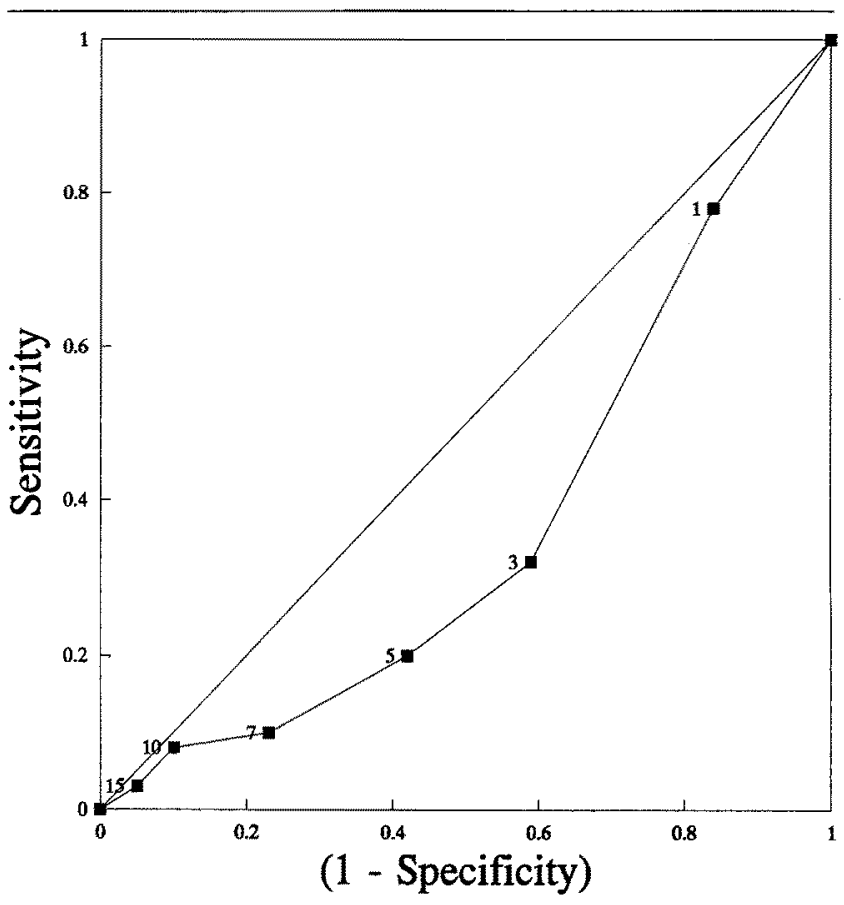

Changes in $\mathrm{SuO}_{2}$ to predict changes in $\mathrm{CO}$.

determine the specificity and sensitivity of changes in $\mathrm{SvO}_{2}$ to predict changes in $\mathrm{CO}$.

Methods. This study was approved by the institutional review board. $\mathrm{SvO}_{2}$ was measured with either Abbott Oximetrix or Edwards Sat-20 $\mathrm{SvO}_{2}$ catheters in intensive care unit patients. CO was measured by thermodilution with $10 \mathrm{~mL}$ of room temperature injectate in triplicate. COTD and $\mathrm{SvO}_{2}$ were made simultaneously, and each measurement pair was compared with the preceding measurement pair. The change in $\mathrm{SvO}_{2}$ needed to predict a $10 \%$ change in $\mathrm{CO}$ was tested at cutoff values of $1 \%, 5 \%, 8 \%, 10 \%, 12 \%, 15 \%, 17 \%$, and $20 \%$ Sat differences in $\mathrm{SvO}_{2}$. The sensitivity and specificity at each cutoff was used to create a receiver operator characteristic (ROC) curve.

Results. One hundred fifty-seven measurement sets were made in 26 patients. CO changed by $10 \% 78$ times; $\mathrm{CO}$ increased 38 times and $\mathrm{CO}$ decreased 40 times. The ROC for different $\mathrm{SvO}_{2}$ thresholds to predict changes in COTD is shown in the Figure.

Discussion. Our ROC curve shows that changes in $\mathrm{SvO}_{2}$ did not predict changes in $\mathrm{CO}$ well. The most likely reason for this is that the assumption that $\mathrm{SaO}_{2}, \mathrm{Hb}$, and ${ }^{\circ} 2$ consumption are constant between consecutive $\mathrm{CO}$ determinations may be invalid.

\section{REFERENCES}

1. Int Anesthesia Clin 1987;25:113-136

2. Crit Care Med 1988;16:495-498 


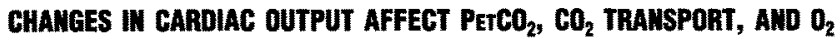 UPTAKE DURING UNSTEADY STATE II HUMAMS}

K. Shibutani, MD, S. Shirasaki, MD, T. Bratz, B. Sivaprakasapillai, * P. Gupte, ME, BME,* Departments of Anesthesiology and Biomedical Engineering, ${ }^{*}$ New York Medical College, Valhalla, NY

Summary. Confirming our previous report, $\mathrm{PETCO}_{2}$, $\mathrm{CO}_{2}$ elimination, and $\mathrm{O}_{2}$ uptake correlated positively with changes in $\mathrm{CO}$. Based on our observations and reasoning, these findings are not due to ventilation changes.

Introduction. Previously, we reported that monitoring endtidal $\mathrm{CO}_{2}$ tension $\left(\mathrm{PeTCO}_{2}\right.$ ) provides noninvasive real time cardiac output change tracking in patients undergoing surgery with constant ventilation [1]. In this study, we further examined the relationship between $\mathrm{CO}$ changes $(\Delta \mathrm{CO})$ and $\mathrm{CO}_{2}$ elimination.

Methods. Nine patients undergoing surgery for abdominal aortic aneurysm under general anesthesia were studied during periods of constant ventilation. $\mathrm{PETCO}_{2}$ was continuously monitored with a Raman Scattering Analysis System (RASCAL, Ohmeda Monitoring, Louisville, CO) and mixed inspired and expired $\mathrm{O}_{2}$ and $\mathrm{CO}_{2}$ concentrations were continuously monitored from mixing chambers [2]. Digital data were collected and stored on the disk contained in the SpaceLabs PC physiologic monitor. Differences between expired and inspired $\mathrm{CO}_{2}$ concentrations $\left(\mathrm{P}_{\mathrm{E}}-{ }_{1} \mathrm{CO}_{2}\right)$ and differences between inspired and expired $\mathrm{O}_{2}$ concentrations $\left(\mathrm{P}_{\mathrm{I}}-\mathrm{O}_{2}\right)$ were graphically presented using Lotus $1-2-3$ software. The changes in $\mathrm{P}_{\mathrm{E}}-{ }_{\mathrm{I}} \mathrm{CO}_{2}$ and $\mathrm{P}_{\mathrm{I}}-{ }_{\mathrm{E}} \mathrm{O}_{2}\left(\Delta \mathrm{P}_{\mathrm{E}}-{ }_{\mathrm{I}} \mathrm{CO}_{2}\right.$ and $\left.\Delta \mathrm{P}_{1}-{ }_{\mathrm{E}} \mathrm{O}_{2}\right)$ were obtained from the graph. Cardiac output (CO) was measured in duplicate by thermodilution whenever $\mathrm{PETCO}_{2}$ changed. $\mathrm{CO}_{2}$ change was defined as a consistent $\mathrm{PETCO}_{2}$ rise or fall by more than $1 \mathrm{~mm} \mathrm{Hg}$. For graphic demonstration of relationships among variables, a tracheal tube-mounted Doppler flow probe (Cardiovascular Devices) was sometimes used to estimate cardiac output.

Results. There were $15 \mathrm{PeTCO}_{2}$ increases and $17 \mathrm{PeTCO}_{2}$ decreases studied. The correlations between $\triangle \mathrm{CO}, \triangle \mathrm{PETCO}$, $\mathrm{P}_{E}-{ }_{\mathrm{I}} \mathrm{CO}_{2}$, and $\mathrm{P}_{1}-{ }_{E} \mathrm{O}_{2}$ are shown in the Table and in Figure 1. Directions of individual change between $\mathrm{P}_{\mathrm{E}}-{ }_{1} \mathrm{CO}_{2}$ and $\mathrm{PETCO}_{2}$ are shown by arrows in Figure 2 and directions of change between $\mathrm{P}_{E}-{ }_{1} \mathrm{CO}_{2}$ and $\mathrm{P}_{1}-{ }_{E} \mathrm{O}_{2}$ are shown by arrows in Figure 3. A typical example of the trend of $\mathrm{P}_{\mathrm{E}}-{ }_{1} \mathrm{CO}_{2}$, $\mathrm{P}_{\mathrm{I}}-{ }_{\mathrm{E}} \mathrm{O}_{2}$, and continuous $\mathrm{CO}$ is shown in Figure 4. Time between paired measurements was $11.7 \pm 5.6$ minutes (mean $\pm \mathrm{SD})$

Correlation Between the Changes of $\mathrm{CO}, \mathrm{PETCO}_{2}, \mathrm{PE}_{\mathrm{E}}-\mathrm{CO}_{2}$, and $P_{1}-{ }_{E} \mathrm{O}_{2}$

\begin{tabular}{lllll}
\hline & & & $r$ & $p$ \\
\hline$\Delta \mathrm{CO}$ & $v$ & $\Delta \mathrm{PETCO}_{2}$ & .87 & $<10^{-3}$ \\
$\Delta \mathrm{CO}$ & $v$ & $\Delta \mathrm{P}_{\mathrm{E}}-{ }_{\mathrm{C}} \mathrm{CO}_{2}$ & .84 & $<10^{-3}$ \\
$\Delta \mathrm{CO}$ & $v$ & $\Delta \mathrm{P}_{\mathrm{I}}-{ }_{\mathrm{E}} \mathrm{CO}_{2}$ & .88 & $<10^{-3}$ \\
$\Delta \mathrm{PETCO}_{2}$ & $v$ & $\Delta \mathrm{P}_{\mathrm{E}}-{ }_{\mathrm{C}} \mathrm{CO}_{2}$ & .90 & $<10^{-3}$ \\
$\Delta \mathrm{PETCO}_{2}$ & $v$ & $\Delta \mathrm{P}_{\mathrm{I}}-{ }_{\mathrm{E}} \mathrm{CO}_{2}$ & .91 & $<10^{-3}$ \\
$\Delta \mathrm{P}_{\mathrm{E}}-{ }_{\mathrm{I}} \mathrm{CO}_{2}$ & $v$ & $\Delta \mathrm{P}_{\mathrm{I}}-{ }_{\mathrm{E}} \mathrm{CO}_{2}$ & .87 & $<10^{-3}$ \\
\hline
\end{tabular}

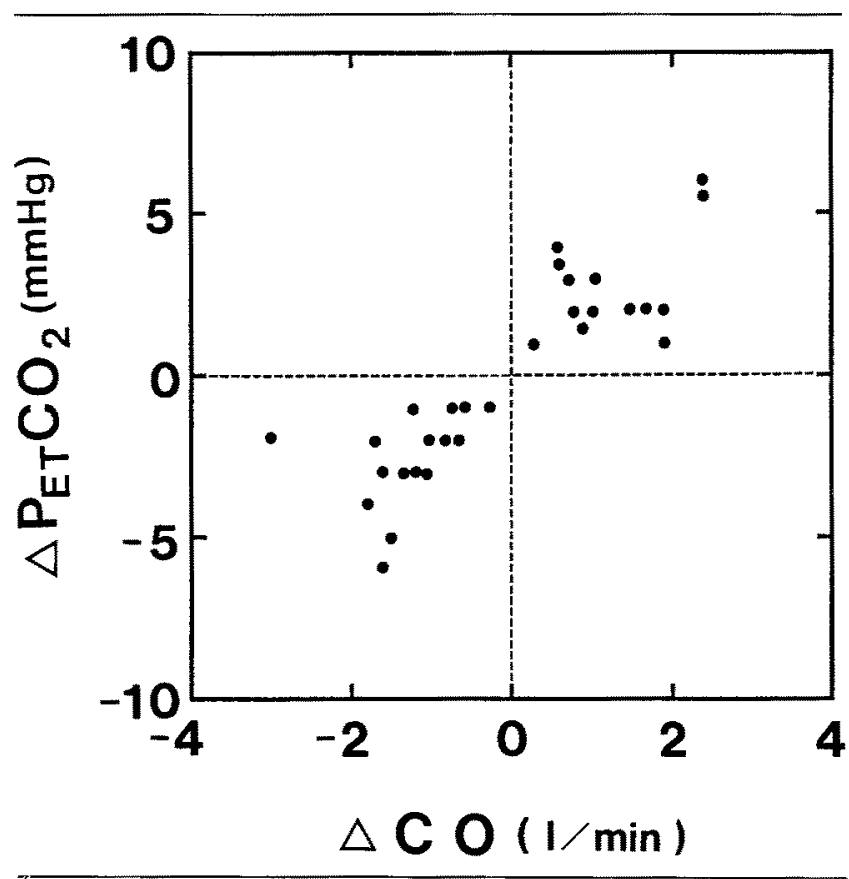

Fig 1. Correlation between $\triangle \mathrm{CO}$ and $\triangle \mathrm{PETCO}_{2}$.

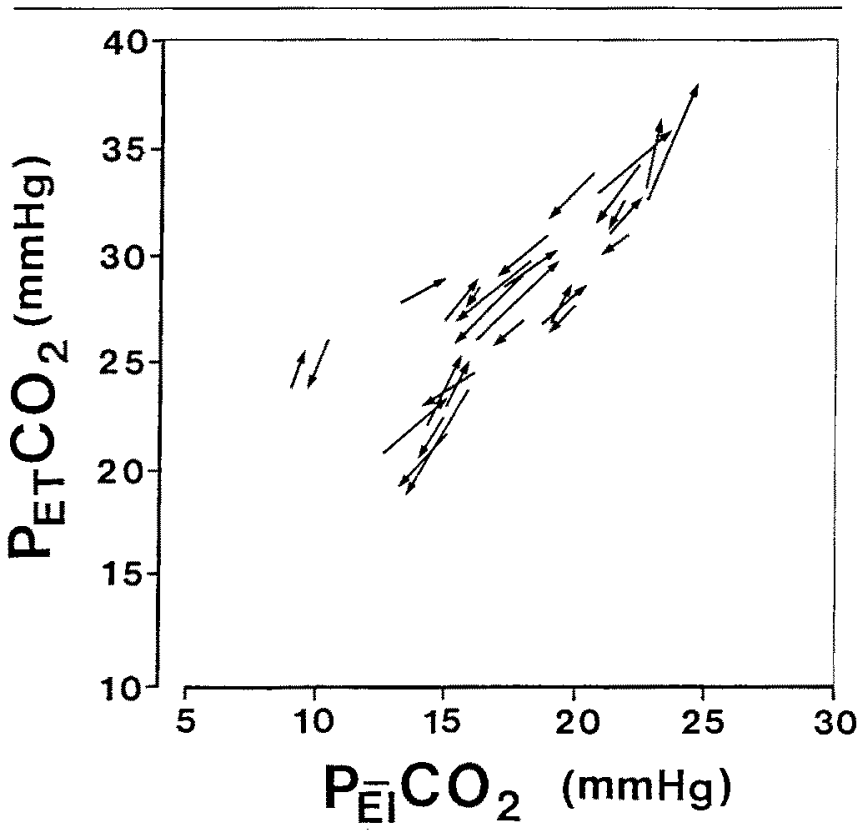

Fig 2. Direction of the changes of $P_{E}-{ }_{1} \mathrm{CO}_{2}$ and $\mathrm{PETCO}_{2}$ in 15 hemodynamic events.

Discussion. Under constant ventilation, $\mathrm{CO}$ changes were associated with corresponding changes in $\mathrm{PETCO}_{2}, \mathrm{CO}_{2}$ elimination, and $\mathrm{O}_{2}$ uptake. These findings suggest that changes in $\mathrm{CO}$ affect $\mathrm{CO}_{2}$ storage, and accordingly, transport of $\mathrm{CO}_{2}$ from the tissues to the lung. The positive correlation between changes in $\mathrm{P}_{\mathrm{E}}-\mathrm{CO}_{2}\left(\mathrm{CO}_{2}\right.$ elimination $)$ and $\mathrm{P}_{\mathrm{I}}-{ }_{\mathrm{E}} \mathrm{O}_{2}\left(\mathrm{O}_{2}\right.$ up- 


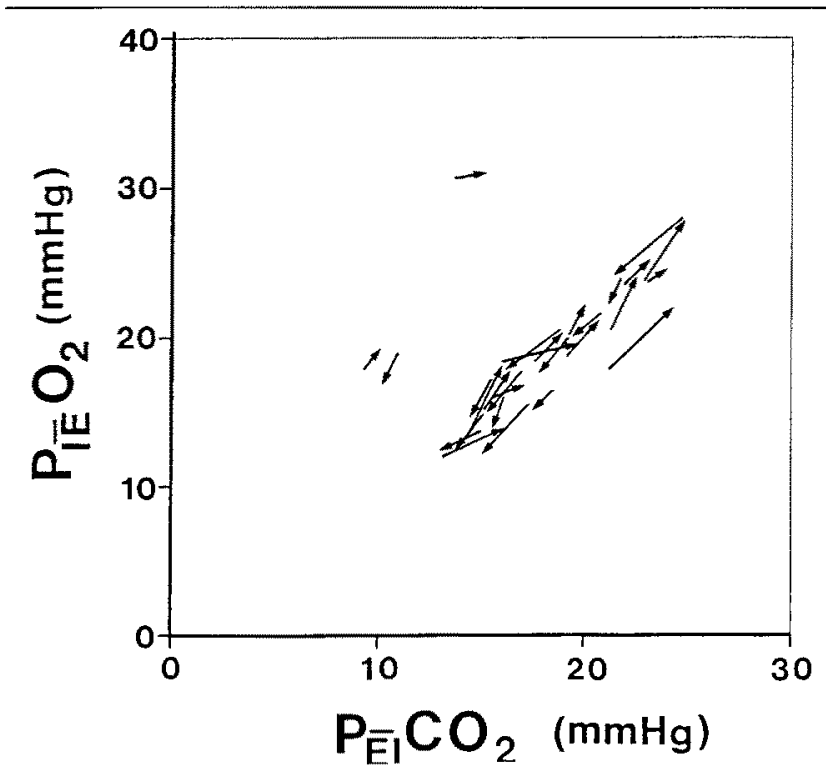

Fig 3. Direction of the changes of $P_{E}-{ }_{1} \mathrm{CO}_{2}$ and $P_{I}-{ }_{E} \mathrm{CO}_{2}$ on the events.
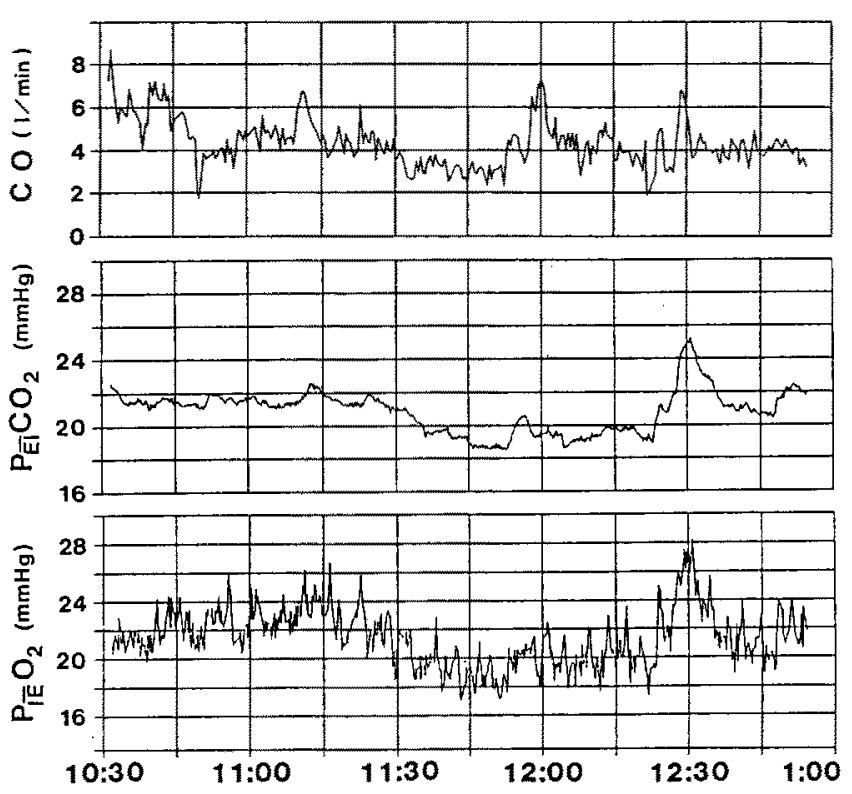

TIME

Fig 4. A typical example of $P_{E}-{ }_{1} \mathrm{CO}_{2}, P_{1}-{ }_{E} \mathrm{CO}_{2}$, and $\mathrm{CO}$ (measured by continuous Doppler technique).

take) during these hemodynamic changes suggest that even perfusion of tissues did not occur during the unsteady state and explains the mechanism whereby changes in CO correlated positively with the changes in $\mathrm{PeTCO}_{2}$. Another possibility is that in these clinical situations $\mathrm{CO}$ changes were actually driven from changes in oxygen consumption and carbon dioxide production rather than the reverse.

\section{REFERENCES}

1. Shibutani $\mathrm{K}$, et al. End-tidal $\mathrm{CO}_{2}: \mathrm{A}$ clinical noninvasive cardiac output monitor. Anesth Analg 1991;72:S251

2. Sanjo Y, Ikeda K. A small mixing chamber for monitoring metabolic rate and anesthetic uptake. J Clin Monit $1987 ; 3: 235-243$

\section{IUSPIRATORY FLOW RATE AFFECTS IMSPIRED $\mathrm{CO}_{2}$ CONGENTRATION IN THE PRESENGE OF A CIRCLE CIRCUIT EXPIRATORY YALVE LEAK}

Julian M. Goldman, MD, University of Colorado, Denver, $\mathrm{CO}$

Summary. With a constant expiratory valve leak, inspired $\mathrm{CO}_{2}$ concentration varies inversely with inspiratory flow because as flow increases, a smaller portion of each breath passes through the incompetent expiratory valve.

Introduction. When a patient's lungs are mechanically ventilated using an anesthesia circle breathing circuit, an expiratory valve (EV) leak may produce an increase in inspired carbon dioxide concentration $\left(\mathrm{FICO}_{2}\right.$ ). This increase in $\mathrm{FICO}_{2}$ occurs because the incompetent valve permits the reverse flow of $\mathrm{CO}_{2}$-rich expiratory limb gas during inspiration. Therefore, the increase in $\mathrm{FICO}_{2}$ is a function of the mixing of expiratory limb reverse gas flow and inspiratory limb forward gas flow at the $Y$ piece. If the $E V$ leak is small, there is little EV reverse flow relative to forward flow through the inspiratory valve (IV), so that $\mathrm{FICO}_{2}$ will increase little, if at all. Conversely, the increase in $\mathrm{FICO}_{2}$ will be greater with a larger $\mathrm{EV}$ defect.

During experiments involving ventilation of a mechanical lung, we observed that despite a constant $\mathrm{EV}$ leak, $\mathrm{FICO}_{2}$ varied with total inspiratory flow (TIF). (TIF is defined here as inspiratory limb flow plus reverse expiratory limb flow.) Thus, the ratio of expiratory limb flow to TIF appeared to be affected by the size of the EV defect and TIF. We performed this investigation to evaluate the effect of TIF on the flow distribution through a normal IV and a defective EV.

Methods. A mechanical lung (TTL, MI Instruments, Inc.) was ventilated with $40 \% \mathrm{O}_{2}$ and $60 \% \mathrm{~N}_{2}$ by a volume-cycled ventilator at 10 breaths $/ \mathrm{min}$. The $\mathrm{EV}$ was rendered incompetent by cutting a $72-\mathrm{mm}^{2}$ circular hole in the center of the valve disk. Inspiratory and expiratory limb flows were measured simultaneously with pneumotachographs. $\mathrm{CO}_{2}$ was insufflated into the lung at a rate sufficient to achieve end-tidal $\mathrm{CO}_{2}$ concentrations of 5 to $6 \%$.

Flow distribution was evaluated with tidal volumes of 0.6 , 0.8 , and $1.0 \mathrm{~L}$. In addition, trials at inspiratory to expiratory ventilation ratios (I:E) of $1: 1$ and $1: 3$ were performed at each tidal volume setting. $\mathrm{CO}_{2}$ insufflation rate was adjusted with each change in tidal volume, but was held constant during changes in I:E setting.

Results. As indicated in the Table, the ratio of expiratory limb reverse flow to TIF decreases as TIF increases. As a result of this change in flow distribution, the ratio of $\mathrm{FICO}_{2}$ to endtidal $\mathrm{CO}_{2}$ decreased as TIF increased. Thus, at higher flow rates, the effect of an incompetent $\mathrm{EV}$ becomes less pronounced.

Discussion. These results indicate that in the presence of a constant EV defect, as flow increases, a smaller fraction of each breath passes through the expiratory limb. This may be 
Ratio of Expiratory Limb Flow

\begin{tabular}{lllll}
\hline $\begin{array}{l}\text { TIF } \\
(\mathrm{L} / \mathrm{min})\end{array}$ & VEL/TV & FI/FE CO2 & TV & $\begin{array}{l}\text { I:E } \\
(\mathrm{L})\end{array}$ \\
\hline 14.5 & 0.51 & 0.73 & 0.6 & $1: 1$ \\
18.1 & 0.46 & 0.65 & 0.8 & $1: 1$ \\
21.6 & 0.43 & 0.51 & 1.0 & $1: 1$ \\
21.6 & 0.43 & 0.50 & 0.6 & $1: 3$ \\
34.2 & 0.38 & 0.26 & 0.8 & $1: 3$ \\
43.1 & 0.36 & 0.19 & 1.0 & $1: 3$ \\
\hline
\end{tabular}

Data are sorted in order of increasing flow.

Abbreviations: TIF, total inspiratory flow (sum of forward flow in inspiratory limb and reverse flow in expiratory limb during inspiration); $\dot{V} E L$, expiratory limb reverse flow; TV = tidal volume; Fi/FE $\mathrm{CO}_{2}$, mean inspired $\mathrm{CO}_{2}$ /end-tidal $\mathrm{CO}_{2}$.

due to (1) an effective increase in EV resistance or (2) an effective decrease in IV resistance as TIF increases. This study was not designed to differentiate between these possibilities. A high TIF may completely normalize the capnogram produced by an EV leak and may mask the presence of an incompetent EV.

\section{A COMPARISOH OF NEW SENSORS FOR RESPIRATORY RATE MOMITORING}

M. Vegfors, MD, * H. Ugnell, MSc, $+B$. Hok, Prof, $\neq$ P. A. Oberg, Prof, t and C. Lenmmarken, $M D, P h D, *$ Departments of Anesthesiology and Hiomedical Engineering, Linkoping University Hospital, Linkoping, Sweden; and the Institute of Technology, University of Uppsala, Uppsala, Sweden

Summary. Results from a fiberoptic sensor and an acoustic monitor correlate well with traditional methods.

Introduction. Respiratory frequency and heart rate are physiologic parameters that are important to monitor. The clinically used methods for respiratory monitoring are transthoracic impedance plethysmography, capnography, and visual observation. Two new techniques recently have been developed: an acoustic monitor for monitoring of respiration and a fiberoptic sensor for monitoring of respiratory and heart rates. The aim of this investigation was to compare these 5 methods simultaneously.

Methods. Ten healthy young men breathing air were studied in the supine position. The study was performed in three situations: when the subjects were spontaneously breathing at their "own" frequency, when the subjects were breathing at a fixed rate of 13 breaths/min, and during the performance of an apnea test. The respiratory-related signals from the 5 methods described below were simultaneously printed and recorded on a tape recorder and analyzed thereafter.

1. Capnography: a Datex Normocap 200 was used. A $3.0-\mathrm{m}$ $(10-\mathrm{ft})$ sampling line with a nasal adapter was attached to the subject.

2. Transthoracic impedance plethysmography: a HELLIGE Servomed was used.

3. Acoustic method: a Respi Rate Meter (Hok Instrument *ab) that measures the acoustic noise from the expired air

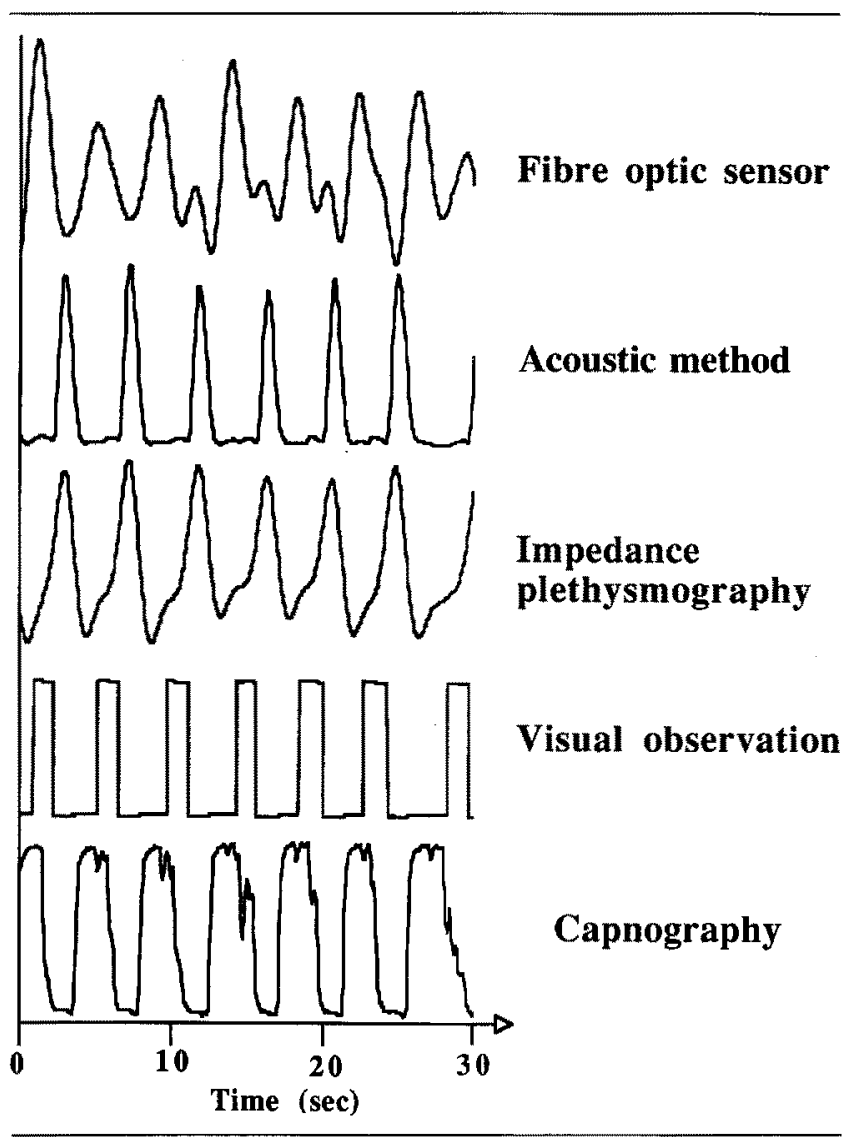

The raw signals from one simultaneous recording.

was used. The signals were picked up by a pair of polymer tubings placed outside the mouth and nostrils [1].

4. Fiberoptic sensor (prototype): the signal obtained from a fiberoptic sensor based on photoplethysmography was analyzed for information about heart rate and respiratory rate. The sensor was attached to the subject's forearm. Low-pass filter characteristics were chosen to identify the respiratory-related signal.

5. Visual observation: an assistant observed the subject's respiratory movements and the signaled respiration with a specially constructed switcher.

Results. The Figure shows the simultaneous recordings from one of the subjects. Capnography, photoplethysmography, impedance plethysmography, acoustic method, and visual observation were all in good agreement. Capnography was delayed in time.

Discussion. The new fiberoptic sensor offers several important advantages. First, with a single sensor it may be possible to simultaneously measure respiration rate, heart rate, and arterial oxygen saturation. Second, the sensor does not interfere with the airway. Third, the sensor location seems to be relatively uncritical, making it possible to suppress motion artefacts that are a problem with respiratory monitors detecting respiratory effort. The acoustic sensor has advantages in its simplicity, low cost, and suppression of different sources of interference. Despite its location in the flow path, it interferes minimally with flow. 
Using the two new sensors in combination, it will be possible to continuously monitor respiration and receive an immediate response to apneic events. Since the two methods respond differently to central and obstructive apneas, their combination can be used for differential diagnosis of such events.

\section{REFERENCES}

1. Henneberg S, Hok B, Wiklund L, et al. Remote auscultatory patient monitoring during magnetic resonance imaging. J Clin Monit (in press)

2. Lindberg L-G, Ugnell H, Oberg PA. Monitoring of respiratory and heart rates using a fibre optic sensor. Med Biol Eng Comput (in press)

\section{ON-LIME DATA COLLECTION FOR RESPIRATORY AMALYSIS}

Andrew M. Sopchak, MD, George J. Sheplock, MD, Enrico M. Camporesi, MD, SUNY, Syracuse, NY

Summary. We have fully automated our respiratory analysis laboratory to provide reliable, precise, and accurate collection of breath-to-breath data using the Macintosh computer and customized respiratory analysis software written in LabVIEW II. The system provides a significant advance in physiologic data collection and rapid on-line calculation of complex respiratory information.

Introduction. We studied respiratory depression and analgesia during the investigational phase of two new short-acting narcotics. To do so, we developed a personal computer-based data collection and analysis system that is currently in use in our department's respiratory laboratory. The system provides accurate and precise collection and subsequent analysis of respiratory data.

Methods. The subject undergoing a respiratory study has the following variables monitored: heart rate, $\mathrm{SaO}_{2}, \mathrm{EtCO}_{2}$, $\mathrm{FIO}_{2}$, respiratory flow, blood pressure, and ECG. The analog signals from all of these monitors, with the exception of ECG and blood pressure, are collected by a National Instruments NB-MI016XH analog to digital converter installed in a Macintosh IIci computer. The Respiratory Analysis software package that collects and analyzes all the data was written using LabVIEW II. This Respiratory Analysis software does realtime breath-to-breath analysis of the flow signal to produce tidal volume and respiratory rate, and computes minute ventilation. BTPS correction is performed on-line from entered temperature and pressure. In addition, our customized respiratory acquisition system records end-tidal $\mathrm{CO}_{2}$ values, controls $\mathrm{FIO}_{2}$, and generates graphs and statistics that are immediately printed.

Results. We have now used this system for two investigational drug studies with over 20 volunteer subjects. Values are reproducible, as seen by the consistency with which calibration volumes are recorded. Hypoxic studies are carefully controlled for constant $\mathrm{CO}_{2}$ levels (isocapnic), while hypercapnic studies are conducted with $21 \%$ inspired $\mathrm{O}_{2}$ (isoxic). The system is easy to use, even by a novice, and is reliable, as demonstrated by its flawless use in over 150 hypercapnic and hypoxic ventilatory response challenges.

Discussion. The Respiratory Analysis software was written in LabVIEW II, which is a graphic data flow programming

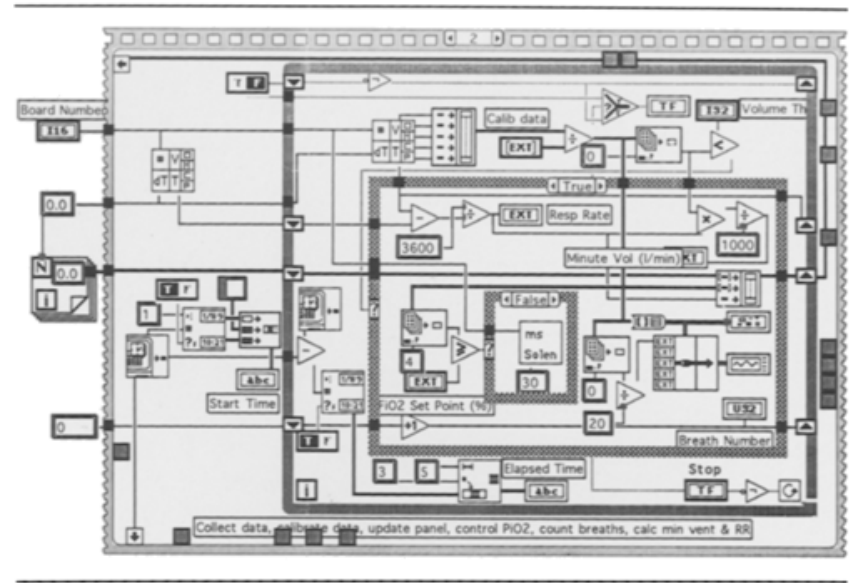

Fig 1. Portions of software.

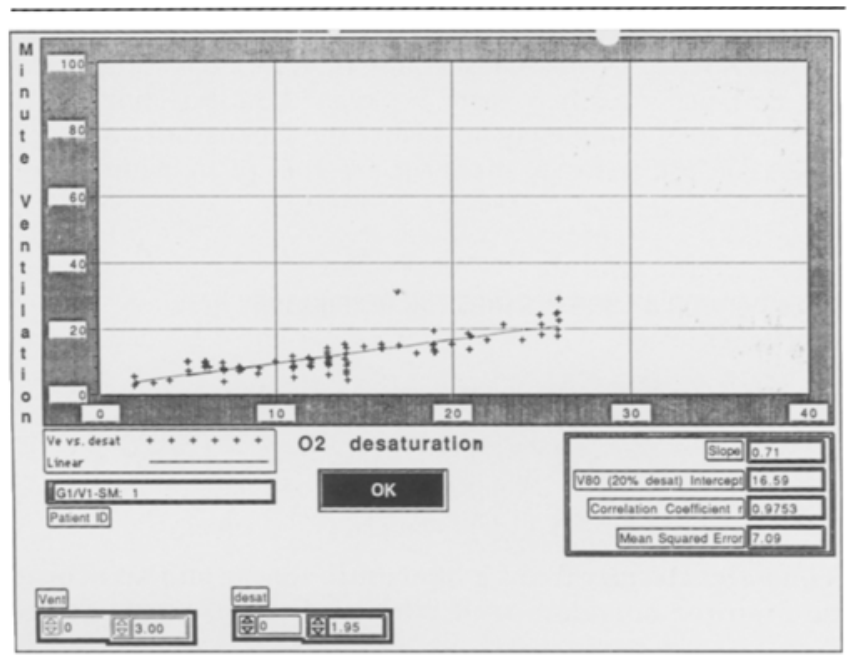

Fig 2. Sample data outputs.

language (called G). Portions of the software can be seen in Fig 1. Breath detection and flow integration to compute tidal volume are performed in real time. Sample data outputs can be seen in Fig 2.

The use of LabVIEW II for this project represents a significant advance to produce timely reports in the laboratory. Plans are under way for the use of LabVIEW II in numerous other projects involving data collection and analysis.

\section{GAS MAN SIMULATION OF TISSUE TIME CONSTANTS IS VERIFIED BY COMPARISOH TO ANALYTIC SOLUTION}

J. H. Philip, MD, I. D. Calalang, BS, Brigham and Women's Hospital, Harvard Medical School, Boston, MA

Summary. Gas Man's ability to provide a numeric solution within $2 \%$ of the analytic solution to the simultaneous differential equations that govern inhalation anesthesia pharmacokinetics is demonstrated. Vaporizer adjustment manipulations suggested by Gas Man should therefore be clinically applicable. 
Introduction. The Gas Man [1] simulation uses Euler's method to integrate and solve the simultaneous differential equations that govern the behavior of a 5-compartment pharmacokinetic model for inhalation anesthesia. The model structure knows nothing of exponential behavior, but exponentials are calculated in response to step changes presented as inputs to individual compartments.

We tested the ability of Gas Man $[1,2]$ to correctly calculate the theoretically correct tissue time constants in response to step changes in alveolar anesthetic tension. Correct tissue time constants are required (1) to demonstrate that the program's computational algorithms faithfully simulate theoretical effects that have been validated by others and (2) to quantify vaporizer adjustment necessary to achieve and maintain constant alveolar tension and anesthetic depth.

Methods. The theoretical relationship between predicted tissue anesthetic tensions and alveolar anesthetic tension is

$P_{T}=P_{A}\left(1-e^{-t / T}\right)$

[eq. 1]

where

$\tau=\mathrm{V}_{\mathrm{T}} \lambda_{\mathrm{T} / \mathrm{B}} / \mathrm{F}_{\mathrm{T}}$

and where $\mathrm{P}_{\mathrm{T}}$ represents tissue tension, $\mathrm{P}_{\mathrm{A}}$ represents alveolar tension, $\tau$ represents tissue time constant, $V_{T}$ represents tissue volume, $\lambda_{\mathrm{T} / \mathrm{B}}$ represents the tissue to blood solubility ratio, and $F_{T}$ represents the tissue blood flow. Venous return of anesthetic was disabled in the simulation to maintain constant alveolar tension without the need for inspired tension adjustment.

The Table summarizes the Methods and Results sections line by line. Several anesthetics are simulated (no. 1). Tissue/ blood (no. 2) and tissue/gas solubilities (nos. 3-5) are tabulated along with tissue volumes and relative flows to compute tissue time constants from eq. 2 (nos. 6-9). To produce alveolar $1 \mathrm{MAC}$ anesthesia, appropriate [2] overpressures were computed and used (nos. 10 and 11). Predicted tissue tensions at specific times were computed from eq. 1 (nos. 12-14).

Results. Tissue anesthetic tensions observed (nos. 15-17) were within $2 \%$ relative to those predicted (nos. 12-14).

Discussion. To convey the concept of tissue equilibration with alveolar and blood anesthetic tension, the numeric solution to the simultaneous differential equations must yield the same solution as the analytic approach. Gas Man's ability to do this has been demonstrated.

\section{REFERENCES}

1. Philip JH. Gas Man ${ }^{\text {B }}$-Understanding Anesthesia Uptake and Distribution. Chestnut Hill: Med $\operatorname{Man}^{\top \mathrm{M}}$ Simulations, 1990

2. Philip JH. Gas Man simulation of overpressure is verified by correct alveolar plateaus. Anesthesiology 1990;73: A1025 (abstr)

\section{A THEORETICAL ANALYSIS OF THE FAGTORS AFFECTING MAC AWAKE}

D. C. Sutton, FFARACS, I. D. Calalang, BS, D. B. Raemer, PhD, J. H. Philip, ME(E), MD, Brigham and Women's Hospital, Harvard Medical School, Boston, MA

Summary. End-expired anesthetic concentration at the time of eye opening is significantly lower than the 0.58 MAC level present in the brain at the same time. This value is affected by ventilation, blood/gas partition coefficient, and duration of anesthesia.

Introduction. MAC awake remains the only clearly defined point in recovery that relates alveolar concentration $\left(F_{A}\right)$ to an easily reproducible clinical sign (eye opening on command). It may be concluded from the studies of MAC awake using a pure inhalation steady-state technique that eye opening occurs at $0.58 \mathrm{MAC}$ in the brain. Reported values for $F_{A}$ at MAC

Summary of Methods and Results Sections (VA $=4 ; C O=5)$

\begin{tabular}{|c|c|c|c|c|c|c|c|c|}
\hline 1 Agents and solubilities & & & $\mathrm{Hal}$ & Enf & Iso & Sevo & Des & $\mathrm{N}_{2} \mathrm{O}$ \\
\hline 2 Blood/gas solubility & & & 2.47 & 1.90 & 1.30 & 0.67 & 0.42 & 0.47 \\
\hline 3 VRG/blood solubility & & & 1.94 & 1.47 & 1.62 & 1.64 & 1.29 & 0.89 \\
\hline 4 MUS/blood solubility & & & 4.01 & 2.42 & 3.46 & 3.58 & 2.31 & 1.15 \\
\hline 5 Fat/blood solubility & & & 60.73 & 33.16 & 53.85 & 55.22 & 30.95 & 2.30 \\
\hline \multicolumn{9}{|c|}{ Predicted tissue time constants (min) } \\
\hline $6 \mathrm{VRG}=$ brain $+\ldots$ & 6.0 & 0.76 & 3.1 & 2.3 & 2.6 & 2.6 & 2.0 & 1.4 \\
\hline 7 Muscle & 33.0 & 0.18 & 147.0 & 88.8 & 126.9 & 131.3 & 84.7 & 42.1 \\
\hline 8 Fat & 14.5 & 0.06 & 2,935 & 1,603 & 2,603 & 2,669 & 1,496 & 111 \\
\hline 9 Fat (hr) & Vol (L) & Rel F & 48.9 & 26.7 & 43.4 & 44.5 & 24.9 & 1.9 \\
\hline \multicolumn{9}{|c|}{ MAC and overpressure required to maintain $1 \mathrm{MAC}$} \\
\hline $10 \mathrm{MAC}\left({ }^{*}\right.$ except $\left.\mathrm{N}_{2} \mathrm{O}\right)$ & & & $0.8 \%$ & $1.7 \%$ & $1.1 \%$ & $2.0 \%$ & $6.0 \%$ & $63.0 \%$ \\
\hline 11 Inspired for $1 \mathrm{MAC}$ (ref 1$)$ & & & $3.27 \%$ & $5.74 \%$ & $2.89 \%$ & $3.68 \%$ & $9.15 \%$ & $100.0 \%$ \\
\hline \multicolumn{9}{|c|}{ Predicted (exponential) tissue tensions (\%) at selected time (min) } \\
\hline $12 \mathrm{VRG}=$ brain $+\ldots$ & & $t=5$ & 0.65 & 1.51 & 0.95 & 1.72 & 5.51 & 61.3 \\
\hline 13 Muscle & & $t=60$ & 0.27 & 0.84 & 0.42 & 0.73 & 3.0 & 47.9 \\
\hline 14 Fat & & $t=300$ & 0.08 & 0.29 & 0.12 & 0.21 & 1.1 & 58.8 \\
\hline \multicolumn{9}{|c|}{ Simulated (Gas Man) tissue tensions (\%) at selected time (min) } \\
\hline $15 \mathrm{VRG}=$ brain $+\ldots$ & & $\mathrm{t}=5$ & 0.64 & 1.50 & 0.94 & 1.68 & 5.4 & 60.8 \\
\hline 16 Muscle & & $t=60$ & 0.27 & 0.83 & 0.41 & 0.73 & 3.0 & 47.7 \\
\hline 17 Fat & & $\mathrm{t}=300$ & 0.08 & 0.29 & 0.12 & 0.21 & 1.1 & 58.8 \\
\hline
\end{tabular}




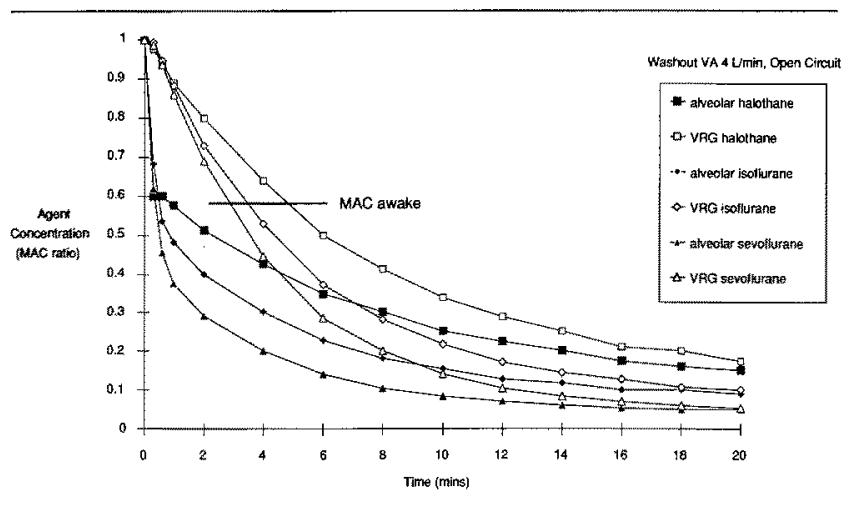

Fig 1.

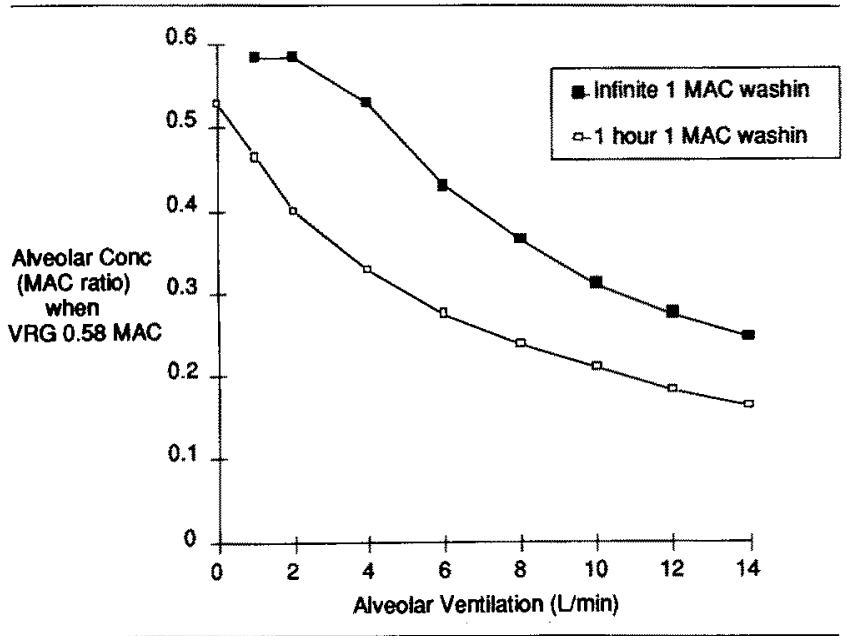

Fig 2.

awake during continuous recovery, however, have been much lower, ranging from 0.17 to $0.50 \mathrm{MAC}$.

The objective of this study was to examine the effect of alveolar ventilation $\left(\mathrm{V}_{\mathrm{A}}\right)$, blood/gas partition coefficient, and duration of anesthesia on the $F_{A}$ at eye opening.

Methods. The initial compartment values of the Gas Man [1] computer simulation of anesthetic uptake and distribution were modified to reflect the beginning of wake-up after 1 hour and infinite duration $1 \mathrm{MAC}$ alveolar anesthesia. The effects of $V_{A}(0-14 \mathrm{~L} / \mathrm{min})$ in an open circuit on $\mathrm{F}_{\mathrm{A}}$ when the vesselrich group (VRG) reached $0.58 \mathrm{MAC}\left(\mathrm{F}_{\mathrm{VRG}}=0.58 \mathrm{MAC}\right.$ ) were recorded for halothane, isoflurane, and sevoflurane. The concentration effect was eliminated by disabling the uptake function in the program and the cardiac output remained at 5 $\mathrm{L} / \mathrm{min}$ for all experiments.

Results. Figure 1 shows the $F_{\mathrm{VRG}}$ curve lagging behind the $F_{A}$ curve during recovery from 1 hour of $1 \mathrm{MAC}$ alveolar anesthesia at $V_{A}$ of $4 \mathrm{~L} / \mathrm{min}$. The rapid initial decline in $F_{A}$ common to all agents is interrupted by a knee at a variable height specific for each agent. The values for $F_{A}$ when $F_{V R G}$ $=0.58 \mathrm{MAC}$ for halothane, isoflurane, and sevoflurane are $0.39,0.33$, and $0.25 \mathrm{MAC}$, respectively (Fig 2).

Discussion. In contrast to the steady-state method of allowing $F_{A}$ and $F_{V R G}$ to come to equilibrium, usual clinical practice allows $F_{A}$ to fall continuously. As the gradient between the alveoli and venous return after 1 hour of $1 \mathrm{MAC}$ alveolar anesthesia is low, the effect of ventilation to washout the functional residual capacity is unopposed by uptake of agent into the alveoli.

When a gradient develops between the venous return and alveoli, agent uptake occurs producing a knee in the common rapid downslope. Depression of the knee is caused by decreased blood/gas solubility, increased $V_{A}$, or lowered cardiac output, each leading to the gradient between $F_{A}$ and $F_{V R G}$ at $F_{\text {VRG }}=0.58 \mathrm{MAC}$.

Similar software incorporating a Gas Man-like pharmacokinetic model could be incorporated into breath-by-breath gas monitors to inform the clinician of expected agent concentration in the brain and, thus, wakefulness. With the growing emphasis on rapid recovery from outpatient anesthesia and introduction of more insoluble agents into the operating room, this information could be useful. It will be important to define the effect of residual intravenous sedatives on depression of $F_{V R G}$ at MAC awake.

\section{REFERENCE}

1. Philip JH. Gas Man ${ }^{\circledR}$-Understanding Anesthesia Uptake and Distribution. Chestnut Hill: Med $\operatorname{Man}^{\top M}$ Simulations, 1990

\section{AMALYSIS OF EUCAPNIC HYPERPIEA AS AN ALTERNATIVE TO OVERPRESSURE FOR INDUCTION OF INHALATION AMESTHESIA}

D. C. Sutton, FFARACS, I. D. Calalang, BS, D. B. Raemer, PhD, J. H. Philip, ME(E), MD Brigham and Women's Hospital, Harvard Medical School, Boston, MA

Summary. Eucapnic hyperpnea reduces the overpressure required for rapid induction with insoluble inhalation anesthetics and produces results similar to those achievable with the less soluble inhalants, sevoflurane and desflurane.

Introduction. Overpressure $\left(\mathrm{P}_{\mathrm{I}}\right)$ is commonly used on induction to achieve deep levels of anesthesia. However, if the vaporizer is inadvertently left above the desired alveolar tension $\left(\mathbf{P}_{\mathrm{A}}\right)$, overdose and severe cardiovascular depression will result. An alternative technique is eucapnic hyperpnea with the vaporizer set to a safe concentration. The objective of this theoretical study was to compare these two techniques.

Methods. Gas Man, a computer simulation of inhalational anesthetic uptake and distribution, was used to record the time to fractions of $1 \mathrm{MAC}$ in the vessel-rich group ( $\mathrm{t}_{.5 \mathrm{MAC}}, \mathrm{t}_{75 \mathrm{MAC}}$, $\left.t_{9 M A C}\right)$ over a range of delivered isoflurane concentrations $\left(P_{D}\right)$ at normal and high levels of alveolar ventilation $\left(\mathrm{V}_{\mathrm{A}}\right)$ in a semi-closed circuit at a fresh gas flow of $10 \mathrm{~L} / \mathrm{min}$.

Results. The results are display in the Table. Overpressure is much faster than hyperpnea at $1 \mathrm{MAC}$ (delivered) in establishing reasonable levels of anesthesia. Both methods are much faster than simply leaving the vaporizer at $1 \mathrm{MAC}$ (delivered) with normal ventilation.

Discussion. From basic principles the overpressure ratio can be calculated as follows [1]:

$\mathrm{P}_{\mathrm{L}} / \mathrm{P}_{\mathrm{A}}=1+\left(\mathrm{CO}{ }^{*} \lambda_{\mathrm{B} / \mathrm{G}}\right) / \mathrm{V}_{\mathrm{A}}$ 


\begin{tabular}{llllllll}
\hline & $\begin{array}{l}\text { Normal } \\
(\%)\end{array}$ & $\begin{array}{l}\text { Hyperpnea } \\
(\%)\end{array}$ & $\begin{array}{l}\text { Overpressure } \\
(\%)\end{array}$ & & & & \\
\hline $\mathrm{P}_{\mathrm{D}}$ & 1.1 & 1.1 & 1.1 & 2.2 & 3.3 & 5 \\
$\mathrm{~V}_{\mathrm{A}}$ & 4 & 8 & 12 & 4 & 4 & 4 \\
$\mathrm{t}_{5 \mathrm{MAC}}$ & 9.3 & 6.3 & 5.5 & 3.7 & 2.6 & 1.9 \\
$\mathrm{t}_{75 \mathrm{MAC}}$ & 95.6 & 20.5 & 14.0 & 5.8 & 3.6 & 2.6 \\
$\mathrm{t} .9 \mathrm{MAC}$ & 654 & 286.2 & 206.5 & 7.7 & 4.5 & 2.9 \\
\hline
\end{tabular}

where $\mathrm{CO}$ represents cardiac output and $\lambda_{\mathrm{B} / \mathrm{G}}$ represents blood gas partition coefficient. In practice, however, difficulties arise as the agent is recirculated by the venous return, producing a gradual rise in the alveolar tension curve above that predicted. As the desired end-point is reached, the clinician must learn to drastically reduce the inspired concentration to avoid overshoot. Recirculation of agent from the expired gas in the semi-closed circuit makes this difficult to accomplish. Breath-by-breath gas monitoring highlights the problem of controlling alveolar tension when an input (the delivered tension) is two compartments away.

Hyperpnea avoids the possibility of overdose and the requirement for frequent vaporizer manipulations. The simulations show that mild overpressure may still be necessary for rapid induction of deep anesthesia. The maintenance of eucapnia during hyperpnea could be achieved by the addition of inspiratory carbon dioxide $\left(\mathrm{CO}_{2}\right)$, safely controlled by an open loop or closed loop feedback from end-tidal $\mathrm{CO}_{2}$. In addition, the cardiovascular effects of short periods of hyperpnea need to be considered.

Alternatively, the less soluble agents, sevoflurane and desflurane, produce a similar reduction in the $\left(\mathrm{CO} * \lambda_{\mathrm{B} / \mathrm{G}}\right) / \mathrm{V}_{\mathrm{A}}$ portion of eq. 1 and will provide a safe and easy means of achieving rapid, predictable, and controlled induction.

\section{REFERENCE}

1. Philip JH. Gas Man ${ }^{\circledR}$-Understanding Anesthesia Uptake and Distribution. Chestnut Hill: Med Man ${ }^{\top M}$ Simulations, 1990

\section{EUCAPIIC HYPEAPNEA WITH ISOFLURANE PRODUCES SIMILAR EMERGENCE TIMES TO SEVOFLURANE OR DESFLURANE BUT REQUIRES ANESTHESIA MAGHINE DESIGN CHANGES}

D. C. Sutton, FFARACS, I. D. Calalang, BS, D. B. Raemer, PhD, J. H. Philip, $M E(E), M D$ Brigham and Women's Hospital, Harvard Medical School, Boston, MA

Summary. Eucapnic hyperpnea with isoflurane produces emergence times similar to those achieved with sevoflurane and desflurane but would require costly and confusing anesthesia machine design changes. Use of the new inhalation agents appears more prudent.

Introduction. The development of the new insoluble volatile anesthetics sevoflurane and desflurane has promised faster emergence times than present agents. Elimination of inhalational anesthetics, however, depends on alveolar ventilation $\left(V_{A}\right)$, cardiac output, and fresh gas flow (FGF), as well as the blood/gas partition coefficient $\left(\lambda_{\mathrm{B} / \mathrm{G}}\right)$. The objective of this theoretical study was to compare emergence times of present

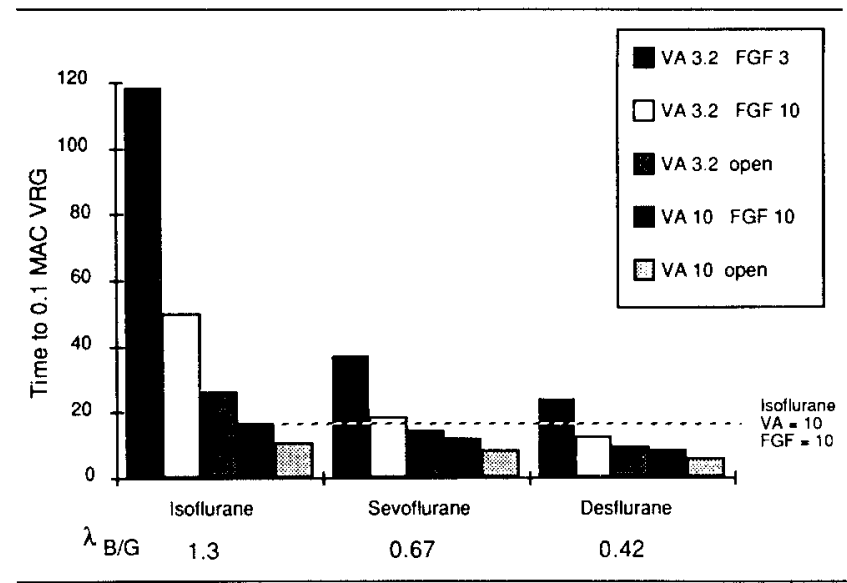

agents using eucapnic hyperpnea at high FGF with conventional methods.

Methods. The initial compartment values of Gas Man, a computer simulation of inhalational anesthetic uptake and distribution, were modified to reflect the beginning of wake-up after a 1-hour, $1 \mathrm{MAC}$ alveolar anesthetic. The times for the vessel-rich group to return to $0.1 \mathrm{MAC}\left(\mathrm{t}_{.1 \mathrm{MAC}}\right)$ from this standard wash-in were recorded over a range of $V_{A}$ and $F G F$ $\left(t_{1}\right.$ MAC/FGF/VA $)$ in a perfectly mixed, semi-closed and open (nonrebreathing) circuit model.

Results. The results are demonstrated in the Figure. At the same $V_{A}$ and circuit conditions, $t_{11 \text { MAC }}$ decreases as the agent

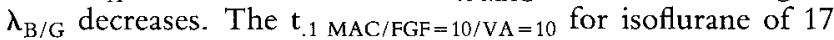

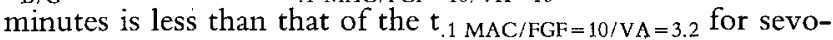

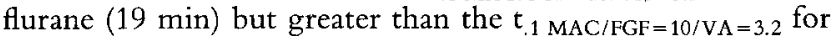
desflurane $\left(13 \mathrm{~min}\right.$ ). Use of high $\mathrm{V}_{\mathrm{A}}$ and FGF with the less soluble agents desflurane and sevoflurane produces relatively smaller improvements in recovery times than with isoflurane.

Discussion. At high levels of $\mathrm{V}_{\mathrm{A}}$ and $\mathrm{FGF}$ the limiting factors for recovery become cerebral blood flow and brain/blood partition coefficient, not $\lambda_{\mathrm{B} / \mathrm{G}}$. The recovery time for the more soluble agent isoflurane is comparable to the newer insoluble agents, sevoflurane and desflurane. We see that emergence from the less soluble agents is not improved much by hyperpnea since the blood/gas solubility achieved the same objective. However, high FGF or open circuit is required to derive the benefits of either low solubility or hyperpnea. Note that breathing circuits that do not achieve homogeneous and instantaneous mixing will be washed out by a given FGF faster than simulated, tending toward the results from the open circuit.

The maintenance of eucapnia during the hyperpnea phase could be achieved by the addition of inspiratory carbon dioxide $\left(\mathrm{CO}_{2}\right)$, safely controlled by an open- or closed-loop feedback from endtidal $\mathrm{CO}_{2}$ levels. This would allow decoupling of $\mathrm{V}_{\mathrm{A}}$ from the effects on $\mathrm{CO}_{2}$ homeostasis and allow independent control of anesthetic depth.

Breathing circuits that do not achieve homogenous and instantaneous mixing will be washed out by a given FGF faster than simulated, tending toward the results from the open circuit model. Thus, the $t_{1} \mathrm{MAC} / \mathrm{open} / \mathrm{VA}=10$ for isoflurane of 10 minutes compares with the $\mathrm{t}_{1} 1 \mathrm{MAC} / \mathrm{open} / \mathrm{VA}=3.2$ for sevoflurane and desflurane values of 14 and 10 minutes, respectively. The 
$\mathrm{CO}_{2}$ addition, however, would require major changes in anesthesia machine design, which might be more costly and confusing than changing to the new, less-soluble agents when they become available.

\section{REFERENCE}

1. Philip JH. Gas Man ${ }^{(}$-Understanding Anesthesia Uptake and Distribution. Chestnut Hill: Med Man ${ }^{\mathrm{Tm}}$ Simulations, 1990

\section{CLOSEB-GIRCUIT COASTIKG FROM HIGH FLOW ISOFLURANE ANESTHESIA}

Ahmed Mohamed El-Attar, MS, MD, King Fahd Hospital, King Faisal University, Al-Khobar, Saudi Arabia

Summary. Closed-circuit coasting from high flow anesthesia is safe, simple, predictable, and practical.

Introduction. Coasting is a technique commonly used by closed-circuit anesthesia practitioners. Toward the end of the operation, anesthetic administration is stopped while the circuit is maintained closed for some time, during which concentrations of anesthetics decrease slowly due to continual tissue uptake $[1,2]$.

There has been no mention in the literature of closed-circuit coasting after high flow anesthesia. This study was aimed at evaluating the practicality of coasting from high flow anesthesia, to determine the target end-tidal anesthetic concentration to be reached by the end of the coasting interval, and to find a correlation between the coasting time and the duration of high flow anesthetic delivery.

Methods. The closed-circuit coasting technique after high flow anesthesia was used in 30 adult ASA I and II patients undergoing operations expected to last more than 1 hour ( $\mathrm{Ta}-$ ble 1).

Oral diazepam, intravenous fentanyl $1 \mu \mathrm{g} / \mathrm{kg}$, and thiopentone $5 \mathrm{mg} / \mathrm{kg}$ were followed by pancuronium $0.1 \mathrm{mg} / \mathrm{kg}$ for induction. Anesthesia was maintained with $1 \%$ isoflurane in $6 \mathrm{~L} /$ minute of $70 \% \mathrm{~N}_{2} \mathrm{O}$ in oxygen delivered through a circle circuit with absorber. Ventilation was controlled by a Manley Pulmovent MS Medishield ventilator at a rate of $12 / \mathrm{min}$. Tidal volume was set to maintain end-tidal $\mathrm{CO}_{2}$ at 3.2 to $4 \%$.

Inspired and end-tidal concentrations $\left(\mathrm{C}_{1}\right.$ and $\left.\mathrm{C}_{E}\right)$ of isoflurane (ISO), $\mathrm{N}_{2} \mathrm{O}, \mathrm{O}_{2}$, and $\mathrm{CO}_{2}$ were monitored with sidestream sampling using a Capnomac Ultima (Datex) gas moni-
Table 1. Demographic Data and Operations

\begin{tabular}{ll}
\hline Data (mean \pm SD) (range) & \\
Age (yr) & $30.1 \pm 10.1(14-51)$ \\
Weight $(\mathrm{kg})$ & $68.9 \pm 14.9(42-115)$ \\
Male:female & $21: 9$ \\
Operations (n) & \\
Orthopedic & 15 \\
Abdominal & 7 \\
ENT & 5 \\
Plastic & 3 \\
Total & 30 \\
\hline
\end{tabular}

tor. Inspired isoflurane concentration was maintained at $1 \%$ throughout anesthesia delivery duration $\left(\mathrm{T}_{\mathrm{AD}}\right)$.

Near the end of the operation, the circuit was closed by shutting off $\mathrm{N}_{2} \mathrm{O}$ and isoflurane and reducing oxygen flow to that necessary to maintain constant end-tidal volume of the ventilator reservoir bag throughout coasting duration $\left(T_{C}\right)$.

In the pilot study, signs of light anesthesia were found to not start before $\mathrm{C}_{\text {Erso }}$ fell below $0.5 \%$, so that level was considered a safe target for coasting. If the surgical procedure was still ongoing when $\mathrm{C}_{\mathrm{EISO}}$ reached $0.5 \%, 1 \%$ isoflurane was added to the fresh oxygen flow to deepen the level of anesthesia.

At the end of the procedure, the circuit was opened and the fresh gas flow of $\mathrm{O}_{2}$ was increased to $8 \mathrm{~L} / \mathrm{min}$ to wash out the circuit and enhance recovery.

Results. In the 30 patients, the mean $\mathrm{T}_{\mathrm{AD}}$ was 117.2 minutes and the mean $T_{C}$ was 37.2 minutes. The mean $C_{\text {EIso }}$ at the end of $T_{C}$ was $0.47 \%$.

In 11 patients the procedure extended beyond the target $\mathrm{C}_{\text {Erso }}$ and in 5 ended earlier than expected (Table 2, b and $c$ ). The $T_{C}$, to reach the target $C_{\text {EISO }}$ (Table 2, a and $b$ ), showed significant correlation to $T_{A D}$ (Fig 1). There was significant correlation between $\mathrm{C}_{\mathrm{EISO}}$ and $\mathrm{C}_{\mathrm{EN} 2 \mathrm{O}}$ during $\mathrm{T}_{\mathrm{C}}$ (Fig 2). $\mathrm{C}_{\mathrm{IO} 2}$ increased progressively and $\mathrm{O}_{2}$ saturation was maintained above $97 \%$ (Fig 3).

After opening the circuit at the end of the surgical procedure, patients moved after $3.7 \pm 2.4$ minutes, were extubated after $4.2 \pm 2.3$ minutes, opened their eyes spontaneously after $10.7 \pm 7.2$ minutes, and responded to verbal command after $14.3 \pm 10$ minutes. None recalled intraoperative events on the next day.

Table 2. Coasting Events

\begin{tabular}{|c|c|c|c|c|c|}
\hline & $\mathrm{n}$ & $\begin{array}{l}\mathrm{T}_{\mathrm{AD}} \\
(\mathrm{min})\end{array}$ & $\begin{array}{l}\mathrm{T}_{\mathrm{C}} \\
(\min )\end{array}$ & $\begin{array}{l}\text { Time to Target } \\
\text { CErso }_{\text {(min) }}\end{array}$ & $\begin{array}{l}\text { CErso at } \\
\text { End of } \mathrm{T}_{\mathrm{C}}(\%)\end{array}$ \\
\hline a & 14 & $\begin{array}{l}112.3 \pm 51.1 \\
(60-210)\end{array}$ & $\begin{array}{l}31.0 \pm 15.3 \\
(15-63)\end{array}$ & $\begin{array}{l}24.3 \pm 10.5 \\
(15-45)\end{array}$ & $\underline{0.5} \pm 0.0$ \\
\hline b & 11 & $\begin{array}{l}94.9 \pm 29.7 \\
(55-150)\end{array}$ & $\begin{array}{l}46.1 \pm 19.2 \\
(20-75)\end{array}$ & $\begin{array}{l}21.8 \pm 6.0 \\
(15-35)\end{array}$ & $\begin{array}{l}0.36 \pm 0.07 \\
(0.2-0.4)\end{array}$ \\
\hline$c$ & 5 & $\begin{array}{l}180.0 \pm 117.8 \\
.(60-375)\end{array}$ & $\begin{array}{l}35 \pm 22.1 \\
(10-65)\end{array}$ & - & $0.6 \pm 0.0$ \\
\hline Total & 30 & $\begin{array}{l}117.2 \pm 65.3 \\
(55-375)\end{array}$ & $\begin{array}{l}37.2 \pm 18.7 \\
(10-75)\end{array}$ & $\begin{array}{l}23.2 \pm 8.8 \\
(15-45)\end{array}$ & $\begin{array}{l}0.47 \pm 0.1 \\
(0.2-0.6)\end{array}$ \\
\hline
\end{tabular}

Values are expressed as mean $\pm S D$. Numbers in parentheses represent range. $a, b$, and $c: T_{C}$ ended at, after, and before target $C_{E I s o}$ was reached, respectively. 


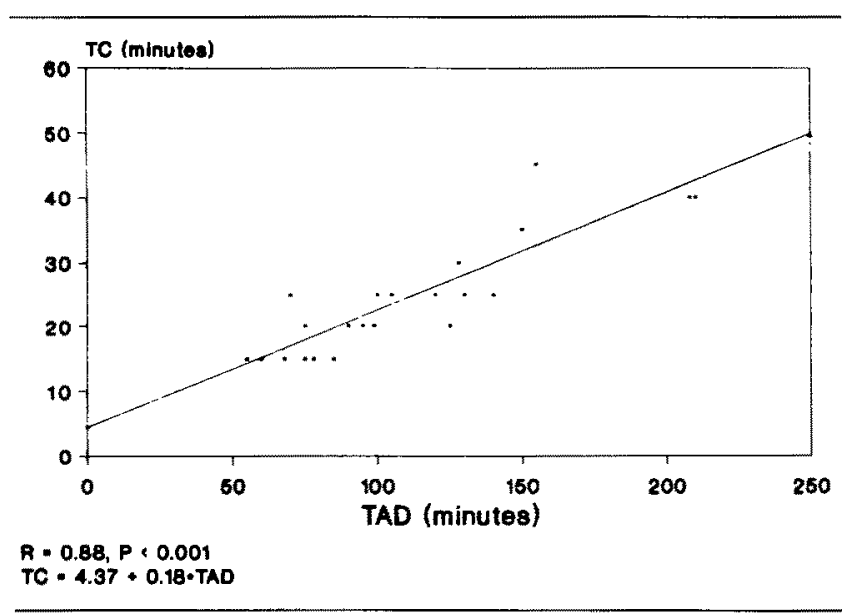

Fig 1. Correlation of coasting and anesthetic delivery durations $(n=25)$.

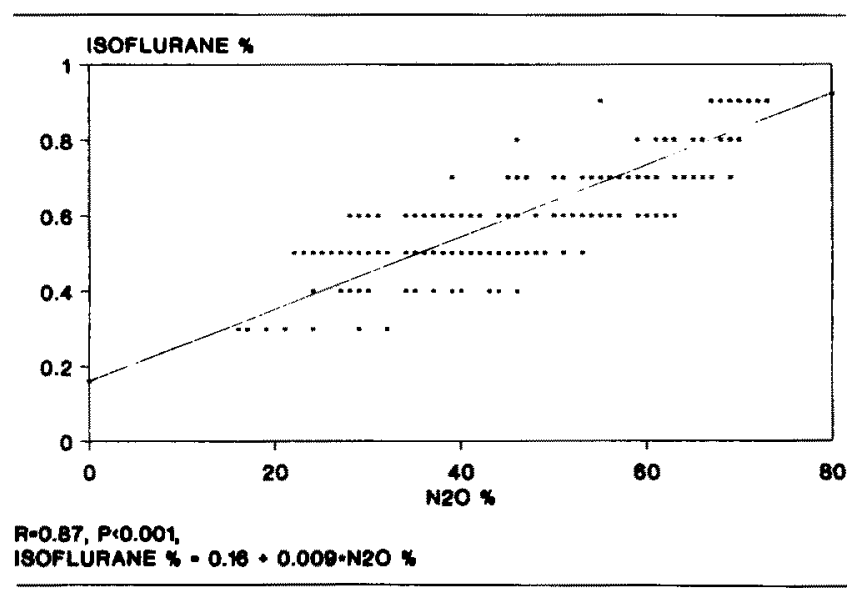

Fig 2. Correlation of nitrous oxide and isoflurane end-tidal concentrations during coasting.

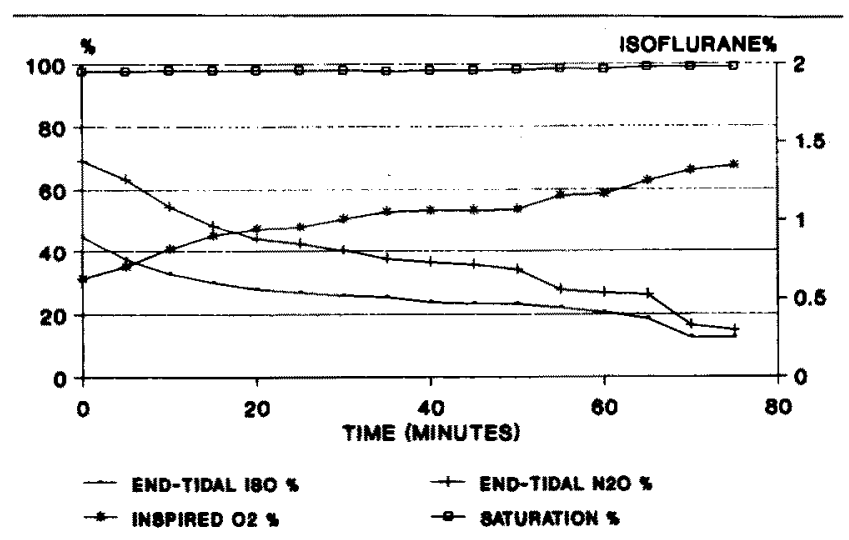

Fig 3. Concentrations and oxygen saturation during the coasting duration.
Discussion. $\mathrm{C}_{\mathrm{EISO}}$ equal to $0.5 \%$ isoflurane is a safe target for coasting. There has been good correlation between $T_{C}$ and $T_{A D}$. Summarized simply, 15 minutes is a reasonable $T_{C}$ for every hour of $\mathrm{T}_{A D}$. Twenty percent to $25 \%$ of anesthetics are saved. The technique provides the advantages of closed-circuit anesthesia, reducing costs, minimizing pollution, conserving heat and humidity, etc, without worry about oxygen and anesthetic concentrations and without using tables or equations. This simple technique is a good start for those interested in closed-circuit anesthesia. Closed-circuit coasting from high flow anesthesia is safe, simple, predictable, and practical.

\section{REFERENCES}

1. Lowe HJ, Ernst EA. The Quantitative Practice of Anaesthesia: Use of Closed. Baltimore: Williams \& Wilkins, 1981

2. El-Attar AM. Guided isoflurane injection in totally closed circuit. Anaesthesia 1991;46:

\section{AN EXPERIMENTAL APPROACH TO RECYCLIHG VOLATILE ANESTHETICS}

F. Groß-Alltag, PhD, T. Marx, MD, W. Friesdorf, ME, $M D$, University of Ulm, Ulm, Germany

Summary. The current waste of volatile anesthetics could be avoided using available techniques of charcoal absorption and recovery, thereby providing environmental and economic benefit.

Introduction. Today's standard anesthetic techniques use the volatile anesthetic agents halothane, enflurane, and isoflurane. Volatile anesthetics are usually administered in a semi-closed circuit and an appreciable amount of anesthetic may be wasted. In addition, all of these volatile anesthetics are chlorofluorocarbons and may contribute to ozone depletion in the upper atmosphere. Additionally, the economics of anesthetic agent recovery may become important with the new volatile agents desflurane and sevoflurane.

Methods. We applied charcoal filters from Draeger (type 633) at the exhaust of the anesthesia machines in one of our operating rooms and investigated the following questions:

- Is it possible to desorb the volatiles adsorbed in the filter and thus enable the initial step of a recycling process?

- How much of the anesthetic absorbed will be released?

- May the filter be reused after volatiles have been salvaged?

- How pure are the recycled volatiles as measured with gas chromatography?

- How efficient are the filters in adsorbing volatile anesthetics?

We used a simple laboratory setup consisting of a heating chamber, a water jet pump, and a cold trap to study recovery of halothane, enflurane, and isoflurane from a semi-closed circuit.

Results. Our experiments yielded the following results:

- All three volatiles investigated could be desorbed by heating the filter to $220^{\circ} \mathrm{C}$.

- In our simple setup, approximately $60 \%$ of the amount supplied during anesthesia was recovered.

- One filter may be used at least five times without significant degrading.

- Quality of recycled enflurane and isoflurane is identical to 
that delivered. Recovered halothane was contaminated with known metabolites.

- Filters absorb more than $95 \%$ of the volatiles passing through at standard flow and concentration, up to their capacity.

Discussion. Our experiments show that it is possible to desorb the anesthetics trapped in carbon filters without great effort and without any change in chemical structure. After a suitable recovery procedure, the filters as well as the anesthetic agents may be reused.

Problems not yet solved are the separation of different anesthetics collected in a single absorber, the possibility of crosscontamination of patients, and the legal restrictions. We roughly estimated the efficiency of a hospital-wide system applied at the central exhaust of the operating room scavenging system and found such an approach not adequate.

OH-LIME DETERMIHATION OF $\mathrm{MA}^{+}, \mathrm{K}^{+}, \mathrm{CA}^{++}$, AND PH DURING CARDIAC SURGERY AND TRANSURETHRAL RESECTION OF THE PROSTATE

Michael L. Smith, MD, N. Ty Smith, MD, David Wong, $P h D, V A M C$, UCSD, US Naval Hospital, and VIA Medical Corp., San Diego CA

Summary. We successfully measured electrolytes $\left(\mathrm{Na}^{+}\right.$, $\mathrm{K}^{+}$, and $\mathrm{pH}$ for TURP and $\mathrm{K}^{+}, \mathrm{Ca}^{++}$, and $\mathrm{pH}$ for cardiac surgery) in 9 on 18 patients using an automatic- withdrawal-reinjection analytic system and found results to be accurate and clinically useful.

Introduction. Electrolytes can change markedly and rapidly during certain procedures, such as cardiac surgery (C) and transurethral resection of the prostate $(T)$. Changes in electrolytes can affect cardiovascular and central nervous system (CNS) function both mechanically and electrically. A method for frequently determining serum electrolytes would be useful for many areas in the hospital. In the operating room and recovery room, we tested a system that allows on-line determination of a set of 3 variables, chosen from 4 possible options: $\mathrm{Na}^{+}, \mathrm{K}^{+}, \mathrm{Ca}^{++}$, or $\mathrm{pH}$.

Methods. After obtaining approval from our IRBs and written informed consent from each patient, we studied 21 patients, 10 undergoing $\mathrm{T}$ and 11 undergoing $\mathrm{C}$. We used a VIA Medical 1-01 bedside blood chemistry monitor, which is based on PVC membrane-based, ion-selective electrodes. On-line samples were drawn every 5 to 15 minutes, either through an intravenous (IV) cannula (T) or an intraarterial cannula $(\mathrm{C})$. We used $\mathrm{Na}^{+}, \mathrm{K}^{+}$, and $\mathrm{pH}$ for $\mathrm{T}$ and $\mathrm{K}^{+}, \mathrm{Ca}^{+}$, and $\mathrm{pH}$ for $\mathrm{C}$. The 1-01 is an infusion pump that can withdraw a small sample $(0.6-1.2 \mathrm{ml})$ and reinfuse it after each determination. Calibration is performed automatically as part of each determination using lactated Ringers solution with added heparin and phosphate as the standard. Each determination takes about 40 seconds. Off-line samples were analyzed by an IL $1312(\mathrm{pH})$, a NOVA $1\left(\mathrm{~K}^{+}\right.$and $\left.\mathrm{Na}^{+}\right)$, and an IL BGELECTROLYTE $1400\left(\mathrm{Ca}^{++}\right)$.

Bias and Sensitivity for Each Patient, and Pooled Data

\begin{tabular}{|c|c|c|c|c|c|c|c|c|c|c|}
\hline PT No. & $\mathrm{N}$ & $\mathrm{n}$ & $\mathrm{NaB}$ & $\mathrm{NaS}$ & $\mathrm{KB}$ & $\mathrm{KS}$ & $\mathrm{CaB}$ & $\mathrm{CaS}$ & $\mathrm{pHB}$ & $\mathrm{pHS}$ \\
\hline $1 \mathrm{~T}$ & 24 & 2 & -1 & 1 & -0.2 & 0.1 & & & 0.02 & 0.01 \\
\hline $2 \mathrm{~T}$ & 19 & 4 & 3 & 1.7 & -0.25 & 0.23 & & & 0.01 & 0.04 \\
\hline $3 \mathrm{~T}$ & 30 & 5 & 0.2 & 1.7 & -0.34 & 0.22 & & & 0.01 & 0.03 \\
\hline $4 \mathrm{~T}$ & 21 & 3 & 0.33 & 1.7 & -0.07 & 0.05 & & & -0.01 & 0.02 \\
\hline $5 \mathrm{~T}$ & 27 & 13 & & & 0.14 & 0.36 & 0.04 & 0.05 & -0.19 & 0.07 \\
\hline $6 \mathrm{~T}$ & 12 & 3 & -3.33 & 1.66 & -0.1 & 0.17 & & & -0.26 & 0.067 \\
\hline $7 \mathrm{~T}$ & 7 & 2 & 0.5 & 0.5 & -0.25 & 0.05 & 0.04 & 0.02 & & \\
\hline $8 \mathrm{~T}$ & 9 & 2 & 2.5 & 0.5 & -0.05 & 0.15 & 0.15 & 0.05 & & \\
\hline $9 \mathrm{~T}$ & 7 & 2 & 2.5 & 5.5 & -0.3 & 0.00 & & & -0.09 & 0.02 \\
\hline $10 \mathrm{~T}$ & 9 & 2 & -7 & 2 & & & 0.005 & 0.005 & -0.15 & 0.25 \\
\hline $11 \mathrm{C}$ & 51 & 12 & & & -0.45 & 0.41 & & 0.07 & 0.03 & 0.04 \\
\hline $12 \mathrm{C}$ & 46 & 7 & & & -0.06 & 0.2 & 0.43 & 0.16 & 0.00 & 0.05 \\
\hline $13 \mathrm{C}$ & 60 & 14 & & & 0.04 & 0.22 & 0.19 & 0.12 & 0.03 & 0.06 \\
\hline $14 \mathrm{C}$ & 37 & 10 & & & 0.09 & 0.21 & 0.03 & 0.06 & 0.00 & 0.02 \\
\hline $15 \mathrm{C}$ & 16 & 7 & 0.714 & 2.112 & -0.01 & 0.15 & 0.02 & 0.04 & & \\
\hline $16 \mathrm{C}$ & 21 & 10 & & & 0.07 & 0.24 & 0.02 & 0.04 & -0.12 & 0.08 \\
\hline $17 \mathrm{C}$ & 19 & 9 & & & -0.19 & 0.32 & 0.02 & 0.08 & -0.12 & 0.23 \\
\hline $18 \mathrm{C}$ & 10 & 5 & & & -0.26 & 0.24 & 0.004 & 0.07 & -0.01 & 0.07 \\
\hline $19 \mathrm{C}$ & 20 & 13 & & & 0.15 & 0.32 & 0.07 & 0.07 & 0.06 & 0.05 \\
\hline \multicolumn{11}{|l|}{$20 \times X X$} \\
\hline \multicolumn{11}{|l|}{$21 \mathrm{XXX}$} \\
\hline Average & 425 & 112 & & & & & & & & \\
\hline $\mathrm{W}$ & & & 0.16 & 1.838 & -0.11 & 0.202 & 0.084 & 0.064 & -0.05 & 0.069 \\
\hline WO & & & 0.16 & 1.838 & -0.08 & 0.188 & 0.052 & 0.054 & -0.05 & 0.036 \\
\hline
\end{tabular}

$\mathrm{B}=$ bias, $\mathrm{S}=$ sensitivity, $\mathrm{PT}=$ patient, $\mathrm{W}=$ including electrodes that did not perform well, $\mathrm{WO}=$ excluding electrodes that did not function well. 
Results. The $\mathrm{K}^{+}$did not function in 2 of 18 cases, the $\mathrm{Ca}^{++}$ electrode in 2 of 12 cases, and the pH electrode in 5 of 16 cases (in bold in the Table). All of the $\mathrm{pH}$ electrodes were relatively old. These failures were diagnosed and indicated by the machine. Otherwise, the electrodes functioned well for the entire case. In two patients (both $\mathrm{C}$, denoted in the Table by "XXX") we were unable to maintain access to the artery after the case had begun. The Table shows the bias (B) and sensitivity (S) for each case, as well as for the pooled data. Although the changes in the $T$ cases were relatively small, the changes in the $C$ cases were satisfactory: 3.4 to 6.5 for $\mathrm{K}^{+}$and 0.75 to 1.36 for $\mathrm{Ca}^{+}+$.

Discussion. These preliminary results indicate that the electrolyte monitoring system is accurate and stable in the clinical setting. The frequency of sensor failures can be reduced in the manufacturing process. Several advantages accrue to this system: (1) more frequent determinations can be done (for example, we could follow the effect of cardioplegic solution on $\mathrm{K}^{+}$and end of bypass injections of $\mathrm{CaCl}_{2}$ on $\mathrm{Ca}^{++}$), (2) the risk of transmitting blood-borne infections from the patient is decreased since the system is closed, (3) similarly, the risk of transmitting infection to the patient is decreased, (4) since the sample is returned to the patient, there is no blood loss from sampling, an important consideration in pediatric patients, and (5) either venous or arterial access can be used.

Supported in part by the Medical Research Service, Department of Veterans Affairs, and Via Medical Corp.

\section{CUTANEOUS IMJURIES ASSOCIATED WITH PULSE DXIMETERS}

S. Mark Poler, MD, Sandra S. Walker, MS, CRNA, Michael $J$. Kibelbek, MD, Michele Maroon, MD, Geisinger Medical Center, Danville, PA

Summary. We noted what appear to be thermal burns under pulse oximeter probes in $2 \%$ of pediatric patients and in $0.02 \%$ of adult patients and have been unable to determine a specific cause. The manufacturers of the two devices involved are investigating the situation with us.

Introduction. Cutaneous burns and other injuries associated with the use of pulse oximeters have occasionally been reported. However, previous reports involved single cases or small numbers of cases. We report 26 incidents of cutaneous injury under the diodes of sensor probes occurring between July 11 and November 8,1991 . At this time, neither instrument problems nor other causes for this series of injuries have been identified.

Methods. After determining that a problem existed, a surveillance program was implemented to identify causes of injury and the pulse oximeter manufacturers were notified. A data sheet was completed for every surgical patient monitored with pulse oximetry. Approximately 5,500 surgical procedures were surveyed, $16 \%$ involving children under 16 years of age. Complaints of pain or injury appearing to be burns were collected. Transient cutaneous erythema and edema resolving quickly were not recorded for analysis. Photographs or a dermatology consultation was obtained to document abnormalities. No injured patient consented to skin biopsy. We then carefully sought causes of the identified injuries. Temperature at the probe site was studied in a series of patients using 2 temperature-sensitive dots placed adjacent to the diodes and sensors. Other studies performed are summarized below.
Results. Sporadic patient complaints of heat under pulse oximeter probes began in May 1991. Two nursing "incident reports" of cutaneous injuries resembling burns with central blisters came from the postanesthesia recovery room in July.

Most cases occurred with disposable (flexible) probes. One ear injury occurred with a reusable ear probe. The injuries occurred with brand A (24) and brand B (2) pulse oximeters. Injuries occurred in the operating room suite (OR) and in the neonatal and pediatric intensive care units. One brand $B$ injury occurred in the $O R$, the other in the neonatal intensive care unit. In each case, the pulse oximeter produced normal monitoring data while injuries were occurring. All monitors associated with injuries passed routine electrical safety checks.

Injured patients ranged in age from newborn to 89 years; 17 patients were less than 16 years old. Overall, injuries occurred in $2 \%$ of pediatric and $0.02 \%$ of adult cases. Injuries typically resolved completely in less than 1 day; bullous injuries resolved over 2 to 5 days.

Because of frequent complaints of heat under the probes, we investigated thermal causes first. The highest temperature documented with temperature-sensitive dots under a probe was 43-C. However, no injuries were associated with the probes monitored for temperature. Other unrevealing investigations of nonthermal etiologies included monitor or probe faults or misconnection, electrical supply wiring and voltage variations, various attempts to induce probe failure, association with electrocautery, patient location within the hospital, OR humidity, pressure on skin, medications, and patient condition.

Discussion. We recognize that these data could be injurious to the specific manufacturers involved. Since the information collected thus far does not identify any causes, we do not want to insinuate faulty monitor design or component manufacture. Also, other institutional users of brand $A$ and brand $B$ pulse oximeters whom we have contacted have not had similar experiences. Therefore, we have not identified the manufacturers involved.

Fortunately, these injuries were usually not severe and have all resolved. However, our pediatric patients seem to be at much higher risk than our adult patients. Since we have been unable to elucidate an etiology, we present this abstract of our experience to stimulate discussion, identify etiologies that we may have missed, and to increase awareness among pulse oximeter users that cutaneous injuries may occur under otherwise routine circumstances. Since these injuries represent a new complication with no determined mechanism, we are continuing our investigation with the assistance of the manufacturers. As we have undertaken surveillance of this problem we have found injuries where none were formerly detected. From our data, it appears that minor injuries associated with pulse oximetry are more frequent than previously appreciated. Patients are now routinely informed of a 1 to $2 \%$ risk of finger burns and none have refused the use of a pulse oximeter.

\section{ROUTINE USE OF NERVE STIMULATOR REDUCES INCIDENCE OF POSTOPERATIVE MUSCLE WEAKNESS}

M. Hartmannsgruber, MD, N. Gravenstein, MD, Departments of Anesthesiology and Neurosurgery, University of Florida, Gainesville, FL

Summary. Routine use of nerve stimulation reduces the incidence of postoperative muscle weakness.

Introduction. In 1989, the incidence of neuromuscular blockade $(\mathrm{NMB})$ in one postanesthesia care unit (PACU) was re- 


\begin{tabular}{|c|c|c|c|c|c|c|c|c|}
\hline \multirow{3}{*}{$\begin{array}{l}\text { Muscle } \\
\text { Relaxant }\end{array}$} & \multirow{2}{*}{\multicolumn{2}{|c|}{ Patients }} & \multirow{2}{*}{\multicolumn{4}{|c|}{$\begin{array}{c}\text { Train of Four } \\
\text { Before Reversal (\%) }\end{array}$}} & \multicolumn{2}{|c|}{ Interval $(\min )^{*}$} \\
\hline & & & & & & & \multirow{2}{*}{$\begin{array}{l}\text { Last } \\
\text { Relaxant } \\
\text { to } \\
\text { Reversal }\end{array}$} & \multirow{2}{*}{$\begin{array}{l}\text { Reversal } \\
\text { to } \\
\text { PACU }\end{array}$} \\
\hline & No. & $\%$ & $1 / 4$ & $2 / 4$ & $3 / 4$ & $4 / 4$ & & \\
\hline Vecuronium & 62 & 58 & 38 & 23 & 9 & 30 & $53 \pm 55$ & $32 \pm 27$ \\
\hline Atracurium & 31 & 29 & 49 & 10 & 10 & 31 & $42 \pm 29$ & $28 \pm 22$ \\
\hline d-Tubocurarine & 2 & 2 & 0 & 50 & 50 & 0 & $68 \pm 32$ & $23 \pm 4$ \\
\hline \multicolumn{9}{|l|}{ Pancuronium } \\
\hline Alone & 10 & 9 & 40 & 10 & 20 & 30 & $76 \pm 49$ & $35 \pm 12$ \\
\hline $\begin{array}{l}\text { With vecuronium } \\
\text { or atracurium }\end{array}$ & 2 & 2 & 0 & 0 & 0 & 100 & $113 \pm 11$ & $38 \pm 11$ \\
\hline
\end{tabular}

Values are mean \pm SD except for $\%$.

* See text for explanation.

ported to be $25 \%$ [1]. The level of NMB, however, had not been measured by a nerve stimulator (NS) during operation. We investigated the impact of routine intraoperative NS use on early postoperative neuromuscular function.

Methods. With institutional review board approval, consecutive patients between 5 and 85 years of age undergoing general anesthesia, including competitive $\mathrm{NMB}$, were studied. On arrival in the PACU, each patient was assessed for airway obstruction and was asked to perform a 5-second head lift. Data on type of muscle relaxants and reversal agents (neostigmine, $0.07 \mathrm{mg} / \mathrm{kg}$ to a maximum of $5 \mathrm{mg}$, or edrophonium, $1 \mathrm{mg} / \mathrm{kg}$ ), train of four (TOF) ratio before reversal, and times from last administration of relaxant to reversal and from reversal to evaluation in the PACU were extracted from anesthesia records and recorded.

Results. The study population consisted of 107 patients (Table). Only 1 patient, a $73-\mathrm{kg}, 27$-year-old woman who received $12 \mathrm{mg}$ vecuronium during a 100 -minute procedure, had airway obstruction and headlift of less than 5 seconds. Reversal of her $1 / 4$ TOF with edrophonium, $1 \mathrm{mg} / \mathrm{kg}$, and atropine, $0.02 \mathrm{mg} / \mathrm{kg}$, resulted in $4 / 4 \mathrm{TOF}$; her residual muscle weakness was reversed by neostigmine, $1 \mathrm{mg}$. No other patient had either airway obstruction or a head lift for less than 5 seconds.

Discussion. With routine intraoperatuve use of a NS, more than $99 \%$ of patients in the PACU were able to sustain a 5 -second head lift; this is the highest incidence of normal neuromuscular function on arrival to the PACU reported to date. In our series, 9 of 107 patients $(8 \%)$ received no reversal agent based on TOF and clinical recovery. Of note is that TOF was assessed only clinically, not by electromyograph. Our data also differ from others in that the reversal dosages were independent of twitch number before reversal and generally larger than reported in the literature [1-3]. Our data suggest that routine intraoperative nerve stimulation and high-dose reversal (neostigmine, $0.07 \mathrm{mg} / \mathrm{kg}$ to a maximum of $5 \mathrm{mg}$, or edrophonium, $1 \mathrm{mg} / \mathrm{kg}$ ) prevent muscular weakness in more than $99 \%$ of patients. Because effectiveness is not $100 \%$, however, TOF monitoring does not replace but only supplements clinical assessment by means such as the 5-second head lift.

\section{REFERENCES}

1. Acta Anaesth Scand 33:167-169, 1989

2. Br J Anaesth 54:209-223, 1982

3. Anaesth Intensive Care 14:41-45, 1986

\section{OBJECTIVE ANALYSIS OF PERFORMANCE AND WORKLOAD IN THE ANESTHESIA "COCKPIT"}

M. B. Weinger, MD, O. W. Herndon, M. P. Paulus, MD, D. Gaba, MD, M. H. Zornow, MD, L. D. Dallenm, MD, Departments of Anesthesiology and Psychiatry, UCSD;

Department of Anesthesiology, Stanford University; and the San Diego and Palo Alto VA Medical Centers

Summary. To describe the impact of equipment and human factors on anesthesiologist performance, the task characteristics and workload of experienced anesthetists were compared with those of novices using a comprehensive objective methodology that appears widely applicable.

Introduction. A complete and objective understanding of the entire anesthesia "cockpit" is required to properly design the anesthesia workstation of the future. A comprehensive methodology for performing real-time intraoperative task and workload analysis [1-3] was used to compare novice residents with more experienced practitioners. The results demonstrate the potential power of these tools to elucidate the effects of human (e.g., experience), environmental, and equipment factors on anesthesiologist workload and performance.

Methods. After giving informed consent, junior anesthesia residents (1-8 weeks' experience) or experienced anesthesia providers ( $>2$ years' experience) were studied. Twenty-two cases of general endotracheal anesthesia of 1 to 4 hours' duration in an ambulatory setting were analyzed to examine the effects of experience on task pattern and workload. The methodology involved 3 separate task probes: discrete task analysis, secondary task probing, and subjective workload assessment. The activities of each anesthetist, resolved into 29 task catego- 
ries, were recorded by a trained observer on an Apple Macintosh computer. Latency of response to a "vigilance light" was used as an indicator of workload. A small red light adjacent to the ECG monitor was illuminated at random intervals throughout the case. The observer recorded response latency as the time (seconds) for the subject to indicate recognition of light illumination. Subjective assessment of workload was recorded every 5 minutes by the observer and the subject.

Data obtained from discrete task analysis were further processed with (1) link analysis, (2) task density analysis, and (3) rhythm analysis. Link analysis was used to examine the frequency of links between all successive pairs of tasks. Task density was calculated as the number of tasks per unit time. These data were then transformed by Fourier analysis to detect task rhythmicity. Between and within group comparisons were performed using ANOVA or appropriate nonparametric tests to ascertain statistical significance $(p<0.05)$.

Results. When examined as the percent of the total case time, task distributions differed significantly between novice and experienced anesthetists for several tasks, including attending conversation $(15.3 \%$ vs $2.3 \%)$, observation of the surgical field $(4.2 \%$ vs $10.8 \%)$, and recording $(15.0 \%$ vs $11.7 \%)$. The most common task, observing monitors, did not differ between groups $(18.3 \%$ vs $16.2 \%)$. Workload varied during each case. Self-reported subjective workload correlated highly with observer-perceived workload (Spearman, $r=0.944$ ). Novices were slower in their response to the vigilance light $(p<0.02)$ than were experienced practitioners. In novices, some response latencies were as long as 15 minutes. In experienced practitioners, latencies were invariably less than $3 \mathrm{~min}-$ utes. Overall, the response latency was longer during induction than during the maintenance period $(p<0.001)$.

Over the entire case, the top 5 links represented approximately $28 \%$ of the total in both groups (Table). In novice residents, the top 5 links during induction accounted for over $50 \%$ of the total. The most common links were observe monitors-mask ventilation $(17.7 \%)$ and patient conversation-line placement $(14.2 \%)$. Task density analysis revealed that when the activity level was high, the average amount of time spent per task was low. Conversely, when

Top 5 Links During the Entire Case

\begin{tabular}{|c|c|}
\hline Task Links & $\%$ of Total Links \\
\hline \multicolumn{2}{|l|}{ Novice residents } \\
\hline Observe monitors-recording & $10.0 \pm 1.1$ \\
\hline $\begin{array}{l}\text { Observe monitors-attending conver- } \\
\text { sation }\end{array}$ & $9.0 \pm 1.6$ \\
\hline Recording-attending conversation & $3.5 \pm 1.0$ \\
\hline $\begin{array}{l}\text { Observe monitors-observe surgical } \\
\text { field }\end{array}$ & $2.6 \pm 0.6$ \\
\hline $\begin{array}{l}\text { Observe monitors-observe patient } \\
\text { Total for top } 5 \text { links }\end{array}$ & $\begin{array}{l}2.6 \pm 0.7 \\
27.7 \%\end{array}$ \\
\hline \multicolumn{2}{|l|}{ Experienced residents } \\
\hline Observe monitors-recording & $10.7 \pm 1.1$ \\
\hline $\begin{array}{l}\text { Observe monitors-observe surgical } \\
\text { field }\end{array}$ & $6.7 \pm 1.7$ \\
\hline $\begin{array}{l}\text { Observe monitors-adjust anesthesia } \\
\text { machine }\end{array}$ & $4.0 \pm 0.6$ \\
\hline Observe monitors-bag ventilation & $3.5 \pm 1.1$ \\
\hline Observe monitors-adjust monitors & $3.1 \pm 0.4$ \\
\hline Total for top 5 links & $28.0 \%$ \\
\hline
\end{tabular}

activity level was low, the average time spent per task was higher. There was appreciable periodicity in many cases; the most prominent task density peak occurred at approximately 7 minutes.

Discussion. A few tasks, like observe monitors and recording, dominated cases overall. Other tasks dominated short time periods, particularly during induction and emergence. All anesthetists observed the monitors frequently. However, only experienced anesthetists observed the surgical field frequently. Similar to the findings of others [4], record keeping encompassed 12 to $15 \%$ of the time and was more encompassing in novices. Anesthetists could effectively estimate their own workload. While workload varied substantially throughout each case, induction was consistently a period of high workload, causing an increase in vigilance response latency. Novices were more heavily loaded by equivalent cases than were experienced anesthetists.

In addition to aiding in optimizing workstation design, anesthesia task analysis may prove useful for objective cost/ benefit analysis of new technology or to validate the realism of simulated anesthesia environments.

\section{REFERENCES}

1. Dallen, et al. Anesthesiology 1990;73:A498

2. Hemdon, et al. Anesthesiology 1991;75:A487

3. Gaba, et al. Anesthesiology 1991;75:A1060

4. MacDonald, Dzwonczyk. Br J Anaesth 1988;61:738-742

\section{ANESTHESIA SIMULATION FOR LEARNIMG BASIC ANESTHESIA SKILLS}

M. L. Good, J. S. Gravenstein, M. E. Mahla, S. E. White, M. J. Banner, R. G. Carovano, S. Lampotang, Departments of Anesthesiology and Physiology, University of Florida, Gainesuille, FL

Summary. Beginning anesthesia residents can acquire basic skills from an anesthesia simulator, although additional studies are needed to refine and coordinate clinical and simulator curricula.

Introduction. The first days in the operating room are bewildering to anesthesia residents and, hence, are educationally inefficient. No patient likes to be the subject on whom a resident learns the first lesson. Anesthesia simulators offer new residents a chance to gain proficiency before entering clinical training.

Methods. The Gainesville Anesthesia Simulator comprises (1) a patient mannequin that exhibits important clinical signs (for example, pulses, lung and heart sounds, twitch response, spontaneous breathing), (2) an anesthesia gas machine and mechanical ventilator, (3) standard monitoring instruments, (4) data acquisition and control hardware, and (5) microcomputers running physiologic models and scenario-control software.

Results. Ten learning objectives were identified (Table) and divided among four simulator instructors. Each instructor developed simulation scenarios by describing the time course of changes in the clinical signs and monitored variables and by defining branch points dependent on actions of the trainee (for example, desaturation after 1 minute of apnea after no preoxygenation, no desaturation with apnea after adequate preoxygenation). For each learning objective, 1 instructor led a group of 3 residents through the simulator exercise during 
Simulator Learning Objectives for Beginning Anesthesia Residents

\begin{tabular}{cl}
\hline Day & Task \\
\hline 1 & $\begin{array}{c}\text { Check and operate the anesthesia machine and venti- } \\
\text { lator }\end{array}$ \\
2 & $\begin{array}{c}\text { Conduct an intravenous induction of general anes- } \\
\text { thesia }\end{array}$ \\
3 & $\begin{array}{l}\text { Manage airways and assess ventilation } \\
\text { Diagnose and treat hypertension and hypotension; } \\
\text { operate and interpret noninvasive blood pressure } \\
\text { monitor }\end{array}$ \\
5 & $\begin{array}{l}\text { Induce, monitor, and reverse neuromuscular } \\
\text { blockade }\end{array}$ \\
6 & $\begin{array}{c}\text { Apply concepts of uptake and distribution to clinical } \\
\text { care }\end{array}$ \\
7 & $\begin{array}{l}\text { Diagnose and treat hypercapnia; operate and inter- } \\
\text { pret capnograph }\end{array}$ \\
8 & $\begin{array}{l}\text { Diagnose and treat hypoxemia; operate and interpret } \\
\text { pulse oximeter }\end{array}$ \\
9 & $\begin{array}{l}\text { Assess emergence and extubate appropriately } \\
\text { Recognize and correct malfunctions of the anesthesia } \\
10\end{array}$
\end{tabular}

an allotted $30-$ minute period. The instructor repeated the identical lesson 5 times sequentially ( 15 residents in 3 hours). For each resident, each successive simulator lesson built on previous exercises, that is, on day 1 , pre-use checks of the gas machine and learning how to operate it; on day 2 , a routine intravenous induction of general endotracheal anesthesia; on subsequent days, induction of anesthesia complicated by hypoxemia, hypertension; and, finally, emergence and complications of extubation.

Discussion. Residents spontaneously praised the simulator exercises as being "very valuable." Many forgot that they were dealing with a mannequin and, when problems developed, quickly reached for a stethoscope or to palpate the pulse. "It's nice to have seen a problem and to have had time to think it over before things crash in the OR with a real patient," commented one resident. Instructors had no difficulty adapting to the "learning style" of the simulator and became adept in writing simulation scenarios. The instructors thought that limiting each lesson to 30 minutes was restrictive and robbed the simulator of allowing each resident to repeat exercises until the specific learning objectives were mastered and demonstrated. The simulator training exercise required 1 instructor per day for 3 hours and, thus, was costly in terms of faculty time. Statistical evaluation of written examination scores and faculty evaluation of residents who learned basic skills with and without the anesthesia simulator is underway. Because of the small number of residents in each class, the analysis may take several years.

\section{SPOT ASSESSMENT OF THE DAILY ANESTHESIA MACHIINE CHECK-HUMAN FACTORS ALALYSIS}

Mark G. Ewell, MD, John H. Pennant, MB, BS, Vance E. Shearer, MD, University of Texas Southwestern Medical Center, and Parkland Memorial Hospital, Dallas, TX

Summary. A spot assessment showed that less than half our anesthesia machines were properly checked prior to use. A human factors analysis uncovered human factors that led to this situation and targeted areas for performance improvement.

Introduction. The daily check of the anesthesia machine is considered essential prior to anesthetic administration. Catastrophic failure of an anesthesia machine resulting in significant negative outcome for the patient is infrequent, but still occurs [1]. This exercise was designed to check one component of the daily anesthesia machine check, the primary and secondary oxygen delivery system. Failure to remove the primary and secondary oxygen supply prevents proper assessment of the oxygen supply alarm, fail-safe interlocks, secondary reserve tank amounts, and ability to disconnect from external oxygen supply in the event that a gas other than oxygen is delivered through the oxygen outlet.

Methods. Our operative services uses 18 surgical rooms and 5 operative obstetrics rooms to provide anesthetics 24 hours per day. Anesthesia machines are connected to external gas sources by means of "quick-fit" connectors.

Prior to the first scheduled case of the day, we placed 2 markers to identify that oxygen supplies were checked. A masking tape marker over the quick-connect oxygen fitting disclosed whether the fitting was disconnected for proper check. As a second marker, gas cylinder wrenches were placed so that visual inspection would reveal whether oxygen tanks had been checked. The two markers were checked during or immediately after induction to determine if oxygen sources had been properly checked.

Results. Fifteen rooms were marked in the surgical operating suite ( 3 rooms were excluded due to emergency cases); 4 rooms were marked in the obstetric operating suite 1 room was excluded due to an emergency case). Both markers were altered, demonstrating complete check in 8 of 15 surgical rooms (53\% pass rate) and in 1 of 4 obstetric rooms (25\% pass rate). Neither or only one of the markers was disturbed in the others ( $47 \%$ and $75 \%$ fail rate), demonstrating failure to properly check.

Failure to check oxygen supplies was evenly divided between anesthesia machine brands, as seen in Table 1.

Residents with 6 months or less anesthesia experience had a higher checkout failure rate than residents with more than 6 months' experience (in the surgical operating rooms), as shown in Table 2.

Table 1. Distribution of Anesthesia Machines Not Checked Prior to Use

\begin{tabular}{llll}
\hline Brand & Surgical OR & Obstetric OR & Total \\
\hline Drager & $5 / 8$ & $0 / 1$ & $5 / 9$ \\
Ohmeda & $2 / 7$ & $3 / 3$ & $5 / 10$ \\
Total & $7 / 15$ & $3 / 4$ & $10 / 19$ \\
\hline
\end{tabular}

Table 2. Anesthesia Experience for Residents Failing to Check Oxygen Sources

\begin{tabular}{llll}
\hline Experience & $<2$ mo & $2-6$ mo & $>6$ mo \\
\hline Number of residents & 3 & 4 & 0 \\
\hline
\end{tabular}


Discussion. Resident assignments are different in the two clinical areas studied. Rooms in the surgical operating suite are assigned one resident per room during the day; rooms in the obstetric suite are rotated among all the members of the anesthesia team and 1 person is designated to perform the daily machine check for all 5 rooms. The higher pass rate in the surgical operating rooms (53\%) showed that a 1 to 1 room assignment was associated with a higher machine check rate than when 1 person checked all rooms.

The residents with less than 2 months' experience were surgical and obstetrical residents in their first week of the anesthesia rotation. The remaining 4 residents were questioned regarding their failure to properly check oxygen supplies. Paraphrased answers were as follows:
1. I didn't know that I missed part of the check, I never was instructed.

2. I didn't check; I knew better but I became "complacent."

3. I didn't check-no excuse.

4. Denied failure to check, claiming to have "replaced tape" on connectors. No response when additional lack of cylinder check was pointed out. Did not display insight into actions.

\section{REFERENGE}

1. Dorsch, Dorsch: Understanding Anesthesia Equipment, 2nd ed. Baltimore: Williams \& Wilkins, 1984:401 